\title{
TESIS DE MAESTRIA
}

Maestría en Ciencias Sociales

Facultad de Humanidades y Ciencias de la Educación

Universidad Nacional de La Plata

Año 2012

Recuerdos, espejos y lugares en el teatro comunitario argentino contemporáneo

Memoria colectiva, identidades, y espacio público en las prácticas del Grupo de Teatro Popular de Sansinena (2010-2012).

Autora: Lic. Clarisa Fernández

Directora: Dra. Lola Proaño Gómez

Co director: Dr. Martín Retamozo 


\section{ÍNDICE}

\section{Introducción}

\section{Capítulo I: Estudios sobre teatro comunitario en pueblos rurales}

1. Patricios Unidos de Pie. Se dice de mí...

1.2. De estaciones, proyectos y recuerdos

1.3 Repensando Patricios, apuntando a Sansinena

2. Sansinena, un pueblo de amigos

2.1. Establecerse, nombrarse

2.2. ¿Por qué un antes y un después del 2001?

2.3. De tambos y chacareros

3. La fuerza de la tradición

4. Y donde hubo teatro...

4.1. Grupo de Teatro Popular de Sansinena

Capítulo II: Conservación y transformación: una relación dialéctica posible

1. Proceso de construcción de la obra.

1.1 ¿Qué contar, por qué, cómo?

2. Ser y pertenecer: claves de un relato instituyente

3. Memorias. La nostalgia.

4. Somos lo que somos

5. Por los caminos de mi pueblo: análisis de escenas y puesta en escena.

5.1. Ironías y sátiras que definen el YO sansinense.

5.2. Los caminos

5.3. Cuando se viene el agua

6. Canciones en el teatro comunitario: poéticas colectivas

7. Sobre obras de autor y obras de autor/es

8. La voz del pasado no solo hechiza, ordena. 


\section{Capítulo III: El espacio en cuestión}

1. Nuevas tramas relacionales, subversión y reproducción de roles

2. Incursionando espacios posibles

3. Algo en común/ lo público

4. Prácticas que construyen espacios

5. La creación, motor de la acción

Capítulo IV: De equipos y personalidades. Tensiones de liderazgo, dificultades y potencialidades de la acción.

1. "Tener a Edith y a María Emilia juntas es como tener a Messi y a Maradona en el mismo equipo"

2. Legitimidad adquirida, legitimidad otorgada. Dependencias e interdependencias.

3. Transformar sin irrumpir, construir sin confrontar

4. Sobre representantes y representaciones

5. Ecos de voces que no callan. Lógicas de negociación y potencialidades de una experiencia colectiva.

6. "No importa lo que tengas, ni de qué pueblito vengas, siempre es mejor sumar..."

\section{Reflexiones finales}

Agradecimientos

\section{Bibliografía}

Anexo Metodológico

Anexo 1

Anexo 2 


\section{INTRODUCCION}

El tipo de teatro que comenzó a practicarse desde el año 1983, a partir del nacimiento del grupo Catalinas Sur en el barrio porteño de La Boca, tenía la particularidad de estar compuesto por vecinos del barrio, ajenos al ámbito teatral y artístico, profesionales, estudiantes, amas de casa, desocupados, niños y abuelos de todas las edades. A través de la creación colectiva, por el aporte de anécdotas, experiencias, y documentos, los vecinos construían un relato que contaba la historia del barrio, ciudad o pueblo al cual pertenecían. Los primeros trabajos científicos que intentaron caracterizar a este teatro, alejado de los carteles comerciales y numerosos en cantidad de miembros, lo caratularon como teatro comunitario, teatro de la comunidad para la comunidad (Proaño Gómez, 2006; Bidegain, 2007). Quizá hubiese pasado desapercibido como fenómeno social, de no haberse multiplicado cuantiosamente la cantidad de grupos desde del año $2002^{1}$, momento a partir del cual los mismos se nuclearon en la Red Nacional de Teatro Comunitario.

Encontramos dificultades a la hora de construir categorías unívocas para este teatro, debido a las amplias diferencias existentes entre las estructuras y estrategias que cada grupo de teatro comunitario desarrolla, el entramado de lógicas que atraviesan los contextos particulares y las configuraciones de diversos corpus de expectativas, proyectos y actividades de cada grupo (Fernández, 2010, 2011). Tanto el "mapa" de grupos de teatro comunitario como el campo académico que abordó su estudio, significan un desafío para el investigador. En el primer caso, por la proliferación cada vez mayor de grupos en todo el país, y el surgimiento de casos dispares que envisten interesantes propuestas de análisis. En el segundo caso, porque nos encontramos con una escasa bibliografía, centrada generalmente en el estudio de los mismos grupos (los "fundadores"2 o los casos considerados "paradigmáticos",3), cuya tendencia analítica

\footnotetext{
${ }^{1}$ Actualmente hay aproximadamente cincuenta grupos en todo el país.

${ }^{2}$ Grupo Catalinas Sur o Circuito Cultural Barracas.

${ }^{3}$ Como el caso del grupo Patricios Unidos de Pie.
} 
resalta la novedad del fenómeno y su originalidad, sin profundizar en las tensiones que se tejen en sus tramas relacionales.

Sin embargo, durante los últimos cinco años, el teatro comunitario -como práctica artística y social-, comenzó a despertar interés en estudiantes avanzados de carreras de grado $^{4}$ y de postgrado, quienes eligieron esta temática para el desarrollo de sus trabajos de tesis. Asimismo, investigadores de países como Brasil, y Francia viajaron para realizar estudios sobre diversos grupos del país ${ }^{5}$, y se conformó una Red Nacional de Investigadores de Teatro Comunitario ${ }^{6}$, a través de la cual se generan intercambios de materiales, debates y propuestas de trabajo para reflexionar sobre la práctica. La composición de esta red es heterogénea, ya que en ella conviven diversas perspectivas teóricas, metodológicas y epistemológicas en el abordaje del fenómeno. Cada investigador trabaja con uno o varios casos específicos, intentando generar un vínculo con el / los grupo/s estudiado/ s, a fin de que la construcción teórica pueda dialogar con la práctica.

\section{El caso del Grupo de Teatro Popular de Sansinena}

\section{Perspectiva de análisis y dimensiones analizadas}

La presente investigación intentó alejarse de la novedad del fenómeno para construir, a través de un estudio de caso $^{7}$, una perspectiva que complejice el análisis de la práctica y

\footnotetext{
${ }^{4}$ Podemos citar los trabajos de Alexis Rasftopolo (Desde mover una mesa hasta cambiar el mundo. El teatro comunitario y sus posibilidades. FHCS-UNaM, Posadas, Misiones, noviembre de 2009); Gastón Falzari (Un acercamiento al movimiento teatral comunitario. Reflexiones sobre memoria colectiva, verdad(es) y experiencia. Facultad de Ciencias Sociales y Ciencias de la Educación de la UBA, 2011); Sánchez Salinas, Romina (El teatro comunitario en el proceso de transformación de la sociedad: El caso de Res o no Res en el barrio de Mataderos. Facultad de Ciencias Políticas y Sociales, Universidad de Cuyo, 2011); Bogado, Andrea Gertrudis (Construcción de ciudadanía en el grupo de teatro comunitario Murga de la estación. Facultad de Humanidades y Cs Sociales de la Universidad Nacional de Misiones, 2011).

${ }^{5}$ Se trata de los investigadores Ruckman, Hanna (Patricios Stand United. Impacts of a rural tourism community theater proyect. Master of arts in anthropology, University of California, 2008). En proceso: Elgoyhen, Lucie (Magister, Francia) y Siedler, Clarice (Magister, Brasil).

${ }^{6}$ http://investigadoresdetc.blogspot.com.ar/

${ }^{7}$ El estudio de caso busca focalizar su análisis en un número limitado de hechos y situaciones para poder abordarlos con profundidad (Neiman y Quaranta, 2006; Marradi, Archenti \& Piovani, 2007). Los autores coinciden también en resaltar en el estudio de caso la importancia de la pregunta y el tema por sobre el diseño metodológico, y de la particularidad del caso por sobre la validez de la generalización. En relación
} 
ponga de relieve las tensiones que se generan, las dificultades y potencialidades de la acción. El Grupo de Teatro Popular de Sansinena nunca fue estudiado, cuestión que facilita su abordaje -porque de alguna manera, "todo está por decirse"-, pero a la vez lo dificulta, ya que se trata de un grupo que tiene lugar en un pequeño pueblo rural, con lógicas de socialización y realidades propias que será necesario reconstruir, y que se alejan notablemente de aquellas que caracterizan a las grandes ciudades. El grupo surgió en el año 2006 como una búsqueda ligada al teatro vocacional/ independiente, pero con el paso de los años fue acercándose cada vez más al trabajo con la comunidad y a partir del año 2008 comenzó a formar parte de la Red Nacional de Teatro Comunitario, cuando representó la obra Por los caminos de mi pueblo -en donde se reconstruye la historia del pueblo-.

Tanto la actividad teatral en sí (construcción de la obra, ensayos, puesta en escena, etc.), como las prácticas que vinculaban al grupo con la comunidad (lazo con instituciones, autoridades, vecinos, etc.), eran "campo" inexplorado en Sansinena. Si todo este universo se abría ante la mirada del investigador, ¿cómo hacer el recorte? Frente a esta pregunta, el trabajo con la memoria se convirtió en una cuestión ineludible, que atravesaba las prácticas cotidianas del grupo (en tanto el material "teatral" es construido con recuerdos y anécdotas de los vecinos), interesante para explorar en cuanto se delineaban allí relaciones que estructuraban una lógica propia de los habitantes del pueblo, visiones de mundo y expectativas colectivas. Nos interesaba comprender cómo, por medio de la práctica del teatro, se construían miradas e interpretaciones sobre el pasado.

Nuestra perspectiva de estudio sobre las operaciones de memoria - selecciones, omisiones, censuras, reinterpretaciones, idealizaciones y diversos procedimientos memorialísticos (Candau, 2008) - vincularon analíticamente esas operaciones con procesos de constitución identitaria, configurados por el corpus de valores de la comunidad, vinculados con los sentidos de pertenencia y rasgos que conforman su identidad colectiva. Identidad y memoria, en una relación dialéctica, se ven

a nuestro trabajo, consideramos al Grupo de Teatro Popular de Sansinena un caso paradigmático, un fenómeno nuevo que excede a la teoría existente (Marradi, Archenti \& Piovani, 2007), cuya investigación arrojará resultados de mayor complejidad y diversidad si se estudia en profundidad, de forma holística. 
constantemente interpeladas en el proceso de reconstrucción de la historia, porque si la identidad tiene su fuente en la cultura, la memoria es el principal nutriente de la identidad (Giménez, 2005). A través de las relaciones que se construyen en las prácticas teatrales, se definen sentidos que marcan un "nosotros", un "ellos" y una forma de reconstruir y reinterpretar la propia historia, un modo de reconocerse y querer ser reconocidos por los demás.

La pregunta por la memoria colectiva introdujo el interrogante por la inscripción de la memoria en ese espacio (Halbwachs, 1968), la utilización y reapropiación del mismo a la luz de la actividad teatral. Este teatro performativo del espacio, que construye, modifica y resignifica el espacio a través de su práctica, comportará para los vecinosactores significados que generarán sentidos nuevos y transformarán los existentes. Pero la pregunta por el espacio social y su utilización/ reapropiación, no excluyó una perspectiva de análisis que abrió otras puertas a la indagación: la construcción de un espacio político, donde era necesario complejizar en las relaciones que se daban al interior del grupo (liderazgos, relaciones de poder, legitimidades) y hacia el afuera (vínculos con autoridades, instituciones).

Esta investigación propone tres dimensiones de análisis imbricadas que se identificarán y complejizarán en las prácticas del grupo de teatro: las operaciones de memoria que atravesaron el proceso creativo de la obra (y los sentidos que las mismas construyeron sobre la historia del pueblo), los procesos de constitución y disputa identitaria que se inscriben en las prácticas cotidianas del grupo, la utilización y construcción del espacio público a través de la práctica, las tramas relacionales que atraviesan las prácticas del grupo (lazos de sociabilidad, toma de decisiones, modos organizativos, vínculos con los sectores de poder y las instituciones) y su inscripción en la conformación del espacio teatral.

\section{Estructura, métodos y dificultades}

La tesis está estructurada en cuatro capítulos. En el primer capítulo reconstruimos el campo de estudio que abordó el análisis del teatro comunitario en pueblos rurales, con el fin de demostrar por un lado, el escaso trabajo académico que hay al respecto, y por 
el otro, las divergencias que tenemos con las perspectivas ya elaboradas. Nuevamente nos encontramos con un gran universo inexplorado, con el cual intentamos colaborar a través de la construcción de una mirada desde un caso específico, cuyas lógicas no se detengan en explicar la novedad de un grupo de teatro de 70 personas en un pueblo de 650, sino en profundizar los por qué de los procesos que allí tienen lugar. Para ello, incluimos en el mismo capítulo la presentación del grupo, sus características de composición, origen y desarrollo. Para hacerlo recurrimos a alguna bibliografía antropológica (Ratier, 2009), que nos permita ubicar la práctica en un contexto de ruralidad desde el cual pensar las actividades teatrales de Sansinena.

En el capítulo 2, abordamos las operaciones de memoria y constitución de identidades en el proceso de creación colectiva de la obra Por los caminos de mi pueblo y en el guión teatral. Si bien este apartado introduce la problemática de la(s) memoria $(s)$ y la(s) identidad(es), estas categorías atravesarán toda la investigación, en tanto cuestiones nodulares de nuestro problema de indagación. En el capítulo 3, nos preguntamos por la constitución del espacio y su transformación, poniendo en cuestión la visión del mismo como territorio y como lugar de inscripción de la cultura (Giménez, 1999). Proponemos generar una reflexión que rompa con la dicotomía entre espacio público y privado, comprendiendo que, a pesar de los ámbitos con que cada uno de estos espacios fue asociado en el pensamiento filosófico/ político, el espacio teatral está atravesado por lógicas pertenecientes a ambos, que disputan formas de comprender lo político (Arditi, 1995).

En el capítulo 4, abordamos la pregunta por el espacio teatral en clave de organización social, de colectivo que construye y genera acción. Desde allí retomamos ciertos conceptos que nos ayudan a pensar la práctica del grupo como análoga a algunas manifestaciones populares que se dieron en el post 2001. Profundizamos el debate de las dificultades y las potencialidades de la acción a la luz de los fuertes liderazgos construidos por la referente- María Emilia De la Iglesia-, los vínculos con el poder político y la construcción de nuevos sentidos en una comunidad con fuertes prácticas que tienden a la conservación.

Con una intención de no clausurar sino abrir en debate, y de generar más preguntas que respuestas, planteamos algunos interrogantes sobre los tópicos debatidos en torno a la 
reciente conformación del Grupo de Teatro Comunitario de Rivadavia, en donde el Grupo de Sansinena es sólo un miembro más de los seis pueblos que lo conforman, y de los 200 vecinos que participan.

Es importante destacar ciertas dificultades metodológicas que se presentaron durante el proceso de tesis. Por un lado, la escasez de fuentes que aporten datos sobre el pueblo de Sansinena, su historia, índices laborales o productivos fue una dificultad clara, en tanto el material más completo que encontramos fue un libro escrito por la misma directora del grupo ${ }^{8}$, que presenta una reconstrucción de la historia del pueblo que va desde su conformación (1910) hasta el año 2001. Allí se presentan datos institucionales, productivos y políticos, estructurados fundamentalmente en base a un relato construido con los testimonios de los mismos vecinos. Este libro es utilizado como material de referencia para las autoridades, como uno de los documentos más precisos y completos de reconstrucción de la historia del pueblo. Si bien durante la última etapa de esta investigación la delegación municipal de Sansinena estaba realizando un trabajo de registro poblacional y laboral, el mismo todavía no se ha terminado.

Por otro lado, fue necesario realizar una vigilancia estricta del vínculo del investigador con los actores, en tanto se presentaron frecuentemente situaciones de naturalización o adaptabilidad al medio. Las características propias del investigador y los modos de recepción y vinculación que establecieron los vecinos con los invitados o visitantes, se prestaron al desarrollo de lazos afectivos y un alto grado de integración del "extraño" en la comunidad. La necesidad del extrañamiento se fue haciendo más evidente con el paso del tiempo, a través del alejamiento o la puesta en cuestión de los parámetros naturalizados, estrategias que se fueron logrando paulatinamente.

El trabajo de campo se llevó a cabo durante los años 2010 y 2011, período en el cual visitamos reiteradamente el pueblo de Sansinena, observamos y acompañamos al grupo en sus actividades, realizamos entrevistas semi estructuradas a unos 25 miembros del grupo y cinco vecinos del pueblo que no participan del mismo. Utilizamos documentos oficiales, recortes de periódicos, folletería, material escrito, audiovisual y fotográfico

\footnotetext{
${ }^{8}$ Bello, Edith \& De la Iglesia, M. Emilia (2009). Sansinena existe. Retazos de memoria. Tejidos de futuro. Buenos Aires: Municipalidad de Rivadavia.
} 
del grupo. Las fuentes principales que nutrieron el trabajo fueron las entrevistas (en donde registramos "la voz de los actores"), los documentos teatrales (guión), y la observación, que en algunos casos resultó participante 9 , en tanto fuimos parte de algunas actividades específicas Fue fundamental acompañar a la directora del grupo en los días previos a las representaciones, en tanto nos permitió observar y registrar los procesos de negociación y vínculos con autoridades, instancias de tensión y disputas por legitimidad de distintos actores políticos ${ }^{10}$.

\footnotetext{
${ }^{9}$ Entendemos a la observación participante como el involucramiento del investigador en una variedad de actividades y por un periodo prolongado de tiempo, con el fin de observar a los miembros de una cultura en su vida cotidiana y participar en sus actividades facilitando una mejor comprensión de los mismos (Marradi, Archenti, Piovani, 2007:195). De esta definición podemos inferir que la observación participante no es solo una herramienta para obtener información, sino también de producción de datos y análisis (Guber, 2004: 177).

${ }^{10}$ VER ANEXO METODOLÓGICO
} 


\section{Capítulo I}

\section{Estudios sobre experiencias de teatro comunitario en pueblos rurales}

En los pueblos rurales del interior de la Provincia se pueden identificar lógicas específicas de una geografía marginal surgidas a la luz de la desaparición del tren. Lo que Ratier (2009) denomina cultura rural bonaerense involucra dinámicas de sociabilidad ligadas a la vida "en el campo", la preferencia por lo gauchesco, las resonancias folclóricas, la militancia asociativa y la identidad pueblerina. Explorar estas características que comparten muchos poblados del interior, incluido el pueblo de Sansinena, nos permite establecer un marco de referencia desde el cual examinar la práctica teatral comunitaria, que se diferencia radicalmente de la que predomina en las grandes ciudades. Retomar los estudios existentes que analizan el desarrollo de esta actividad en pueblos rurales, puede iluminar posibles vacíos conceptuales y/o perspectivas no abordadas, permitiendo la elaboración de nuevas reflexiones.

\section{Patricios Unidos de Pie. Se dice de mí...}

El pueblo de Patricios, ubicado en el Partido de Nueve de Julio, a 260 km de Capital Federal, ha sido objeto de numerosos trabajos en el ámbito académico. El hecho de ser el primer pueblo rural en donde surgió un grupo de teatro comunitario, lo convirtió en un caso de estudio de sumo interés para investigadores nacionales e internacionales. La organización desplegada en torno a la actividad teatral generó proyectos de desarrollo local y turismo rural, lo que atrajo a especialistas de diversas disciplinas interesados en registrar este proceso. Si bien no pretendemos realizar un análisis comparativo entre el grupo de Patricios y el de Sansinena, la observación de rasgos compartidos en los dos casos puede resultarnos esclarecedora. 


\subsection{De estaciones, proyectos y recuerdos}

"El teatro comunitario en Patricios es un motivo de vida, de anudar lazos distintos entre los vecinos, un permiso para jugar, crear, recrear, ponerse frente al otro y decir: acá estoy, soy yo y soy vos". (Mabel Hayes, coordinadora de Patricios Unidos de Pie en Bidegain, 2007:212).

La totalidad de los enfoques que se adoptaron para el estudio del grupo de Patricios (Proaño Gómez, 2006; Bidegain, Marianetti y Quain, 2008; Ruckman, 2008; Ramos y Sanz, 2009; Pironio, 2010), parten de la idea de Patricios como pueblo ferroviario. Este modo de percibir las identidades de los pobladores en vínculo con el ferrocarril, proyecta una serie de sentidos, significaciones y expectativas que ligan la vida del pueblo con la presencia/ausencia del tren. Por este motivo, los trabajos encontrados apuntan a reflexionar desde diversos ámbitos como la antropología, la psicología comunitaria, la filosofía, la comunicación y las artes escénicas, sobre las prácticas desarrolladas por el grupo Patricios Unidos de pie, a la luz de esta temática. Ya sea como proceso de intervención social/ comunitaria, como estrategia de desarrollo local y/o turismo rural, como práctica creadora de nuevas subjetividades y estéticas, los estudios se concentran en esta problemática como punto de partida para sus análisis.

La situación de marginalidad en la que quedó el pueblo, que pasó de tener cerca de 6000 habitantes (antes del año 1955) a unos 600 en la actualidad, fue cuestionada a partir del movimiento que generó la actividad teatral. Desde el ámbito de la antropología, Hanna Ruckman (2008) se preguntó por el impacto que el grupo de teatro provocó en los participantes del grupo y en el entorno más amplio de la comunidad. Bajo la consigna teatro como herramienta de desarrollo, los resultados de su investigación afirmaron la existencia de beneficios individuales de los vecinos participantes, en cuanto a la promoción de una mayor sensación de comunidad, efectos terapéuticos, el surgimiento de un sentimiento de orgullo por el pueblo, y mayor esperanza en el futuro. En cuanto a los procesos más amplios que tuvieron incidencia en el resto de la población, advierte que el hecho de haber recibido muchas visitas en el pueblo y acaparado la atención de los medios de comunicación a partir de la actividad teatral, generó la alteración de la concepción que los vecinos tenían de sí mismos. Bidegain (2008) coincide en resaltar la importancia que tiene para los habitantes de Patricios la mirada "de afuera" en la 
construcción de un nosotros, en cuanto visibiliza la situación de un pequeño pueblo que busca aparecer en el mapa.

Como contracara de estos procesos virtuosos, Ruckman (2008) identifica que las principales limitaciones observadas en torno a la actividad de Patricios Unidos de Pie como una herramienta de desarrollo local, radicaban, por un lado, en la imprescindible figura de las coordinadoras, quienes establecían relaciones de liderazgo muy fuertes que obstaculizaban un trabajo más participativo-, el poco apoyo del resto de la comunidad y, finalmente, los problemas de financiación. Si bien los emprendimientos que el Grupo Patricios Unidos de Pie inició en la comunidad ${ }^{11}$ constituyeron una alternativa para el crecimiento del lugar, cambiaron la postura de los pobladores en cuanto a la idea de participación y lograron posicionar ciertas demandas -como el asfalto- en la agenda de las autoridades municipales (Ramos y Sanz, 2009), no se alcanzó a conformar un plan estratégico de desarrollo local sustentable a largo plazo (Ruckman, 2008), porque las actividades no mantuvieron una continuidad.

Dentro de los estudios de comunicación y artes escénicas (Bidegain, Marianetti y Quain, 2008), la existencia de una identidad ferroviaria como rasgo medular de la historia del pueblo, se convirtió en el argumento central de la primera obra estrenada por el grupo, llamada Nuestros Recuerdos (2003). Para las autoras, el proceso de creación colectiva que los vecinos realizaron para armar la obra construyó un entramado de historias individuales que se unieron para armar "la historia a contar", siempre teniendo en cuenta que se buscó decir aquello que está silenciado. La característica transformadora radicó en la edificación de nuevas visiones sobre los hechos, "que se encuentran orientados a la elaboración de sentidos contrahegemónicos" (Bidegain, Marianeti y Quain, 2008:113). Por otro lado, la identificación de los vecinos-espectadores con la problemática que los vecinos-actores representaron en el escenario fue indiscutible, en tanto el relato teatral retomó situaciones y hechos que habían sido vivenciados por todos.

\footnotetext{
${ }^{11}$ El grupo de teatro generó un proyecto denominado AVECINARTE, junto con la Fundación Pasos y el Grupo de Cine comunitario de Saladillo, con la idea de construir un espacio de creación comunitaria. También participó en un Plan de Desarrollo Local, un programa de turismo local -para el cual se requirió de la capacitación de técnicos de turismo municipales- y creó el sistema D y D (Dormir y desayunar), por medio del cual los vecinos ofrecen sus casas de familia a modo de alojamiento.
} 
La obra cuenta la historia de las consecuencias que tuvo para el pueblo la supresión del servicio de pasajeros. El drama de los que se fueron, la falta de oportunidades, las parejas, las familias separadas, la esperanza de los que insistieron en quedarse en el pueblo (Borba, 2008:5).

El producto teatral, esa poética del testimonio colectivo (Proaño Gómez, 2006), habría significado la devolución al pueblo de "su razón de ser", y la proyección de una imagen positiva de Patricios al resto de la sociedad (Bidegain, Marianeti y Quain, 2008). A través de la praxis de la celebración los vecinos pudieron crear un nuevo espacio de relación social (Borba, 2008), en donde hay una propiedad colectiva de los medios de producción (Proaño Gómez, 2006). Realizaron un ejercicio del poder atravesado por diálogos y consensos que les permitió gestar otro tipo de vinculación con la administración del gobierno municipal -no asistencialista- y reconstruir subjetividades (Pironio, 2010). Para Proaño Gómez (2006) en la escena comunitaria se produjo el regreso de la potentia de la gente con sus demandas, como poder constituyente.

Según Proaño Gómez (2006), dentro de las prácticas teatrales de Patricios Unidos de Pie, la recuperación de la estación abandonada como lugar de reunión y ensayo, constituyó un proceso de intervención de gran significación para los vecinos. Para la autora, esta apropiación significó una ruptura con la rutina -en cuanto se utilizó como espacio no convencional- y la aparición de un espacio donde se actualizó la memoria y surgieron nuevas reglas y normas opuestas a las tradicionales. Al implementarse allí una nueva lógica de valores (lógica de la igualdad), la espacialización de esta práctica en la estación implicó su transformación en un lugar polémico, en donde se desenmascaranron los intereses que trajeron la muerte al pueblo.

\subsection{Repensando Patricios, apuntando a Sansinena}

Las reflexiones que retomamos sobre los trabajos que estudiaron la práctica teatral comunitaria en pueblos rurales, constituyen un mapa de situación desde el cual pararnos para nuestro estudio. Los mismos reflejan la ausencia de bibliografía sobre otros grupos de teatro comunitario en ámbitos rurales, ya que se concentran exclusivamente en la experiencia de Patricios. Las publicaciones que realizamos a lo largo de los últimos dos años constituyen el único material que aborda el análisis del Grupo de Teatro Popular de 
Sansinena ${ }^{12}$, que junto con el grupo de Timote, y otros que se están gestando en el Partido de Rivadavia, Mechita, General Bermúdez y San Antonio de Areco, conforman el conjunto de pueblos que albergan proyectos de teatro comunitario.

Reconocemos la necesidad de profundizar el análisis del proceso de construcción colectiva por el que se crea la obra de teatro, observando las disputas y tensiones que se presentan a la hora de construir el relato. El ejercicio de la memoria colectiva implica procesos de olvido y de selección, de omisión y transmisión inter generacional (Halbwachs, 1968), que no están incluidos como materia de análisis en los trabajos apuntados.

Si bien en Sansinena la desaparición del ferrocarril tuvo consecuencias significativas en cuanto a la situación laboral y vida social de los pobladores, y el relato teatral incluye esta temática, no es un elemento central como lo es en Patricios. Será necesario, entonces, generar un estado de distanciamiento en cuanto a la asociación de los pueblos rurales con una identidad ferroviaria indiscutible, para poder construir, desde nuestro caso, un conocimiento desde el concreto histórico del pueblo.

Por último, encontramos en los trabajos registrados el abordaje de la cuestión "espacial" vinculada fundamentalmente con las transformaciones a nivel individual y colectivo que generó la reapropiación de la estación de ferrocarril. Proponemos, en este punto, crear nuevas líneas de reflexión orientadas a concebir al espacio público no sólo en su dimensión física y simbólica, sino fundamentalmente política. Ello implicará complejizar la mirada en torno a esta categoría, extrañarnos del espacio y de lo público para autonomizar los vínculos que asocian su uso, y poder encontrar la riqueza de cada uno de ellos a la luz de las prácticas concretas que el Grupo de Teatro Popular de Sansinena desarrolla. Esto es, ver ambos espacios como categorías separadas y no en constante oposición.

\footnotetext{
${ }^{12}$ Se trata de las publicaciones tituladas "Procesos de memoria en el teatro comunitario argentino" (Número 11, año 4, Palos y Piedras, revista del Centro Cultural de la Cooperación) y "La transmisión de la memoria en el teatro comunitario argentino. El caso del Grupo de Teatro Popular de Sansinena" (Revista académica Question, Volumen 1, Número 31 de invierno, año 2011).
} 


\section{2. "Sansinena, un pueblo de amigos"}

"El designio llegaba con el ferrocarril, con el telégrafo, con la distribución de las tierras, con el nuevo camino, con el límite, con los alambrados, con los carros, con el molino, con el ganado, con el trigo y con el avance de una civilización diferente, muchas veces importada" (Orga, 2010:39)

Proponemos reconstruir los orígenes y la historia del pueblo no sólo para ubicar este trabajo en un marco contextual determinado, sino también para identificar en ese relato acontecimientos relevantes, marcas y huellas del pasado, que luego serán fundamentales para emprender el análisis de las prácticas culturales desarrolladas por el grupo de teatro. Elementos claves que conforman las identidades amalgamadas en los habitantes del pueblo, y que funcionan como hilos conductores de las disputas que guían el ejercicio de la memoria colectiva. Sitios físicos, espacios y "lugares" que se utilizarán y resignificarán a partir de los sentidos construidos por el "quiénes somos" y "quienes son los otros".

Sansinena es una localidad del Partido de Rivadavia, que se encuentra al noroeste de la Provincia de Buenos Aires y tiene una superficie de 44.690 hectáreas, incluyendo zonas rurales. Según la delegación de Sansinena, los resultados del CENSO 2011 indicaron que el pueblo tiene una población total de entre 620 y 650 habitantes ${ }^{13}$, incluidos los parajes rurales.

Antes de la llegada del ferrocarril y de la gran inmigración, las tierras del Partido de Rivadavia estuvieron habitadas por comunidades de pueblos originarios, principalmente araucanos y ranqueles, que fueron disminuidos, masacrados y expulsados por la llamada Campaña del Desierto entre 1878 y 1879. La Zanja de Alsina, construida por éste para marcar una línea divisoria que surque la distancia con los pueblos originarios, se convirtió en una huella simbólica. A su alrededor, los fortines General Conesa y Colazo se establecieron en lo que luego sería tierra sansinense ${ }^{14}$.

\footnotetext{
${ }^{13}$ Información del Censo 2011 del INDEC

${ }^{14}$ Revista "Nacer, crecer y realizarnos", publicación de la Municipalidad de Rivadavia por el Centenario del Partido de Rivadavia.
} 
Bajo la consigna de "poblar el país" se implementaron políticas para fomentar la inmigración ${ }^{15}$, lo que generó, conjuntamente con el éxodo de europeos que dejaron sus tierras a partir de la Primera Guerra Mundial, una masiva entrada de extranjeros al suelo argentino. Pero esas mismas políticas no permitirían que los recién llegados accedan a la tierra, por lo que se fueron afincando en grandes latifundios pertenecientes a poderosos terratenientes -principalmente alemanes e ingleses- que ya habían comprado esas tierras de manos del Presidente Roca, quien entregó las primeras hectáreas de lo que luego sería el Partido de Rivadavia hacia el año 1882. El aumento de inversiones extranjeras en la región marcó los rasgos europeos de las futuras propiedades y las hibridaciones culturales entre gauchos, gringos y pueblos originarios que se amalgamarían en las generaciones venideras (Orga, 2010).

Sansinena contaba en los albores de su nacimiento, con grandes estancias como La Palatina, que en sus 100.000 hectáreas contenía en sus tierras a las actuales: La Marianita, La Chita, San José, La Primavera, La Elisa, La Blanca, La Juanita y Los Nietos (Bello y De la Iglesia, 2009). Las primeras familias arribaron a la región hacia 1902 y fundaron sus colonias ${ }^{16}$, instalando pequeños comercios.

Las tierras que formarían luego el pueblo de Sansinena pasaron por sucesivas manos durante los primeros años del nuevo siglo, llegando a venderse en 1908 a la Sociedad Anónima Compañía Tierras del Oeste; un año después la Compañía realizó la venta de los lotes del pueblo. Pero la fundación de Sansinena está marcada desde su inicio por un factor que atravesaría el origen de muchos poblados en esa época: la llegada del tren. Si bien la empresa del Ferrocarril Oeste de la Provincia de Buenos Aires arribó a la zona hacia 1903, la señora Agustina Luro de Sansinena donó sus tierras para la creación de la estación de trenes en el año 1910. Fue el establecimiento de la estación Sansinena - que adquirió su nombre en honor a Agustina y a su marido fallecido- lo que determinaría la constitución del pueblo. En el año 1913 se aprobaron los planos para la conformación de un centro poblacional sobre la estación de Sansinena, con la previa advertencia del

\footnotetext{
${ }^{15}$ Como la Ley de Inmigración en el año 1876.

${ }^{16}$ Alfredo Piccini, el primer residente, era de La Plata y fundó en Sansinena una colonia con su nombre (Orga, 2010).
} 
Departamento de Ingenieros sobre la insalubridad del agua y una incorrecta ubicación de la planta urbana (Bello y De la Iglesia, 2009).

Como afirma Ratier (2009), muchas de las pequeñas poblaciones de principios del siglo $\mathrm{XX}$ se afincaron a partir de la aparición del tren, y por eso fueron conocidas como “estaciones". El nexo que la población instauró con el tren excedió su función de transporte y se extendió a vínculos ligados a los sentidos y significaciones de una época “de oro". El tren no sólo permitía la comunicación con los grandes centros urbanos, sino que además era el encargado de transportar la producción agrícola y ganadera, de traer las noticias, la correspondencia y las innovaciones (Orga, 2010). El tren pasó por última vez en Sansinena en el año 1992.

La venta de tierras de parte de la Compañía de Tierras del Oeste fue conflictiva, debido a que no cerraban los acuerdos sobre las zonas que debían venderse y las que debían utilizarse para que los pobladores se afincaran. Ya pasaron más de cien años, y según testimonios de los vecinos, todavía hay terrenos que siguen a nombre de esta Compañía.

\subsection{Establecerse... nombrarse}

Si bien el plano del pueblo trazado a comienzos de la década de 1910 pautaba la existencia de varias instituciones, la mayoría de ellas fueron creadas gracias al aporte y voluntad de los vecinos, quienes en muchos casos las edificaron ellos mismos. Las comisiones, forma que tomaba la organización interna entre los pobladores, fueron las encargadas de fomentar y gestionar la necesidad de contar con instituciones como la escuela, la policía, el teléfono o los caminos. Atravesando trasversalmente estas gestiones y negociaciones, numerosos obstáculos producidos por tensiones políticas entre facciones, o simplemente por negligencia, impidieron la rápida concreción de los proyectos. Tal es así que la sala de primeros auxilios se inauguró recién en el año 1961, entre 1947 y 1948 se completó la primaria hasta sexto grado, los sistemas de iluminación se instalaron en 1973, las líneas telefónicas en 1979 y todavía no han terminado los sistemas de agua potable, obra que se inició en el año 2008. Otras instituciones se establecieron más rápidamente luego de la fundación del pueblo, como la Delegación Municipal (1911), la escuela en sus primeros años (1913), la estafeta 
postal (1913), la formación del equipo de fútbol Sportivo Sansinena (1920), el Centro Recreativo Sansinena (1928), el cementerio local (1942) y posteriormente la iglesia católica (1970) (Bello y De la Iglesia, 2009).

Es interesante destacar que las instituciones que menos tardaron en formarse están fuertemente ligadas a la vida cultural y religiosa del pueblo, y si bien son aquellas que pueden instalarse prescindiendo de herramientas tecnológicas y de infraestructura, manifiesta la fuerte necesidad de los recién llegados en contar con espacios físicos y simbólicos que cobijen y conserven sus costumbres y creencias.

Durante las últimas décadas del siglo $\mathrm{XX}$, por medio del trabajo de las distintas sociedades de fomento que se crearon en el pueblo y los reiterados pedidos a las autoridades, se logró implementar el sistema de educación secundario, un bachillerato de adultos, crear un centro de jubilados, un cuartel de bomberos voluntarios, una radio FM y una biblioteca. Muchos de estos proyectos siguen en pie, otros desaparecieron y otros se re-crearon luego de lo que sería el capítulo recordado como el más oscuro de la historia del pueblo: las inundaciones del año 2001.

\section{2. ¿Por qué un antes y un después del 2001?}

El año 2001 significó un quiebre en la historia del pueblo de Sansinena. A fines de ese año el desborde del Río Quinto, ubicado al sur de la provincia de Córdoba, generó inundaciones de una gravedad inédita en la región del distrito de Rivadavia. Si bien los conflictos por el agua fueron regulares desde 1980, a fines del 2001 el desborde del río, la intensidad de las lluvias y la ausencia de planes estratégicos que puedan solucionar el problema de raíz se conjugaron, y las aguas cercaron al pueblo de Sansinena aislándolo del resto de las localidades. Los canales de contención y canalizaciones que se hicieron en provincias cercanas para alejar al agua no respetaron el escurrimiento natural del río, lo que provocó que las crecidas llegaran a lugares inusitados; tal es así que "Sansinena, oficialmente, dicho por Hidráulica de la Provincia de Buenos Aires, desaparecería bajo el agua (...) por eso empezaron a evacuar el pueblo" (Testimonio Oscar De la Iglesia, vecino de Sansinena). 
Los testimonios de los vecinos coinciden en recordar aquella época como la más traumática de la historia del pueblo, cuando los unimog del ejército entraron a llevarse a las personas mayores y a los niños a América, una de las localidades más cercanas. Un grupo personas, en su mayoría adultos jóvenes, se quedaron en el pueblo "resistiendo" para que el agua no entre al pueblo; construyeron canales de contención con bolsas, e incluso redactaron un plebiscito para desvincularse de la provincia de Buenos Aires, empezar a pertenecer a La Pampa y de esa manera captar la atención de las autoridades.

Cuando regresaron a Sansinena, muchos de los habitantes habían perdido todas sus pertenencias, sus viviendas y grandes superficies de tierras utilizadas para la producción agrícola y ganadera. Por otro lado, la Radio FM dejó de funcionar porque una de las tormentas eléctricas de ese año dañó los equipos; también en el 2001 cerró la estafeta postal porque se privatizó el Correo Argentino y la Delegación pasó a ser el lugar de recepción de correspondencia. Según testimonios de los vecinos, el descontento generalizado que generó las inundaciones, paralizó los proyectos colectivos que se habían iniciado años antes.

\title{
2.3. De tambos y chacareros
}

\author{
La ruta asfaltada marca una muralla, los límites de este \\ universo cuyas poblaciones y poblados son distintos (...) \\ donde termina el asfalto comienza otro mundo que merece ser \\ estudiado" (Ratier, 2009: 5)
}

Es importante tener en cuenta que la pampa es una región de gran importancia en lo económico y en lo simbólico. Su centralidad dentro del imaginario social está asociada con "la nación", al ser considerado un sector eminentemente productivo. Durante los años 90 en los sectores agro ganaderos tuvo lugar el llamado proceso de sojización, promovido por los cambios en los sectores productivos, que comenzaron a buscar un nuevo lugar en la división internacional del trabajo. Se fortalecieron las grandes corporaciones agroindustriales, profundizando la precarización del mercado rural, los procesos de descampesinización, la liberalización de la economía, el fin de proteccionismo y la omnipresencia del mercado como patrón regulatorio (Ratier, 2009). 
Si bien las medidas económicas implementadas por el gobierno de facto en los 70 apuntaban a la liberalización de la economía, esta tendencia fue profundizada por el gobierno de Carlos Menem, en donde:

Los grupos que habían resultado vencedores en las pujas distributivas desde 1975 en adelante, y se habían apropiado de todo tipo de rentas creadas por el sector público antes, durante y después del Proceso, no eran ya el problema, sino la solución (Novaro, 2009:339)

En este estado de cosas, el disminuido valor de la leche y los altos costos para producirla llevaron a los tamberos a alquilar sus campos para la producción de soja, desmantelando el sistema productivo instalado desde hacía años. El proceso de agriculturación desplazó a la producción ganadera y láctea, obligando a los productores a optar por otros sistemas como los feed lots, los pools de siembra, la siembra directa o los paquetes de insumos. El denominado "boom de la soja" se convirtió en uno de los fenómenos más destacados, ya que adquirió dimensiones insospechadas a raíz de la incorporación de la soja transgénica ${ }^{17}$, que hacia los últimos años de la década del '90 comenzó a reemplazar al maíz, al sorgo y a la producción ganadera, ocupando mayores superficies de tierra (Teubal, 2006).

Durante los años 30 funcionaba en Sansinena una fábrica de quesos, crema y caseína que proporcionó trabajo a muchos de los habitantes del pueblo. La fábrica Halley, única industria que existió en esta región, se proveía de tambos que funcionaban en tierras alquiladas. Ésta dejó de producir con la llegada de las grandes empresas Sancor y La Serenísima, contra quienes le fue imposible competir ${ }^{18}$.

La actividad tambera también se vio afectada por las modificaciones del sistema productivo, ya que tanto la actividad tambera como ganadera requieren mayor mano de obra y preparación de las instalaciones que el cultivo de soja, y el suelo no necesita preparación. Esta ventaja, sumada a la retirada del Estado como regulador de la articulación entre soja/ industria, condujo a la imposición de los precios por parte de ésta

\footnotetext{
${ }^{17}$ Se trata de la semilla RR, resistente al glifosato, que es producida por Monsanto.

${ }^{18}$ Según los testimonios de Beba Felleti, vecina de Sansinena (78 años).
} 
última (Rodríguez, 2005), y a que las tierras antiguamente utilizadas para la ganadería y la actividad tambera se convirtieran en terrenos aptos para el cultivo de soja, de mayor rentabilidad.

Al cierre de la industria de quesos y de las grandes estancias, como La Marianita -que proveía de trabajo al $80 \%$ del pueblo-, se sumó el éxodo en los años 50, de personas que se fueron a trabajar en las fábricas de las grandes ciudades. Por eso el pueblo pasó de ser uno de los más poblados del distrito -3000 personas en la década del 40- a ser uno de los más pequeños en el nuevo siglo. La falta de oportunidades laborales y el aislamiento del resto de las localidades por la ausencia de una ruta asfaltada, generaron una lógica de geografía marginal ${ }^{19}$ (Ratier, 2009). Desde el año 1911 los sansinenses están reclamando la construcción de una ruta asfaltada o mejorado que les permita salir del pueblo los días de lluvia. Pasaron más de cien años y "la ruta en la nada" ${ }^{20}$. Todavía conservan los documentos de los reiterados pedidos a las autoridades de turno, que fueron respondidos con promesas aún no cumplidas.

Si bien en los últimos diez años se puede observar un crecimiento de la población del 35\% (se pasó de 400 a aproximadamente 630 habitantes), y un aumento en la producción ganadera que había disminuido a raíz de las transformaciones del sistema productivo implementadas en los años 90, el problema del desempleo persiste, porque no hay propuestas de inversión a largo plazo que signifiquen una fuente de trabajo realmente sustentable para el pueblo. Algunos autores como Lattuada y Neiman (2005) identifican una declinación en la vida de pueblos o localidades rurales que se manifiesta en la desaparición de servicios (como el ferrocarril); otros destacan una profundización

\footnotetext{
${ }^{19}$ Cuando aludimos a la marginalidad geográfica hacemos referencia a las distancias entre el pueblo y otras localidades cercanas a las que es difícil acceder por falta de rutas, a la espera por la instalación de los sistemas de agua potable y de gas que colaboren en la independencia del pueblo frente a los recursos naturales básicos, a la falta de instituciones educativas de nivel universitario, las dificultades con el acceso a la salud, entre otros.

${ }^{20}$ Fragmento de una canción del grupo de la obra Por los caminos de mi pueblo, del Grupo de Teatro Popular de Sansinena.
} 
de la conflictividad social y las luchas de diversos sujetos sociales generados a partir de la situación de exclusión ${ }^{21}$ (Azcuy Ameghino, 2004).

Liliana Marcantonio, la delegada actual del pueblo y reelecta en las últimas elecciones de octubre de 2011, enfatizó el rol que desempeñan las empresas multinacionales en los pueblos pequeños, en este caso, la empresa Cargill ${ }^{22}$, a través de la cual se gestionó, conjuntamente con la Asociación Responde ${ }^{23}$, la instalación de una planta de alimento balanceado. El Municipio proveyó el terreno, y el Ministerio de Asuntos Agrarios colocó el dinero para hacer la planta que aun no está en funcionamiento porque no se han terminado de limpiar los terrenos en los que se instalará la planta.

\section{La fuerza de la tradición}

"Yo perdí la juventud en el campo, trabajando como un hombre, y siempre lo llevo en el alma"24

La vida cultural de un pueblo es en gran medida fruto de la convergencia de intereses, historias y tradiciones de sus habitantes. En una comunidad como Sansinena, nacida a la luz de la hibridación de culturas producidas por la inmigración, las actividades recreativas tuvieron un sesgo particular, fuertemente atado a las instituciones, los edificios y el territorio. El fútbol, actividad deportiva que nació casi acompañando el surgimiento del pueblo en los primeros años del siglo XX, tuvo gran repercusión en su momento pero duró sólo unos diez años. Los tradicionales bailes populares, la elección de la reina y el baile del chocolate se realizaron principalmente en las décadas del 70/80. Eran muy esperadas las fondas, las visitas a los campos vecinos, los tés danzantes, las

\footnotetext{
${ }^{21}$ Como los cortes de ruta y piquetes de 1994 o la conformación del Movimiento de Mujeres en Lucha (1995).

${ }^{22}$ Cargill es una de las siete empresas exportadora multinacionales que acaparan la exportación de cereales nacional (Teubal, 2006).
}

23 "RESPONDE es una Organización No Gubernamental de Promoción y Desarrollo, fundada por la Dra. Marcela Benítez en 1999 como resultado de sus investigaciones científicas en el marco académico del CONICET. Pone en acción su know-how para dar respuesta a la problemática de un sector de la población rural de la Argentina que se encuentra en crisis por despoblamiento". (texto de la página oficial: http://www.responde.org.ar/index.html)

${ }^{24}$ Vecina de Sansinena (66 años). 
quermeses de los carnavales, las actuaciones de grupos folclóricos y la orquesta de los Hermanos Bello ${ }^{25}$.

Retomando las reflexiones de Ratier, coincidimos en señalar la existencia en Sansinena de "formas económicas no orientadas exclusivamente por el lucro, una solidaridad activa traducida en múltiples asociaciones comunitarias y estilos propios de hacer política" (2009:11). Los carteles que reciben a los visitantes portan las leyendas: "Sansinena, pueblo de amigos" y "Sansinena existe, venga y disfrute", consignas que el mismo autor señala como comúnmente utilizadas en los pueblos bonaerenses del interior, como una estrategia de autoafirmación y resistencia a la desaparición. Es una forma de diferenciarse de los demás, constituirse identitariamente apoyándose en la tradición (Ratier, 2009). Tal como reflexiona Candau (2008) en torno a la importancia del nombre propio como apuesta a un marco identitario y memorialista, el slogan elegido fusiona la idea de la visibilizacion del pueblo $-\mathrm{y}$ resistencia frente a los discursos que sostenían que el pueblo iba a desaparecer- con la de la oferta de aquello que para los pobladores es lo más atractivo del pueblo: la atención y deferencia de los vecinos para con el visitante.

La fuerza que tiene la tradición y las costumbres en los pueblos ${ }^{26}$ es notable, y se evidencia en la lucha por mantener vigentes ciertos "códigos" que caracterizaron usualmente las relaciones laborales, familiares y sociales en general. Por un lado, la informalidad de las relaciones laborales, revestidas de un sesgo patriarcal-clientelar, se mantienen en un acuerdo basado en la oralidad, donde el patrón es el que manda, y lo más importante entre patrón y peón es la confianza (Ratier, 2009).

En una ocasión tuvimos la posibilidad de presenciar una charla en donde una mujer que habitaba un campo cerca de Sansinena, manifestaba su agradecimiento y alegría, porque el patrón la dejaba a ella y a su familia comer en la mesa del living de la casa (generalmente reservado a los dueños del campo, ya que los peones comen en la cocina), y les permitía tener un número de vacas y otros animales de granja para su

\footnotetext{
${ }^{25}$ Hay numerosas referencias a estas festividades en los testimonios registrados a los vecinos del pueblo.

${ }^{26}$ Tradición y costumbre se diferencian, según Hobsbawm (2002), en que mientras la primera tiene como objetivo la invariabilidad, la segunda no descarta el cambio y la innovación en un momento determinado.
} 
consumo personal. A este caso se le suman otros en los que hemos presenciado una actitud sumisa y abnegada del peón frente al patrón, en donde los pequeños gestos de gratitud de estos últimos se sobredimensionaban en una exacerbación de las "bondades del empleador" por parte del peón.

Por otro lado, el peso de la tradición se descarga en el respeto a las instituciones, principalmente la escuela, la Iglesia, los clubes, el centro de salud, e, indiscutidamente, la máxima autoridad local: el Intendente, representado en la figura del delegado. Estas organizaciones generan actividades que ponen en movimiento al pueblo, generando núcleos de sociabilidad, recaudando fondos para otras instituciones y funcionando como portadoras de poder político. Representantes del asociativismo local (Ratier, 2009), las cooperadoras y comisiones que se instauran en estas instituciones detentan diversos grados de poder político en el pueblo, porque hacia ellas se dirige el Intendente para negociar o comunicarse con la comunidad. Es importante destacar que, en las comisiones de los clubes Centro Recreativo de Sansinena y el Club Social de González Moreno, por ejemplo, no se les permite participar a las mujeres ${ }^{27}$. Esta modalidad de funcionamiento de la política local, que apunta a invisibilizar las jerarquías, está atravesada por una informalidad cargada de rituales, en donde es primordial acudir a la festividad o conmemoración de hechos significativos o personajes emblemáticos del pueblo, para lograr la apelación a la identidad del lugar. Es decir, que las festividades adquieren significación como táctica de cohesión de los pobladores, en tanto apelan a un pasado común que los identifica como portadores de esa singularidad identitaria.

Como vimos en el caso de Patricios, muchos pueblos rurales del interior esbozan estrategias de supervivencia ligadas al turismo rural (Ratier, 2009), apostando a generar un atractivo basado en la conservación del pasado (tanto material como simbólico), destacando las bondades de los modos de reciprocidad que se mantienen en estos pueblos en contraposición con la anonimia y alienación de las grandes ciudades. Si bien Sansinena no desarrolló aun este tipo de proyecto, las lógicas que rigen las

\footnotetext{
${ }^{27}$ El día 9 de marzo del 2012 el Grupo de Teatro Comunitario de Rivadavia presentó a través de la Cooperativa Comunitaria un proyecto al Concejo Deliberante, con el fin de que las mujeres puedan participar en las comisiones directivas de los clubes Centro Recreativo de Sansinena y el Club Social de González Moreno.
} 
celebraciones y actividades promovidas apuntan a destacar las virtudes del pueblo en ese sentido (aquí todos nos conocemos, es tranquilo, somos solidarios, accesibles, etc.), principalmente ante la visita de foráneos. Al mismo tiempo que se intenta atraer nuevos pobladores que colaboren con la activación económica y social del pueblo, existe un rechazo a lo nuevo, y un miedo creciente a todo lo desconocido. Tal es así que una vecina nos contaba que comenzó a cerrar la puerta de noche porque "cada vez viene más gente que no es del pueblo, que uno no conoce" 28 . La tensión entre lo nuevo y lo viejo, lo de adentro y lo de afuera, será constante en las prácticas cotidianas de los vecinos y vecinas del pueblo, al igual que en las del grupo de teatro comunitario.

Por último, destacamos que a pesar de que no encontramos en el pueblo sectores de la población que estén atravesando situaciones de indigencia o extrema pobreza, observamos que existe una marcada estratificación de condiciones sociales diferenciadas, que se visualiza fácilmente en la distribución del espacio. Si consideramos a Sansinena una matria, una "micro región cultural de fuerte sabor localista, como esos espacios cortos que se abarcan con una sola mirada y se puede recorrer de punta a punta en un solo día" (González en Giménez, 1999:46), destacamos con Giménez (1999) que aún en localidades tan pequeñas se distribuye el espacio geográfico según la polaridad centro-periferia. En las calles más alejadas de las instituciones simbólicamente importantes como la delegación municipal o la iglesia, que se encuentran en lo que sería "el centro" del pueblo, se levantan las casas que los vecinos denominan como casas de barrio, que son aquellas edificaciones construidas por los gobiernos de turno para los pobladores que no podían construirse su casa propia. Por negociaciones frustradas y problemas de propiedad de la tierra las casas de barrio que encontramos en Sansinena se encuentran despobladas, y las construcciones a medio hacer, con excepción de una sola que fue ocupada.

\footnotetext{
${ }^{28}$ Testimonio una vecina de Sansinena (66 años).
} 


\section{Y donde hubo teatro...}

Las primeras expresiones teatrales de las que se tiene conocimiento en Sansinena fueron los sketches realizados durante los carnavales en la década del 40, en donde se realizaban sátiras italianas arriba de las "chatas"29.

En 1952 el grupo de Teatro Vocacional dirigido por Abelardo Moure llevó a escena la obra Alma de suburbio y unos ocho años después el mismo director formó el grupo Florencio Sánchez. Participaba de esa experiencia un joven del pueblo, Osvaldo de la Iglesia, quien instituye en los años 60 un grupo de teatro vocacional juvenil, donde gran cantidad de jóvenes oficiaban de escenógrafos, iluminadores y ayudantes de dirección. En 1985 representaron la obra "Los Mirasoles", que tuvo gran repercusión en el pueblo y es frecuentemente evocada en la memoria de los habitantes. Cuando Osvaldo de la Iglesia falleció en las postrimerías de los años 90, la actividad teatral se fue con él, y no sería hasta los primeros años del nuevo siglo que su hija, María Emilia de la Iglesia, reflotaría la actividad teatral en el pueblo ${ }^{30}$.

No han sido pocos los vecinos que señalaron la afección de Sansinena hacia el teatro, y el apoyo que siempre se ha brindado a esta actividad desde los pobladores. Tal es así que el Grupo de Teatro Popular de Sansinena lleva ya seis años de existencia, superado sólo por el equipo de fútbol Sportivo Sansinena, que llegó a los diez años de permanencia.

\subsection{Grupo de Teatro Popular de Sansinena}

A comienzos del año 2005, una joven oriunda del pueblo llamada María Emilia de la Iglesia, se encontraba finalizando sus estudios en la facultad de Comunicación de la Universidad Nacional de La Plata, y en la Escuela de Teatro de La Plata. Si bien conocía la experiencia del teatro comunitario de los grupos Catalinas Sur y Barracas, la motivación que la llevó a convocar a los vecinos para hacer teatro fue la intención de

\footnotetext{
${ }^{29}$ Camionetas que cuentan con una cabina delantera y una caja trasera.

${ }^{30}$ La reconstrucción de la trayectoria que tuvo la actividad teatral en el pueblo la realizamos acudiendo al testimonio de los vecinos y al libro de Bello, Edith \& de la Iglesia, M. Emilia. (2009). Sansinena existe. Retazos de memoria. Tejidos de futuro. Buenos Aires: Municipalidad de Rivadavia.
} 
unir lo teatral con lo comunicacional, en pos de generar una actividad inclusiva para los vecinos del pueblo.

La idea es ver que había algo que estaba faltando en el pueblo, y volver a tomar el ritual del teatro en el pueblo. Porque el teatro había sido muy importante, y una muestra de eso son los clubes que tienen un escenario a la italiana, que son muy grandes, donde la gente se juntaba y hacía un montón de actividades teatrales. Entonces había una herencia de eso, en la memoria de la gente estaba el tema del teatro pero hacía, en el caso de Sansinena 17 años que no se hacía teatro ${ }^{31}$.

Luego de conseguir el apoyo de la Jefatura de Cultura de la Municipalidad de Rivadavia hacia fines del año 2005, se comenzaron a dictar los talleres, los que eran abiertos a todo aquel que quiera sumarse. Si bien la convocatoria no tenía restricciones, los vecinos no se acercaron inmediatamente, ya que la misma atravesó un proceso de resistencia durante el cual los sansinenses manifestaban desconfianza y poco interés en participar del grupo -con excepción de un grupo reducido que acudió a la primera convocatoria-, aunque hubo una masiva presencia de espectadores en el primer estreno de De pie como un árbol. La tenacidad de María Emilia y de su madre, Edith Bello, para integrar cada vez más personas al grupo, cobijó innumerables visitas y charlas a los vecinos, a los que había que convencer de que el teatro era algo bueno para ellos y para el pueblo y que valía la pena participar.

Por un lado, todos los testimonios coinciden en aseverar que las consecuencias devastadoras de las inundaciones del año 2001 apagaron los ánimos de los vecinos, forjando un estado generalizado de parálisis y recluimiento en los espacios privados de sus hogares. Por otro lado, la vida cultural del pueblo profundizó el mismo camino, con la ausencia de propuestas o iniciativas que construyeran nuevos espacios de intercambio o reunión entre los vecinos. También observamos en las entrevistas que existía un endiosamiento de la figura del actor, como aquel personaje "talentoso" que pertenece exclusivamente a las grandes ciudades y que estudió para poder ejercer el oficio. Por lo tanto, el inicio y desarrollo del grupo de teatro significó un lento proceso de asimilación, tanto para aquellos que querían participar como para los que no lo hacían, al igual que

\footnotetext{
${ }^{31}$ María Emilia De la Iglesia, directora del Grupo de Teatro Comunitario de Sansinena y directora general del Teatro Comunitario de Rivadavia.
} 
un trabajoso camino de aceptación para muchos que veían en el teatro una forma de perder tiempo.

Hacia el año 2006 se estrenó De pie como un árbol, una adaptación de Los árboles mueren de Pie, del dramaturgo Alejandro Casona. La repercusión del estreno, que tuvo más de 300 espectadores, colaboró en la configuración de una imagen nueva sobre el grupo de teatro, tanto para los vecinos como para las autoridades. Al igual que sucedía en el caso de Patricios, observamos que, la mirada desde el "afuera", la visita de foráneos y la atención de los medios de comunicación ${ }^{32}$, fueron fundamentales para que el teatro adquiriera un nuevo sentido, ya no marginal, sino asociado a un "nosotros" legitimado que se muestra al resto de la sociedad.

En el año 2007 el grupo estrenó una adaptación de La zapatera prodigiosa, de Federico García Lorca, y la repercusión tuvo la misma magnitud. Desde un comienzo las funciones se realizaban en articulación con alguna institución del barrio, con la idea de poder colaborar así con el pueblo ${ }^{33}$

A partir del año 2008, y con la fiesta del Centenario de Sansinena que se cumpliría el marzo del año siguiente, los vecinos comenzaron a pensar en construir una obra teatral que cuente su historia. Con el ingreso del Grupo de Teatro Popular de Sansinena a la Red Nacional de Teatro Comunitario ${ }^{34}$ en el 2008, la actividad teatral adquirió características más definidas en consonancia con los discursos de la Red, en tanto lo primordial pasó a ser el trabajo de construcción colectiva y la suma de más personas al grupo. La participación en la Red Nacional implicó la inserción del grupo de Sansinena en un marco de visibilidad que antes no tenía, ya que comenzó a ser parte de un movimiento cultural más amplio, y a ser incluido en los registros de difusión de la red. Esta pertenencia, sin embargo, está atravesada por una tensión: mientras que la

\footnotetext{
${ }^{32}$ El estreno de la obra fue noticia en los diarios locales Actualidad y la Nueva Prensa. En el caso de $L a$ zapatera prodigiosa, el Suplemento N de Clarín publicó una nota titulada "Cachetazo de campo".

${ }^{33}$ Así lo afirman María Emilia de la Iglesia y Edith Bello, directora y coordinadora, respectivamente, del grupo de teatro.

${ }^{34}$ La Red Nacional de Teatro Comunitario nuclea a todos los grupos de teatro comunitario del país, con el objetivo de construir un espacio de intercambio de experiencias y saberes (www.teatrocomunitario.com.ar).
} 
visibilidad que otorga la Red promueve la difusión de la actividad del grupo y le otorga cierto reconocimiento como parte de un movimiento mayor, los testimonios reflejan con excepción de los coordinadores- un desconocimiento de lo que es la Red y de su actividad. Este desconocimiento de la red y del vínculo que el grupo tiene con ella lo evaluaremos más adelante.

El traspaso de la representación basada en una obra de autor, a la construcción colectiva de un relato autorreferencial, generó tanto adscripciones como disidencias. Registramos que aquellos que contaban con una experiencia teatral previa, o que habían participado tiempo atrás en otros grupos de teatro independiente, concibieron este cambio como una desvalorización de sus aptitudes, ya que en esta nueva dinámica teatral no se buscan los protagonismos, sino la integración de una mayor cantidad de vecinos. Se trataba de un proceso de creación en donde niños, adultos, jóvenes y adultos mayores convivían durante varias horas, con reiteradas situaciones de impuntualidad, desacuerdos y conflictos de regularidad. La apertura en la participación generó, por un lado, la incorporación de personas cuyo primer contacto con el mundo teatral fue este grupo (tanto como actor como de espectador), y por el otro, el alejamiento de aquellos que consideraban que esta lógica inclusiva iba en desmedro de la calidad artística de la obra $^{35}$.

A su vez, se trataba de una actividad en donde se buscaba una división de tareas en diversas áreas de trabajo (escenografía, maquillaje, vestuario, prensa, entre otras), tal como suelen organizarse otros grupos de teatro comunitario (Bidegain, 2007). Pero la escasa cantidad de habitantes llevó a que todas las personas colaboren en todas las áreas de trabajo, aportando cada uno lo que podía desde su lugar. A diferencia de otros grupos en los cuáles la circulación y el recambio de vecinos que entran y salen del grupo es permanente, en el caso del grupo de Sansinena cada uno se convertía en un personaje imprescindible, porque no se contaba con reemplazos regulares que pudieran suplir roles ajenos.

\footnotetext{
${ }^{35}$ Este desplazamiento lo observamos en los testimonios de los vecinos que habían comenzado a participar de las primeras obras del grupo (las obras de autor), y que manifestaron haberse alejado del grupo cuando comenzó a construirse la obra que contaba la historia del pueblo porque era "desprolija", había problemas de "impuntualidad" o "todos hablaban al mismo tiempo".
} 
En la fiesta del Centenario del pueblo - marzo del 2009- se estrenó Por los caminos de mi pueblo, con un público que triplicaba la cantidad de habitantes del pueblo, la presencia de autoridades y pobladores de localidades vecinas. Para esa función se contó con el apoyo de la Comedia de la Provincia y de la Municipalidad de Rivadavia (Bello y de la Iglesia, 2009). La significación que adquirió esta festividad fue notable, ya que por las calles de Sansinena circuló más del quíntuple de personas que conforman la comunidad. A partir de ese estreno, el Grupo de Teatro Popular de Sansinena fue mutando en cantidad de integrantes, pero siempre se mantuvo un núcleo duro de nueve o diez personas que sostuvieron la actividad con regularidad. Por otro lado, María Emilia junto con los coordinadores del grupo de Sansinena, comenzaron a visitar pueblos cercanos con la idea de gestar nuevos grupos de teatro. La primera de las localidades que inició una actividad teatral comunitaria junto con Sansinena fue González Moreno, pueblo ubicado al límite con la Pampa, a unos $45 \mathrm{~km}$ de América, la cabecera del Partido de Rivadavia. Se destacaron las diferencias entre ambos grupos en cuanto a composición, ya que mientras Sansinena está conformado en su mayoría por adultos mayores y niños ${ }^{36}$, González Moreno cuenta con mayoría de jóvenes y adultos jóvenes. La idea de formar grupos se fue profundizando cada vez más, y actualmente los hay en Fortín Olavarría, América, Roosevelt y San Mauricio, todas ellas localidades del Partido de Rivadavia ${ }^{37}$.

El Grupo de Teatro Popular de Sansinena tuvo participación en la obra "Violeta y Jacinto" (2009) del Grupo de teatro comunitario de González Moreno y continuó representando Por los caminos de mi pueblo durante el año 2010. También participó de

\footnotetext{
${ }^{36}$ Como hemos señalado, los jóvenes y adultos jóvenes emigraron del pueblo por cuestiones de estudio o por razones laborales. En palabras de la delegada del pueblo: "El trabajo, dentro de lo que es Sansinena, no es que hay una necesidad enorme, pero sí te ves limitado en algunos puntos. Porque por ejemplo, en algún momento se trabajaba mucho la ganadería, hoy en día la ganadería es muy poca. En consecuencia de eso mucha gente se queda sin empleo. Cuando reflotó ahora la ganadería los precios se fueron por las nubes, asique el que compraba una vaca ahora te compra una pata de la vaca (...) uno viene a vivir acá y sabe que tiene que conseguir trabajo en la delegación, la escuela, la unidad sanitaria o en la casa de la cultura, o de policía (...) en general la gente vive de changas, que no es lo ideal pero es lo que hay y es lo que momentáneamente se viene, porque uno nota que cada vez la gente desemplea más a otra gente y empiezan a dar vueltas".

${ }^{37}$ Los grupos de teatro de estos pueblos del Partido conformaron el Grupo de Teatro Comunitario de Rivadavia.
} 
la obra La historia se entreteje desde abajo, y se cambia desde la comunidad, una representación construida por todos los grupos de teatro comunitario de los pueblos del Partido de Rivadavia. Durante el año 2011 trabajó con Charlatanes, una obra de autor, y fue una de las sedes del IX Encuentro Nacional de Teatro Comunitario, organizado también por los grupos de Rivadavia.

El grupo de teatro se convirtió en la primera organización social existente en el pueblo, accesible para todo aquel que quiera participar, sin ningún tipo de restricción. Cuando hablamos de organización social nos referimos a la conformación de un colectivo, que lleva adelante actividades específicas, que adquiere determinadas lógicas de funcionamiento y que, lentamente, construye su legitimidad a base de acción. No existieron sindicatos, partidos políticos activos u organizaciones sociales previas que hayan marcado el surgimiento del grupo de teatro. Más bien se trató de la conjunción de experiencias individuales -en su mayoría desprovistas de prácticas colectivas previasque por diversos motivos se fueron acercando al grupo.

La composición del grupo es heterogénea. Conviven personas que poseen diversos grados de escolaridad (desde analfabetos hasta universitarios), distintas edades y condiciones de género, de desigual poder adquisitivo (incluso participan patrones y peones de la misma actividad), disímiles intereses y acercamientos hacia la vida cultural (personas que venían haciendo teatro, participando de eventos y experiencias culturales, y otras que la primera vez que vieron una obra de teatro fue la de Sansinena). En la vida de campo que llevaban muchos de los pobladores que residen hoy en el pueblo, toda actividad cultural se convertía en inaccesible, situación que era acentuada por la ausencia de una ruta asfaltada. A la luz de estas dificultades, para muchos sansinenses, la emergencia de un grupo de teatro del pueblo que era de libre acceso, se convirtió en la primera posibilidad de participar en una actividad cultural, que adquirió una mayor adherencia al ser de origen local, conformada por personas de una colectividad de interconocimiento. ${ }^{38}$ Consideramos importante destacar que el grupo innovó en el hecho de conformar un espacio en donde se lleva a cabo una interacción constante entre

\footnotetext{
${ }^{38}$ Ratier (2009), cita a Mendras (1978), para caracterizar a esta colectividad en la que cada uno está ligado a los demás por una relación bilateral de conocimiento y tiene conciencia de ser conocido del mismo modo por el otro.
} 
niños, jóvenes, adultos, y adultos mayores, fomentando procesos de transmisión de conocimientos, aprendizajes, y nuevos modos de sociabilidad.

Muchos de los vecinos han dicho que cuando están en el teatro las diferencias se borran, -refiriéndose a las edades, a las posiciones político partidarias, o los conflictos personales-. Todo se resuelve en ese espacio, y no sale de allí, a la vez que "todos se transforman en niños", porque todos allí juegan y se divierten sin limitaciones etarias. Observamos que los procesos creativos que se desarrollan hacia adentro de la actividad del grupo, las relaciones de poder, las jerarquías, los imaginarios y las prácticas se tejen en esa interacción constante del hacer.

Sin adentrarnos todavía en el tipo de espacio que el grupo construye, sus lógicas y estrategias con el afuera, visualizamos en una primera mirada al teatro como depositario de sentidos y significaciones muy diversas; un entrecruzamientos de expectativas, trayectorias, e intereses diversos que confluyeron en un mismo proyecto teatral. Pero no todos los roles comportan el mismo protagonismo dentro del grupo, ni todos exhiben el mismo compromiso con la actividad. Eso dependerá, por un lado, de las lógicas que configuren el espacio teatral, y por otro, de las historias personales, los procesos de interpelación que el teatro logre hacer en cada vecino y vecina del pueblo, los rasgos que definan el "quiénes somos" y el "quien es el otro".

Si nos preguntamos por la participación juvenil en el grupo, registramos que del escaso número de jóvenes que vive en Sansinena, particularmente aquellos que se encuentran atravesando las últimas instancias del segundo ciclo, han promovido en los últimos años una profusa cantidad de proyectos para presentar en concursos, eventos e instituciones. A pesar de que los jóvenes conforman el sector que se siente menos interpelado por el teatro, participan activamente de otras propuestas, como el proyecto Jóvenes y Memoria $^{39}$, de la Comisión Provincial por la Memoria ${ }^{40}$, o el Concejo Deliberante

\footnotetext{
${ }^{39}$ Para este proyecto realizaron una investigación sobre un estudiante nacido en Colonia Seré (pueblo cercano a Sansinena) que fue desaparecido durante la última dictadura militar, en el año 2010 hicieron un trabajo sobre la pérdida de los derechos del trabajo, relacionado con las políticas socioeconómicas que llevaron al cierre de la fábrica de quesos, y durante 2011 trabajaron con la temática de la pérdida del ferrocarril.

${ }^{40}$ El programa "Jóvenes y memoria, recordamos para el futuro" se lanzó en el año 2002 de la mano de la Comisión Provincial por la Memoria de la Provincia de Buenos Aires, con el objetivo de promover el
} 
Juvenil $^{41}$. Si observamos los temas seleccionados por los jóvenes para desarrollar en estos proyectos, vemos que tanto el cierre del ferrocarril como el de la fábrica de leche son problemáticas que retoma la obra Por los caminos de mi pueblo, mientras que la dictadura militar del 76 y sus consecuencias, no figura como parte de los hechos más significativos de la historia local. Queda pendiente el interrogante en torno a la poca participación de los jóvenes en el teatro, considerando que esta práctica articula las temáticas que ellos abordaron en los proyectos presentados, pero aun así no logra interpelarlos.

Veremos en las próximas páginas cuáles son las dinámicas clave del proceso de producción del grupo, a través del análisis de la creación y puesta y escena de la obra de teatro Por los caminos de mi pueblo, y cómo se constituyen en esas dinámicas las lógicas de producción de identidades, los procesos en los que se pone en juego la existencia o no de una memoria colectiva, y la posibilidad de visualizar al teatro como una práctica performativa del territorio, y generadora de espacios de nuevo orden.

tratamiento de la última dictadura militar en las escuelas secundarias bonaerenses. La propuesta es que sean los adolescentes quienes investiguen y "cuenten" la historia. Los alumnos formulan hipótesis, interpretan y deciden qué y cómo contar. (Página Oficial: http://www.comisionporlamemoria.org/jovenesymemoria/inicio.php)

${ }^{41}$ El Concejo Deliberante Juvenil es un programa lanzado por la Municipalidad de Rivadavia, con el objetivo de que los estudiantes del Colegio secundario puedan "conozcan de manera directa como funciona el Poder Legislativo". 


\title{
Capítulo II
}

\section{Conservación y transformación, una relación dialéctica posible}

\author{
"La cultura hace existir una colectividad en la medida en \\ que constituye su memoria, contribuye a cohesionar a sus \\ actores y legitima sus acciones" (Giménez, 1999:32)
}

Dentro de la literatura que abordó el análisis de la práctica teatral comunitaria, los procesos de memoria que se generan en el momento de la creación de la obra de teatro fueron descriptos y caracterizados a la luz del ejercicio de la memoria colectiva del grupo en cuestión (Bidegain, 2007; Bidegain, Quain y Marianetti, 2008; Proaño Gómez, 2007).

Los grupos de teatro comunitario existentes manifiestan una diferenciación -en relación a grupos de teatro independiente o grandes compañías teatrales- en cuanto a sus modos de producción: se trata de la conjunción de la no-profesionalización de sus miembros, sumada a una estrategia colectiva de creación. Esta metodología implica que todas las personas que componen el grupo pueden participar de la creación de la obra, a través del aporte de vivencias personales, anécdotas (historias de vida), documentos (fotos, cartas, recortes de diarios, videos), entre otros. Como el relato que se intenta armar cuenta la historia del pueblo, todos los que viven allí son pasibles de reconstruir esa historia, porque han sido y son parte de ella. Los procesos de intercambio y transmisión que encontramos allí no son lineales ni unidireccionales, sino que están compuestos por representaciones, pensamientos, expectativas, cuestionamientos, interrogantes y factores emotivos de los vecinos y vecinas de Sansinena. Reconstruiremos en este apartado esos procesos, para dar cuenta de los elementos que lo componen e intentar comprender cómo a través de esta experiencia cultural se ponen en juego visiones sobre el pasado, sentidos del presente y expectativas de futuro. 


\section{Proceso de construcción de la obra}

"El recuerdo del pasado es un desafio lanzado hacia el futuro que consiste en sopesar hoy, lo que ha sido hecho con lo que podría ser hecho" (Candau, 2008:63)

La obra Por los caminos de mi pueblo es un relato que narra los acontecimientos más importantes de la historia del pueblo de Sansinena, desde su origen hasta las inundaciones del año 2001.

María Emilia de la Iglesia (la directora del grupo) propuso la idea de que Sansinena cuente su historia a través del teatro, y para hacerlo comenzó convocando a los vecinos a reuniones o charlas "de amigos" 42 en donde cada uno de los presentes puso en común expectativas, gustos, preferencias, ideas o anécdotas sobre un posible relato. A modo de taller los presentes se armaban en grupos y escribían en un afiche los sucesos de la historia del pueblo que consideraban infaltables. Luego ese material se puso en común, se debatió entre todos cuáles eran los temas que finalmente quedarían y cuáles no, y comenzaron las improvisaciones sobre esos sucesos. El armado de las escenas era definido por María Emilia. Estas estrategias de creación no fueron lineales, y los textos que se fueron eligiendo, al igual que el modo de representarlos, fue material de debate.

\section{1. ¿Qué contar? ¿Por qué? ¿Cómo?}

El primer paso para construir un relato colectivo que configure una narrativa propia es apelar a aquellas cosas que los miembros del grupo tienen en común: la historia, el territorio, las familias que dieron origen al pueblo. La proyección de diapositivas en el Centro Recreativo Sansinena -primer paso de este proceso- mostraba a los primeros habitantes del pueblo, en su mayoría inmigrantes de Europa, provenientes de las grandes oleadas inmigratorias de principios del siglo XX. La intención era identificar vestuarios, rasgos corporales, actitudes y todo aquel elemento que pueda ser utilizado para la reconstrucción de las familias de esa época. En esa proyección se destacó un rasgo

\footnotetext{
${ }^{42}$ Coordinador del grupo de Sansinena.
} 
fundamental de todo el proceso creativo, y pilar del mismo: la emoción, que, junto con los valores y las necesidades, se convierte en la razón de ser que le da energía al recuerdo (Candau, 2008), y articula aquello que debe ser recordado.

Los temas indiscutidos que surgieron en las primeras charlas fueron: la llegada de los inmigrantes, el reparto de tierras, el reclamo histórico de los caminos, el ferrocarril, la llegada de los parientes de Buenos Aires y las inundaciones. Luego se agregaría una escena sobre la peluquería de Federico Rota, un personaje emblemático del pueblo, propuesta por uno de los vecinos que lo conoció y trabajó con él durante muchos años. Darío Fernández, uno de los coordinadores del grupo de Sansinena, comentó que “aunque parezca mentira todos pusimos prácticamente las mismas cosas, porque eso era lo que compartimos y vivimos”.

Los vecinos comentaron haber apelado principalmente a las personas mayores del pueblo para que contaran anécdotas sobre épocas más antiguas. Esta interpelación a los mayores delimitaría la voz "autorizada" para corregir futuros desacuerdos sobre los hechos del pasado. Para los miembros del grupo serán estas personas que vivieron esas historias, las legitimadas como portadoras de la verdad, y a quienes se acudirá al momento de definir cómo fueron los hechos; el parámetro que define quiénes son los poseedores del conocimiento está configurado por los rasgos que aporta la experiencia.

Dentro de este proceso de reconstrucción de la propia historia, los vecinos recuerdan que el tema que presentó mayor discusión en la selección de los hechos se trató de una cuestión que si bien tuvo su origen con el nacimiento del pueblo, es una problemática que continúa hasta hoy: la falta de caminos. Como indiscutible reclamo histórico, la lucha por conseguir un camino asfaltado que una el pueblo con ciudades cercanas figuró en todos los afiches elaborados en los primeros talleres. Pero muchos vecinos no querían que aparezca este reclamo en la obra porque la misma se iba a estrenar para el Centenario, en donde las autoridades (como el Intendente), iban a estar presentes, lo que, según ellos, significaría “opacar" la celebración con una escena que podría representar una interpelación a la responsabilidad estatal. Como la Municipalidad de Rivadavia había colaborado con la infraestructura necesaria para que Por los caminos de mi pueblo pueda representarse en la estación -con instalación de luces y equipos de 
sonido-, esa escena que destacaba el pedido de asfalto desde el año 1911, sería como "morder la mano del que te da de comer". ${ }^{43}$

Lo interesante de este conflicto, prácticamente el único que los vecinos recuerdan del proceso creativo, es que justamente no está enraizado en una discusión sobre el pasado, sino sobre el presente. ¿Por qué consensuar sobre una problemática del presente resultó más conflictivo que acordar sobre un pasado compartido? Si bien pasado y presente son temporalidades que se entrecruzan de modo permanente en las representaciones que las personas construyen sobre sí mismas, cuando incidimos en un proceso de memoria colectiva, las similitudes en la interpretación de la historia pasan a un primer plano, porque "en el momento que considera su pasado el grupo siente que claramente ha seguido siendo el mismo y forma conciencia de su identidad a través del tiempo" (Halbwachs, 1968: 218). El proceso que el autor identifica en el momento en que el grupo "mira" hacia el pasado y se piensa desde el presente, está signado por una búsqueda de conservación, en tanto se identifica a sí mismo percibiéndose como siempre ha sido y seguirá siendo. Si bien la tensión que surgió al momento de debatir la escena de los caminos encuentra parte de su explicación en el vínculo que el grupo mantiene con el poder y las autoridades -tema que abordaremos en el próximo capítulo, nos interesa destacar el ímpetu de preservación identitaria que encontramos en el proceso de la construcción de la memoria colectiva, como un rasgo fundamental que acompañará al lenguaje teatral. Comprendemos que la interpelación a un pasado compartido se transforma en el bastión fundamental para lograr cohesión entre los vecinos del grupo, frente a posibles desacuerdos en cuestiones del presente. La tensión con las autoridades causó un conflicto divisivo en el grupo, que sin embargo mantuvo su cohesión gracias al ímpetu de preservación identitaria que tiene sus bases en el pasado compartido.

Podemos identificar entonces dos elementos: por un lado, una tendencia de la construcción de la memoria colectiva a producir una mirada conservada de la historia, que no cambia a través del tiempo, en tanto percibe la imagen de una comunidad que sigue siendo en el presente igual a como fue en el pasado, que produce un nosotros del

\footnotetext{
${ }^{43}$ Idem.
} 
presente, que define sus rasgos identitarios en función de su oposición/diferenciación a un "otro" y de la imagen que quiere reflejar hacia el afuera. ¿Cuál es, entonces, la definición de ese nosotros que construye el grupo de teatro a partir de la producción teatral? ¿Cuáles son sus rasgos, cómo quiere ser reconocido por los "otros”? ¿Cómo se construye la imagen de ese "otro" y qué fisonomía encarna?

\section{Ser y pertenecer: claves de un relato instituyente}

“QQué tenemos que contarle a los otros y contarnos a nosotros mismos? ¿Qué significa ser y pertenecer a este pueblo? ${ }^{, 44}$

Con esta pregunta inicial el grupo de Teatro Popular de Sansinena comenzó el proceso creativo que dio origen a la obra Por los caminos de mi pueblo. Ser de Sansinena, pertenecer al pueblo, son dos verbos claves que delimitan claramente un factor vinculado a una identidad compartida o colectiva, a la construcción imaginaria de una figura dibujada por nosotros mismos que podamos oponer a la mirada del otro; por lo tanto, lo que podemos llamar una identidad colectiva es un "sí mismo colectivo" (Villoro, 1998), que no es una propiedad intrínseca del individuo, sino que tiene carácter subjetivo y relacional, y que implica un marco de representaciones compartidas. La pertenencia es el factor fundamental que aglutina los elementos que el sujeto comparte con el otro, porque "es reconocido como perteneciendo a un colectivo, siendo una serie de atributos y cargando con un peso biográfico" (Giménez, 1997: 5). Pertenecer a un grupo implica, entonces, compartir el núcleo de representaciones sociales ${ }^{45}$ que los caracteriza y define.

En palabras de Hall (2003: 18): “... a las identidades debemos considerarlas producidas en ámbitos históricos e institucionales específicos, en el interior de formaciones y prácticas discursivas especificas, mediante estrategias enunciativas específicas”. Desde

\footnotetext{
${ }^{44}$ Idem

45 Nos referimos a la representación como un "corpus organizado de conocimientos y una de las actividades psíquicas gracias a las cuales los hombres hacen inteligible la realidad física y social, se integran en un grupo o en una relación cotidiana de intercambios, liberan los poderes de su imaginación" (Moscovici, 1979: 17-18). En palabras de Martín Mora (2002: 7): "es el conocimiento de sentido común que tiene como objetivo comunicar, estar al día y sentirse dentro del ambiente social, y que se origina en el intercambio de comunicaciones del grupo social".
} 
el enfoque "discursivo" de la construcción de identitaria, ésta se encuentra en constante construcción, porque se trata de "puntos de adhesión temporaria" que el individuo construye a través de sus prácticas discursivas.

Reconocemos que existe en el proceso de reconstrucción de la propia historia una dialéctica entre memoria e identidad, porque los recuerdos de diversas épocas de nuestra vida son reproducidos incesantemente, lo que permite que se perpetúe el sentimiento identitario (Halbwachs en Candau, 2008). Ahora bien, si nos abocamos al análisis de las operaciones de memoria involucradas en la construcción de la obra teatral, observamos que adquiere gran centralidad la categoría de memoria colectiva. Para Candau (2008), dicha categoría es una metáfora que junto con otras -como memoria común o memoria social- intenta expresar la existencia de una memoria compartida por un grupo de personas $^{46}$. Más allá de su definición específica lo interesante es tener en cuenta que los diversos estudios sobre memoria colectiva dan cuenta del carácter limitado y selectivo de la memoria, tanto individual como colectiva, porque tiene un carácter parcial, discontinuo y cambiante a través del tiempo. Estas características radican en la imposibilidad de retener la totalidad de los hechos, lo que implica la presencia del recuerdo, el silencio, el olvido y la nostalgia en el mismo proceso (Cuesta Bustillo, 1998) y la imposibilidad de una historia "neutra" y "objetiva”. Comprendemos, por otra parte, que estas operaciones de memoria están atravesadas por circunstancias particulares de cada momento histórico, que construyen significaciones o sentidos diversos en relación a los sucesos.

Las personas que conforman el grupo de teatro poseen un corpus compartido de representaciones sobre su pasado, esto confirma que la memoria colectiva tiene como principal elemento los recuerdos compartidos. Los hechos que conforman el relato de la obra son aquellos acontecimientos significativos que "no pueden faltar", y que son identificados por los vecinos actores como los que marcaron la historia del pueblo, "los más fuertes", "los más importantes". Registramos en los testimonios de los vecinos una

\footnotetext{
${ }^{46}$ La definición clásica de Memoria colectiva es la evocada por Halbwachs como "el conjunto de recuerdos reconocidos por un determinado grupo", mientras que Todorov la definió como una "memoria pública o comunidad de pensamientos" (Candau, 2008). Para Jedlowski, es "la acumulación de las representaciones del pasado que un grupo produce, mantiene, elabora y transmite a través de la interacción entre sus miembros" (Bellelli \& Curci, 1999).
} 
aceptación e identificación de los hechos representados en la obra como aquellos que “dejaron huella" en el pueblo, o "conformaron el pueblo tal como es ahora".

\section{Memorias...}

\section{La nostalgia}

\footnotetext{
"A mí me gusta ir a ver las funciones, que son muy buenas, muy de respeto, y eso es lo que vale para nosotros los antiguos, porque uno se crió así de tanto respeto" $" 47$

"En algún momento tenés que bajar la cabeza debajo del agua, no siempre estar en la superficie de las cosas. Pero a lo mejor no es tiempo todavía”,48
}

Como hemos señalado, escasas discusiones se registraron en el proceso creativo de construcción de la obra, lo que muestra una fuerte uniformidad en las representaciones compartidas sobre el pasado. Los acontecimientos relatados en la obra teatral a través de la utilización del grotesco, la sátira y un leve tono irónico, reconstruye estos sucesos intentando generar una imagen que los reproduzca con el mayor grado de detalle posible, apelando a la identificación de las vivencias compartidas del públicoespectador. La interpelación a ese pasado compartido se convierte en material fundamental para asegurar la permanencia del tiempo y la homogeneidad de la vida, como un intento de demostrar que el pasado permanece, al igual que la identidad del grupo y sus proyectos (Halbwachs, 1968). Es decir, que la representación teatral se convierte en una herramienta que utiliza la apelación a la memoria colectiva, con un fin identitario que apunta fundamentalmente a la estabilización y la permanencia de los rasgos que definen a la comunidad, y los diferencian de otra. El pueblo de Sansinena, caracterizado por sus habitantes por la oposición a los valores "de la ciudad", valorizan positivamente la tranquilidad, la seguridad, la solidaridad, la prolijidad del pueblo, la familia y las tradiciones; todo esto conforma un marco social (Halbwachs, 1968), en donde se tejerán las operaciones memorialísticas.

\footnotetext{
${ }^{47}$ Vecina de Sansinena (82 años)

${ }^{48}$ Habitante de González Moreno nacido en Sansinena (47 años).
} 
La memoria en su procedimiento selectivo, construye un relato que tendrá como basamento una historia que puede integrarse en el sistema de valores de la comunidad (Yerushalmi, 1989); en este sentido, comprendemos que la historia construida por los vecinos estará atravesada por los principios morales y éticos que componen el corpus de valores de la comunidad. Ese sistema que subyace en la selección de acontecimientos manifiesta un tono muchas veces nostálgico, en cuanto el pasado aparece idealizado, magnificado en "aquellos buenos tiempos" (Candau, 2008). Esta operación se observa principalmente en la escena del ferrocarril, momento en el que mucha gente del público lloró al recordar el sonido de la bocina del tren. La revalorización de las tradiciones es explícita en las escenas costumbristas, que retratan momentos "vividos" por muchos de los vecinos, como el baile del chocolate o la visita de los familiares de Buenos Aires. La búsqueda por retratar los sucesos tratando de buscar el mayor grado de detalle posible en la imagen de (vestuario, gestos, modos de hablar, anécdotas, dichos populares) aquellos personajes emblemáticos del pueblo (como el peluquero Federico Rota), da cuenta del valor que los vecinos le otorgan a sus tradiciones y costumbres en la configuración identitaria.

El teatro de acá es muy emotivo, de revivir cosas de tanta gente, de poder decir algún día que yo participé en el aniversario del pueblo (...) cosas que te llegan, hasta para contarle a tus nietos, porque viste que son todas experiencias en la vida. Desde las cosas que te suceden que no las querés recordar hasta lo que te gusta, todo es experiencia ${ }^{49}$.

Se relata una historia muy localista, que intenta reforzar aquellos elementos que dan cohesión al pueblo a través de la construcción de una memoria fuerte (Candau, 2008), compacta, que se impone a la mayoría de los miembros del grupo, y que estructura fuertemente la representación que éstos harán de su propia identidad. Mantiene lo que el mismo autor esboza como ilusión de una comunidad absoluta, que a través de la narrativa produce una ficción unificadora. Es el "yo colectivo" que quiere establecer una unidad, e intenta establecer una coherencia entre las imágenes que tiene de su pasado, las que los demás tienen de él en el presente, y las que proyecta para el futuro (Villoro, 1998).

\footnotetext{
${ }^{49}$ Vecina de Sansinena y miembro del grupo de teatro, docente (55 años).
} 


\section{Somos lo que somos}

Al mismo tiempo que aprendemos sobre nuestro pasado, aprendemos quién constituye la alteridad; en ese proceso el sujeto organiza su relación con el mundo y con los demás, y construye una valorización de sí mismo. Es una búsqueda por "valorar positivamente su identidad, lo que estimula la autoestima, la creatividad, el orgullo de pertenencia, la solidaridad grupal y la voluntad de autonomía" (Giménez, 1997). En la obra de teatro, esta búsqueda de valorizar positivamente la identidad sucede tanto en los momentos que representan una época favorable para el pueblo (como en el periodo ferroviario), como en las desfavorables (durante las inundaciones), ya que, en las situaciones dramáticas, se intenta destacar el esfuerzo y los valores de los vecinos por unir fuerzas en pos de salir de esa situación.

Nosotros pasamos por una inundación, que nos costó un montón reponernos de eso, en la época de la inundación es cuando se notó la solidaridad que todo el mundo estaba trabajando hasta las cuatro de la mañana, y yo no tengo fotos de eso, pero las mujeres cocinaban para darle de comer a los hombres que andaban continuamente trabajando, poniendo bolsas, tapando... ${ }^{50}$

Villoro (1998) afirma que la representación que una comunidad tiene de sí misma se vuelve un tema de reflexión expresa sólo en situaciones críticas. Es discutible esta afirmación, en cuanto no definamos desde qué perspectiva consideramos a la reflexión: como una acción o como un proceso interno. En el primer caso, la reflexión se materializa en una práctica concreta -de carácter colectivo o individual-, mientras que en el segundo se configura como pensamiento individual que no logra transformarse en acción. Todo lo colectivo, para adquirir visibilidad debe ser expresado en acciones e involucra un proceso de puesta en común que guiará a la acción. En el caso del Grupo de Teatro Popular de Sansinena es indiscutible la conformación de un colectivo que implicó la participación de buena parte de los vecinos en prácticas concretas de acción. Sin embargo, la existencia de este proceso no involucra por sí sola la reflexión crítica sobre las representaciones del pasado, porque allí se ven comprendidas diversas operaciones -selección, olvidos, censuras, entre otras- que si bien portan una interpretación nueva de ese pasado, pueden simultáneamente colaborar con su

\footnotetext{
${ }^{50}$ Delegada Municipal del pueblo de Sansinena (33 años).
} 
reproducción acrítica donde esté ausente un cuestionamiento sobre los procesos históricos más profundos que dieron origen a una situación determinada.

A modo ilustrativo, podemos citar la escena de las inundaciones, en donde se ve retratado el dolor de los habitantes por la pérdida de sus casas y el miedo al advenimiento del agua, pero donde no están explícitas las causas que desataron tal inundación ${ }^{51}$. De haber estado explícitas estas causas, hubiese resultado incómodo o impertinente para los vecinos ya que, al igual que la escena del reclamo por los caminos, significaría una acusación o marcación de responsabilidades (en el primer caso a las autoridades municipales, en el segundo a las comunidades cercanas). Algunos testimonios asociaban el reclamo de los caminos con "lo político", y uno de los miedos de incluirlo en la obra era que se "vuelva todo político",52. Dentro de esta lógica, en donde aquello que puede acarrear conflicto o generar una ruptura con el orden es percibido como amenaza, toda transformación que implique un cuestionamiento incluirá un proceso lento y conflictivo, de negociación constante con el ímpetu de conservación del orden. En la interpretación del pasado que se propone en la obra no se complejizan las tensiones que generó el conflicto ni los actores involucrados.

En el proceso creativo, la transmisión de la memoria fue una operación fundamental para la reconstrucción de la historia del pueblo, que estableció nuevos parámetros de legitimidad sobre los cuáles se edificaron criterios de verdad y realidad. Estos parámetros se erigen sobre valores de "respeto a los mayores" que ya existían en la comunidad, y no se proponen como "alternos". Sin embargo, "la verdad que vale" es la de la experiencia vivencial, no la historia propuesta por los libros o los saberes académicos; los adultos mayores eran aquellos portadores del conocimiento, y a los cuales se recurría para delimitar "cómo fueron las cosas realmente". Allí jugaron un rol principal las biografías incanjeables (Giménez, 1997) que hacen referencia a identidades biográficas (Pizzorno, 1989) o íntimas (Lipianzky, 1992), que son aquellas que configuran "la transición entre mi auto narrativa personal y el reconocimiento de la misma por parte de mis interlocutores" (Giménez, 1997: 16). Las historias de vida

\footnotetext{
${ }^{51}$ El desborde del Río Quinto se desvió hacia la zona de Sansinena porque se construyeron canales de contención en localidades cercanas que no respetaron el escurrimiento natural del río.

${ }^{52}$ Coordinador del grupo de Sansinena (25 años).
} 
fueron, junto con los aportes realizados en los talleres, la materia prima desde la cual se estructuraron los hechos que constituyeron el relato.

El carácter intergeneracional de la práctica teatral comunitaria forja una interacción ineludible entre vecinos de diversas edades; este encuentro de edades es vivido en la mayoría de los casos como un borramiento de las fronteras generacionales, que forja una cohesión grupal que no se da en otros espacios de sociabilidad extra familiares. Las personas del grupo manifestaron "sentir que no hay edades, que todos podemos jugar como chicos" ${ }^{, 53}$, que se produce una integración diferente, porque cada uno aporta desde su lugar; se genera una adultización de los jóvenes y una infantilización de los adultos (Fernández, 2011). Sin embargo, son aquellos cuya experiencia de vida es más larga quienes participaron más activamente del proceso creativo.

Multitemporal, denso, y cargado de múltiples dimensiones, el proceso de transmisión de la memoria requiere necesariamente que aquello que recibe el sujeto pueda ser impreso por sus propias huellas y mandatos (Dussel, 2001); es decir, que pueda encontrar allí un espacio de reencuentro con el pasado desde su propio mundo de significaciones (Hassoun, 1996).

La obra de teatro puede ser vista como una herramienta de conmemoración (Cuesta Bustillo, 1998) o como un lugar de memoria (Nora, 1998), en tanto la teatralización significa una reescritura de la historia, en donde las representaciones de la metamemoria -aquellas representaciones que los sujetos realizan sobre su propia memoria- (Candau, 2008) son fundamentales.

Dentro de los procesos de transmisión de la memoria, el ejercicio de reconstruir el relato a través de la historia oral, aporta una mirada de gran riqueza y de historias a pequeña escala, información a la cual no se tiene acceso de otra forma que no sea por el recuerdo de los vecinos (Prins, 2009). Por otro lado, las memorias de cohorte (aquellas que se construyen generacionalmente), son un elemento destacado en este proceso, durante el cual se va construyendo un espacio de intercambio que pocas veces se da en otros ámbitos sociales. La diversidad etaria no sólo estratifica las experiencias según los años

\footnotetext{
${ }^{53}$ Vecina de Sansinena y miembro del grupo de teatro (53 años)
} 
de nacimiento y su contexto histórico determinado, sino también aporta una dimensión más en el estudio de los procesos de memoria, ya que se ven involucrados vecinos que vivieron experiencialmente los hechos, con jóvenes que representan estos hechos en un producto teatral, pero que han recibido la información de adultos o adultos mayores. En el caso del grupo de Sansinena, el factor etario es muy fuerte, ya que el grupo se compone mayoritariamente de adultos mayores y niños, quedando la franja de jóvenes y adultos jóvenes casi ausente. Este reencuentro es más visible en el momento mismo de la puesta en escena, cuando se representa la obra teatral.

\section{Por los caminos de mi pueblo: análisis de escenas y puesta en escena}

\section{La realidad y la ficción en un mismo escenario}

Para comprender de forma más acabada los procesos de sentido que atraviesan la obra de teatro del grupo de Sansinena, comenzaremos por construir una breve estructura con los sucesos que guían el relato.

Introducción- Los personajes que antiguamente pasaban el cine en el pueblo -Julio y Sebastián- se
encuentran en el andén y comienzan a pasar los rollos de películas que irán hilvanando los diferentes
momentos de la historia del pueblo.

Escena 1 -Año 1909. Venta de tierras (remate), bocina del tren y llegada de los inmigrantes. Los dueños de las tierras comienzan a tomar personal para las colonias.

Canción $\mathrm{N}^{\mathrm{o}} 1$

Proyectores Julio y Sebastián. Rollo del año 1947.

Escena 2- Familia de los años 50. Llegada de los familiares de Buenos Aires al pueblo por el cumpleaños de la abuela.

Canción $\mathrm{N}^{\mathrm{o}} 2$

Proyectores Julio y Sebastián. Peluquería

Escena 3- Peluquería de Federico Rota, fábrica de quesos y baile del chocolate.

Julio y Sebastián divisan a una mujer que viene en un auto antiguo y se van.

Escena 4- La viuda de Sansinena, Agustina Luro, viene en un auto antiguo. Figura ser año 1960, y se queja de los caminos sin asfaltar y sin mejorado.

Canción $\mathrm{N}^{\mathrm{o}} 3$

Escena 5- Inundaciones 
Canción $\mathrm{N}^{\circ} 4$

Escena 6- Entran chicos vestidos con guardapolvos y una maestra. Izan la bandera argentina y se escucha la voz en off de la FM Sansinena. Los chicos hacen un juramento al pueblo.

Canción $\mathrm{N}^{\mathrm{o}} 5$

Apagón final

Lo que esta estructura nos permite observar a simple vista, es la apelación directa a los personajes que formaron parte del pueblo, como los relatores de la historia.

Se nos ocurrió que los históricos cineastas que pasaban la máquina de cine en el pueblo, que eran dos personajes muy simpáticos, podían ser explotados y ellos podrían haber encontrado un montón de cintas de películas que les fueran dando vida a esas escenas. Y así fue como conseguimos el hilo conductor, como por arte de magia ${ }^{54}$.

La estrategia de apelar a una experiencia vivida/ pasado común, se vuelve literal en varios sentidos y ocasiones. Por ese motivo, frente a la pregunta por posibles desacuerdos los vecinos reconocían que siempre se llegaba a un acuerdo porque era la realidad de lo que se había vivido, porque la gente sabía que eso había sido cierto. En primer lugar, con la utilización de nombres propios en casi todas las escenas, que representan a los personajes reales que tuvo el pueblo, se afianza el sentido de realidad, y se carga a esa escena de una significación de verdad. A su vez, hay personajes que se representan a sí mismos: como Nino, el músico que entra en la escena de Federico Rota haciendo de él mismo, o Beba Felleti, que representa a la abuela que quieren llevarse del pueblo por las inundaciones, situación que vivió ella misma en el año 2001.

Un recurso utilizado para reforzar el sentimiento de identificación con el público fue la proyección de diapositivas; las mismas aparecían al inicio de cada nueva escena como parte de las películas de Julio y Sebastián, y mostraban fotografías reales de cada una de las situaciones que se desarrollarían en la obra. Se expuso por medio de este dispositivo un mapa de la venta de tierras, una imagen del tren (acompañada por el ruido de la bocina), imágenes de inmigrantes en el campo, una familia de los años 50, fotografías

\footnotetext{
${ }^{54}$ Coordinador del grupo de teatro de Sansinena.
} 
de Federico Rota, la fábrica de quesos y el baile del chocolate, y un mapa de cómo se veía Sansinena durante las inundaciones del año 2001. Muchas de las fotografías eran personales, y fueron donadas por los mismos vecinos que conformaron el público, lo que significó una injerencia directa de los mismos en la constitución de la obra, como partícipes y colaboradores.

Esta búsqueda de generar un acercamiento al público, un impacto emotivo atravesado por la experiencia vivencial de los acontecimientos representados, se complementa con la inclusión de la interpelación al público como parte de la obra. Los actores se dirigen a los espectadores y les hacen preguntas o formulan comentarios, incluyéndolos en la ficción, lo que disminuye aun más la distancia entre actor y espectador. La ruptura del ilusionismo hacen que la ficción y la realidad se junten.

"Julio: estoy rastreando los rollos de las películas (al público): ¿no las vieron por acá?”

"Entran en escena un rematador con puntero y botas altas, traje entallado, representando a Tierras del Oeste y una secretaria (con anteojos grandes, miran al público como si toda esa gente estuviera en el remate)".

La ficción, que se ve un poco desdibujada por la apelación constante a situaciones, anécdotas y personajes que existieron realmente en la historia del pueblo, se afianza con la utilización de los recursos del lenguaje teatral, presentando esas situaciones, muchas veces dolorosas para los vecinos que las experimentaron (como por ejemplo las inundaciones), de modo humorístico o a través de la sátira.

\subsection{Ironías y sátiras que definen características del YO sansinense}

Dentro de cada escena podemos identificar ciertos elementos que, por medio de la utilización de diversas herramientas del lenguaje teatral, establecen sentidos identitarios y ponen de manifiesto ciertas significaciones sobre el pasado. Algunas escenas echan mano de diversos géneros teatrales como el grotesco, el sainete, el absurdo o la comedia del arte, elecciones que permiten elaborar narrativas desde el humor, alejadas del drama y de ciertas tendencias contemporáneas que complejizan el relato a través de la 
codificación simbólica, la fusión de disciplinas, la subversión del uso del espacio, etc. Al respecto, un vecino actor expresa su percepción sobre la obra de teatro Por los caminos de mi pueblo:

\begin{abstract}
“Al principio me pareció un poco extraña, no conocía este fenómeno del teatro comunitario, entonces me parecía como muy fragmentada, no me gustaba el tema de las canciones (...) yo venía de una formación de actor de teatro independiente, de escenario, y me parecía muy extraño, me parecía muy elemental en algunas cosas; yo tenía una mirada demasiado formada en otras particularidades. Después cuando empecé a comprender más la obra, resignifiqué muchas cosas, y me pareció muy valiosa, aparte había sido una creación de la gente, y la gente se involucraba con eso" ${ }^{\text {"55 }}$.
\end{abstract}

Vinculados con los rasgos nostálgicos que identificamos en el guión y las canciones de la obra del grupo sansinense, la elección de géneros que apelan al humor, por medio de la construcción de estereotipos exagerados, ridiculizaciones e ironías, está en consonancia con el grupo de teatro que apunta a una reconstrucción histórica cuyo material se genera en tono emotivo sobre el basamento de la experiencia vivida. La apelación al humor apunta a "decir de un modo no confrontativo" aquello que puede generar alguna tensión. Si bien es un recurso ampliamente utilizado por los grupos de teatro comunitario, en el caso del grupo sansinense la sutileza con que se lleva a cabo se explica por la intención de matizar las posibles reacciones que las críticas pudiesen despertar en las autoridades o en los mismos vecinos.

En la escena del remate de tierras el personaje del rematador es representado desde la parodia, como un usurero a quien lo único que le interesa es conseguir dinero; lo sigue la secretaria, quien, ridiculizada con anteojos grandes es cómplice del rematador. Ambos se valen de la estafa y cobran comisiones por cada venta:

“Rematador: ¡Hay que vender como sea estas tierras!, asíque sonreí Ofelia y mostrá el tobillo”... "Rematador: ¡Vamos Ofelia! Que ya hemos hecho mucho dinero...jmuchas gracias, buenas noches a todos! (solo a Ofelia, pero mirando cómplice al público) ¿Sabés cuando van a escriturar estos?’...

\footnotetext{
${ }^{55}$ Habitante de González Moreno nacido en Sansinena. participó de la construcción y la representación de la obra Por los caminos de mi pueblo (47 años).
} 
La dicotomía ciudad-campo que registramos en las propuestas de muchos de los vecinos de Sansinena, está en la escena del cumpleaños de la abuela. Allí, un notorio contraste entre las actitudes de la gente de la ciudad y la del campo refleja una tensión, principalmente en cuanto a los adelantos tecnológicos y la idea del progreso.

Caracterizados como opuestos, lo rural aparece como lo atrasado, pobre, aislado, de cambios lentos, atado a la naturaleza y a la producción primaria; lo urbano como lo rico, moderno, dinámico, industrial, conectado con el mundo (Reboratti en Craviotti, 2008: 101).

Esta sátira o ridiculización que exacerba los rasgos atribuidos a cada personaje, destaca las oposiciones que distinguen a los estereotipos construidos en base a las vivencias de los mismos vecinos. La crítica que aparece en esta escena -que también apela al humorfunciona como un guiño para el público, conformado principalmente por vecinos del pueblo o de pueblos cercanos, quienes asiduamente conviven con los discursos tipificados:

Si bien actualmente la visión dicotómica se encuentra bastante desdibujada por diversos factores que colaboraron con la hibridación de lo rural y lo urbano (difusión en el ámbito rural de pautas culturales consideradas urbanas, el desplazamiento cotidiano de la población con fines laborales, entre otros) (Craviotti, 2008), la obra propone revertir estos parámetros.

\footnotetext{
Familia que viene de Buenos

"Marisa: ¡Ay, qué lindo está el campo!

Sofía: Pero como se nota la diferencia, mirá como tengo el pelo, lleno de tierra...

Dainana: ¡Mami, quiero ver tele!

Doris: Callate nena, que acá los parientes del campo no tienen tele.

Dainana: ¿Y qué hago?

C: Jugá con tus primitos, dale

Blanca: ¿Adónde estamos nena?

Oscar: Hace dos minutos que pisé el andén y ya extraño el ruido"

Doris: ¿y estará Rosa, siempre tal celosa?

Dainana: O Juana, qué chapada a la antigua

Comadreja: Mirá cuando le muestre la Kodak a la vieja, se desmaya, qué joyita...
}

Familia del campo 
Entran las nenas con globos (Daiana, Betina). Vienen unas señoras apuradas acomodar el lugar...

Susana: apurate que vienen!

Beba B.: Sí, pero como Marta se durmió, nadie acomodó nada ¡iqué desastre!!

Mabel: Bueno, a llorar a la Iglesia, dale iiapurate!!

Tati: Al final mis hermanas se pelean, pero soy siempre yo la que termino fregando como una desgraciada.

Juan: Ustedes discuten, pero el burrito cordobés es el que acarrea esta mesa.

(van acomodando el lugar, mientras van entrando todos)

Susana: Y seguro ahora las pitucas vienen mostrando todo lo que se compran en Buenos Aires

Mabel: Y yo que no me pude hacer ni la permanente con tanto alboroto

La presentación de la oposición ciudad-campo se observa en la enumeración de elementos que representan la cotidianidad del ámbito urbano y rural en tensión. Mientas el primero está asociado con el ruido, los adelantos tecnológicos, la posibilidad de acceso a distintos dispositivos de entretenimiento, la vestimenta "elegante", el segundo se representa con la sencillez, la austeridad, la naturaleza (la tierra).

El mito es otro rasgo presente en la construcción del relato teatral, que interviene como herramienta de identificación apelando al imaginario construido por la comunidad. Sabemos que éste organiza y estructura acontecimientos en función de valores, creencias y concepciones de mundo (Lindón, 2000). Cuando el recuerdo es mitificado y cargado de nostalgia, el pasado se ofrece como un refugio ante la situación actual, o un presente concebido como desgraciado (Cuesta Bustillo, 1998).

Los personajes emblemáticos del pueblo -representados de modo sintético por el peluquero Federico Rota- son caracterizados según el mito creado por la comunidad. El vecino que protagonizó este personaje- Arsenio Ghiorzi- se valió no sólo de su conocimiento directo de Rota (fue su ayudante), sino también de todas las historias que se contaban de él. En esos relatos, que se convirtieron en mitos con el paso del tiempo, se creó el imaginario de que se trataba de un hombre "que se mandaba la parte", porque, como se dedicaba también a confeccionar bombachas de campo, solía comentar que recibía pedidos de personas de Europa que buscaban exclusivamente sus servicios para esta labor.

\footnotetext{
${ }^{56}$ Vecino de Sansinena y miembro del grupo de teatro (47 años)
} 
En la siguiente escena, propuesta y creada principalmente por Ghiorzi, la complicidad con el público está anclada en el conocimiento del mito, y las características atribuidas al personaje. La escena incluye no sólo la idiosincrasia de un día cotidiano en la peluquería, sino también otros dos elementos: el baile del chocolate y el cierre de la fábrica de quesos.

"Cliente: ¿Y Federico?

Juanita: está cortando las bombachas para la gente de La Primavera.

Federico: Buen día, estoy casi sin dormir cortando bombachas para exportar a Alemania, y éstas las mando a la estancia La Primavera".

"Cliente 1: Se enteraron de que Melano anda medio mal, qué macana si se presenta a quiebra...

Federico: Pero no sea exagerado hombre, acá es imposible que cierre la fábrica, si Sansinena es una gran cuenca lechera, yo visito todos los campos con el pibe de Ghiorzi.

Cliente 1: grande será, pero quién se aguanta dos o tres meses adentro sin cobrar, gracias que los almacenes y carnicerías fían que si no..."

El baile del chocolate es una festividad tradicional del pueblo, ocasión de festejo y alegría, que si bien no se representó con una escena propia en la obra, tuvo su lugar en pequeños parlamentos dentro de la escena de la peluquería. En el caso del cierre de la fábrica de quesos, constatamos en las representaciones de los vecinos una memoria melancólica sobre lo que la fábrica significó a nivel laboral en el pueblo, pero como una pérdida menor, no equiparable a la desaparición del ferrocarril o los daños producidos por las inundaciones. El cierre de la fábrica se presenta en el guión como un comentario, pero no se desarrolla en una escena aparte, tampoco se mencionan los actores involucrados, no se problematizan las circunstancias que llevaron a su cierre o el impacto que tuvo en el ámbito laboral del pueblo.

\subsection{Los caminos}

¿Cómo representar en una obra teatral más de cien años de reclamo por un mejorado del camino sin generar conflicto ni identificar a los culpables? Como señalamos, la escena de los caminos fue la más discutida, por su actualidad, por las tensiones que genera, por su repetición, y por la exposición que adquiría en el momento de su estreno (el Centenario del pueblo: marzo del 2009). Con los temores de que un señalamiento de los 
responsables por la permanencia del problema acarrearía conflictos con las autoridades, y de que esta actitud significaría arruinar el clima festivo de la ocasión, los debates se suscitaron hasta llegar a un acuerdo, que se completó luego de que se hizo la función, cuando "muchos de los que participaron, que no estaban convencidos por ejemplo de la escena de los caminos, se dieron cuenta después de que pasó la primer puesta en escena del Centenario, que era sumamente necesario tener esa escena, porque les cayó bien a todos (...) hasta el Intendente se reía de la escena y le gustó". 57

“Aparece en un auto antiguo la viuda de Sansinena sentada arriba del capó un grupo de hombres empujándolo.

Agustina de Luro: ¡Qué olor Don Cacho! Pero cuando yo doné las tierras, me dijeron que estaba entre América y General Villegas. ¿Y aquí donde estamos don Cacho?

Don Cacho: ¡Pero Señora! Una cosa es del Bajo de Tabaso para acá y otra muy distinta es del bajo de tabaso para allá. Pero no todas son malas, señora, pusieron luz eléctrica con bombita y todo. El pueblo instaló un aparato grandote le decimos Radio Pacheco, y se hace así "Pacheco, Pacheco, acá Sansinena a la escucha, Pachecho, pachecho, pacheco no sé escucha una mierda, pacheco. Y bueno, es la ilusión que alguien nos escuche y diga jviven todavía!

A.L: Bueno, basta de cantinela, lleveme al hotel del pueblo.

Don Cacho: No hay hotel, desde que cerró la Fonda de Guerra nos arreglamos con las casas de familia.

A.L.: Hay tengo jaqueca!, a esta altura con tanto taco en la tierra tengo la columna hecha trizas, por favor!, ya estoy para que me internen en el Hospital, necesito masajista.

Don Cacho: No hay masajista, apenas una sala de primeros auxilios, pero el Doctor Nuñez, la Yoly y la Marta la van a dejar nuevecita, no se preocupe señora, póngale onda.

A.L.: Pero mire, usted me trajo por caminos malos, polvorientos, miré cómo tengo el vestido. En 1911 me mandaron una carta ¿sabe? En esa carta, firmada por Don Jesús Lado me comunicaba que la Comisión de Fomento le había reclamado al comisionado para abrir nuevos caminos. Ya estamos en $1960 . .$. usted se tiene que hacer cargo a esta altura...mínimo un mejoradito...

Don Cacho: Pero ellos dicen que somos pocos, no tenemos cantidad de votos, que tenemos que tener paciencia, capaz que lo autoricen, ahora que asumió este gobierno...

A.L.: ¿Y dónde está mi calle? En esa carta me decían que la calle de la Estación llevaría mi nombre...Y yo no puedo llegar ni siquiera a ver mi calle...

No sé, yo no he visto ningún cartel todavía...

Don Cacho, ¿y eso, qué es, qué festeja esa gente, quiénes son?

No sé Doña, esto jamás sucedió, eso se lo puedo asegurar...

${ }^{57}$ Coordinador del grupo de Sansinena (25 años). 
Los recursos teatrales utilizados para poder incluir la cuestión de los caminos sin generar tensión, como señaló también Fernández, se basaron en la manejo de estrategias de ridiculización de los mismos vecinos, respecto a situaciones que deben atravesar cotidianamente por no tener caminos: "que nos quedamos encajados, que se nos tapan los carburadores, que se nos pinchan las cubiertas cuando no llueve porque los tornillos salen a cubierta por el desgaste de la erosión del viento".

Esta escena significó un desafío a la hora de la representación, ya que se intentó visibilizar el reclamo histórico de los vecinos de modo artístico, sin contar con una práctica previa de movilización y lucha por la resolución de esa problemática (ya que todos los pedidos que se hicieron a la autoridades fueron por medio de cartas formales).

\subsection{Cuando se viene el agua}

Los factores que identificamos como partes fundamentales que componen el tejido de la construcción de una memoria compartida -representaciones sobre el pasado que han dejado un sedimento común en la mayoría de los habitantes de una comunidad-, y el factor emocional como pigmento que impregna la experiencia, son resaltados por los vecinos de modo particular en la escena de las inundaciones.

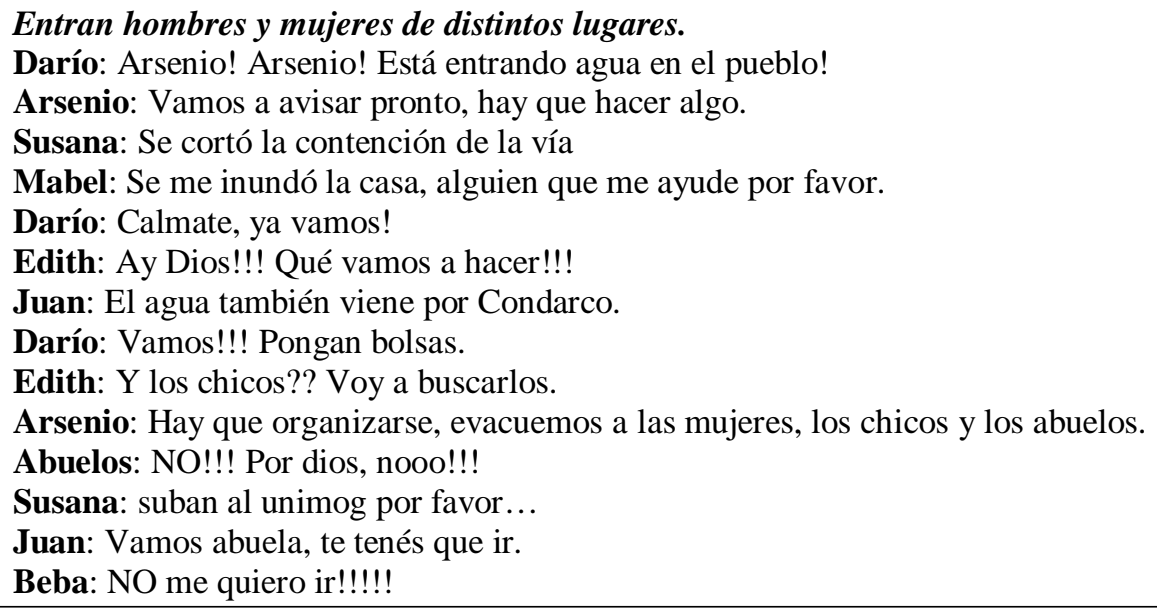

Nuevamente se apeló en la representación a las imágenes visuales que marcaron los momentos más angustiantes, y que son los mismos que evocan los habitantes del pueblo, como aquellos que dejaron una marca en la memoria de la gente. La noche en 
que el agua casi entró al pueblo, cuando los que no habían sido evacuados estuvieron sin dormir armando canales de contención con bolsas, se convirtió en la evocación más reiterada, y fue la que se eligió para el relato teatral. La desesperación fue la emoción que primó en esta escena, seguida de un canto de resistencia que termina con la última parte de la función, signada por la idea de la esperanza y el resurgimiento.

Los actores y situaciones esbozados en la última escena de Por los caminos de mi pueblo plantean una idea de futuro asociada con la educación, la nacionalidad, el crecimiento del pueblo a través de la aparición de nuevas instituciones, la llegada de tecnologías e infraestructura, las actividades culturales y las redes de socialización activadas por éstas (entre ellas el teatro). Pero este espíritu de renacimiento visible en el parlamento está vinculado con un proceso que apareció definido claramente por los vecinos a partir de la fecha del centenario.

"Entra Chichita con el guardapolvo. Pone el mástil. Llama a los chicos.

Chichita: ¡iVamos chicos! ¡iEs hora de comenzar!!

(Entran los chicos con ella. Chichita les da la bandera y se queda a un costado.) Los chicos suben la bandera.

(Se escucha voz en off)

"FM Sansinena en el 93.5 de tu dial, radio comunitaria."

Fm Sansinena, nuestra radio. Informa:

Se formó el Centro de Jubilados y Pensionados, próximamente al aire por nuestra FM escucharán "Mateando con los jubilados" para toda la familia.

Se creó el Destacamento de Bomberos Voluntarios, lograron personería jurídica y ya son Cuartel de Bomberos Voluntarios., tienen nueva sede, herramientas, autobomba y muchas ganas de ayudar al pueblo, Tenemos escuela secundaria propia, luego del esfuerzo de muchos padres, docentes y autoridades, se acabó el desarraigo temprano, los chicos se quedan en el pueblo y colaboran con las instituciones, presentando proyectos y participando de la vida comunitaria.

Llegaron las nuevas tecnologías, tenemos Internet en Sansinena, y próximamente señal de celular.

Se inauguró la casa de la cultura y biblioteca Adela Presta que tiene 6000 libros, se dictan diferentes talleres y cursos.

Volvió el teatro al pueblo! La gente se animó a subir a las tablas y dejar de ser espectadores. También se formó un grupo tradicionalista.

Ahora a practicar deportes al flamante playón municipal.

Tenemos nueva ambulancia. Se inauguró la casa de los abuelos, anexa a la unidad sanitaria.

Hay nuevas calles con cordón cuneta, nuevas luces, nombres en nuestras calles y tendremos la tan ansiada agua potable.

Se escucha por ahí que vuelven los ex residentes a su pueblo, todos los esperan con gran entusiasmo, también se rumorea que se puede salir adelante, depende de todos nosotros...

Informó Fm Sansinena, nuestra radio.

La categoría de marcos sociales de la memoria establece ciertos parámetros sobre los que se construye la memoria colectiva que la atraviesan constantemente, entre ellos los 
espaciales y temporales son los principales, porque allí se pueden localizar los recuerdos, anclados en hitos y fechas significativas para la comunidad (Halbwachs, 1968). Este es el caso de Por los caminos de mi pueblo, en la cual el marco temporal y espacial del Centenario es fundamental. La llegada del Centenario del pueblo constituyó el cierre de una etapa recordada por los habitantes de Sansinena como triste y oscura, que tuvo su origen en las inundaciones del año 2001, con las pérdidas materiales y la sensación de abandono que éstas produjeron. Sansinena pasó a ser asociado e identificado para las localidades de Rivadavia como el pueblo que "casi desaparece bajo el agua", lugar desde el cual había que irse porque ya no quedaría nada. Al acercarse la fecha del centenario, casi diez años después, el festejo de un aniversario número cien significó un momento de balances, de proyectos y de nuevos horizontes, donde se recapituló el pasado pensando en el porvenir (Candau, 2008). En este proceso se vieron acentuados los sentidos de pertenencia, anclados en el sentimiento de "orgullo" por el pueblo, de "resistencia" y visibilizacion, que se puede identificar en el Juramento, última parte de la escena final de la obra.

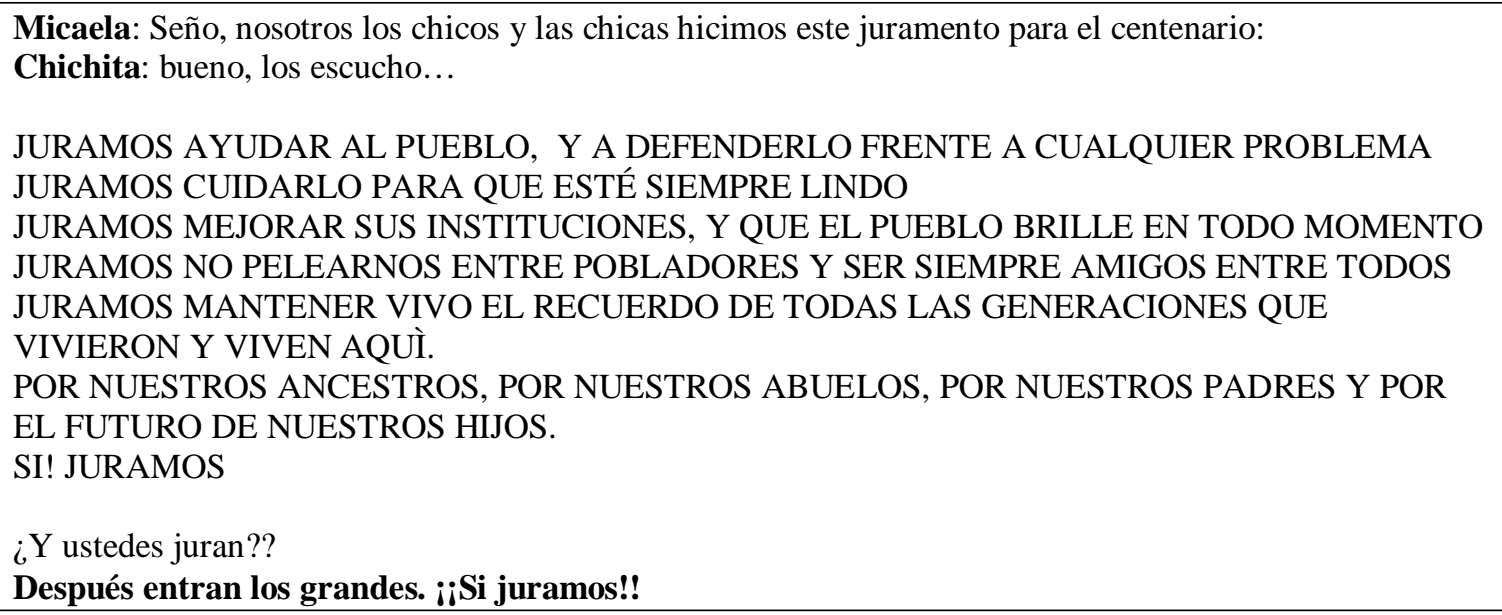

Un juramento es un acto caracterizado por la solemnidad y veracidad de lo que se dice, que apela a un futuro inmutable, y porta una responsabilidad para quien lo evoca. María Emilia de la Iglesia, la directora del Grupo de Teatro Popular de Sansinena, comentó que esta escena surgió sobre una idea de los chicos del pueblo. El imperativo que encontramos en el juramento está vinculado con sentidos relacionados con el pueblo, construidos por los vecinos, en donde se conjuga la temporalidad del presente -la jura-, con la del pasado- mantener vivo el recuerdo- y la del futuro. Las acciones de "ayudar al 
pueblo", "defenderlo", "mejorarlo" y "cuidarlo", apelan a una externalidad material, a un pueblo físico e institucional, que porta una gran significación para los vecinos de Sansinena en tanto y en cuanto se vincula con un compromiso en mantener el pueblo vivo, en una resistencia frente a los riesgos de su desaparición o abandono. En este sentido queda en evidencia la geografía marginal de la que habla Ratier (2009), ya que el juramento otorga protagonismo al papel de los vecinos como constructores y generadores de las condiciones de vida que caracterizan al pueblo, y no hace alusión a responsables externos, o autoridades que deberían suplir ese rol. La marginalidad material del pueblo, se profundiza en aspectos del campo de lo simbólico y se evidencia con la construcción de consignas como "Sansinena existe", o "Sansinena, pueblo de amigos", en donde se articula, por un lado, la necesidad de visibilizacion y "presencia en el mapa", por el otro, la idea de que su gente debe contribuir para que el pueblo se mantenga y crezca.

Se comprende que el juramento plantea la necesidad de un futuro sin conflicto, en donde "todos seamos amigos". En ese horizonte posible, utópico e ideal, juega un papel importante la memoria, anclada en el recuerdo de las generaciones previas, conectadas por medio de la acción presente con las futuras, depositarias del futuro promisorio del pueblo. La idea de conservación vuelve a aparecer nuevamente, de la mano de un juramento que establece un vínculo irrompible entre el que jura y el pueblo, como entidad por momentos externa y con identidad propia, y por otros como comunidad unívoca, estable y tradicional.

\section{Canciones en el teatro comunitario: poéticas colectivas}

La canción es fundamental en la práctica teatral comunitaria porque el coro adquiere la fuerza de "la gente que canta". El canto colectivo se ha utilizado en el Grupo de Teatro Popular de Sansinena como herramienta articuladora de relatos - dentro del proceso de creación colectiva- , como instrumento de estructuración del guión teatral, como espacio de experiencia personal y desarrollo de aptitudes individuales postergadas por los vecinos y como material dramatúrgico excepcional para el establecimiento de climas en la representación. El ritmo de la composición musical colabora con la tarea de generar 
estados de ánimo y se constituye como elemento efectivo de sutura para cerrar la idea principal de cada escena.

\begin{tabular}{|c|c|c|c|c|}
\hline Inmigrantes & $\begin{array}{l}\text { Partiendo a } \\
\text { Buenos Aires }\end{array}$ & $\begin{array}{l}\text { La ruta viene } \\
\text { demorada }\end{array}$ & Inundaciones & Canción final \\
\hline 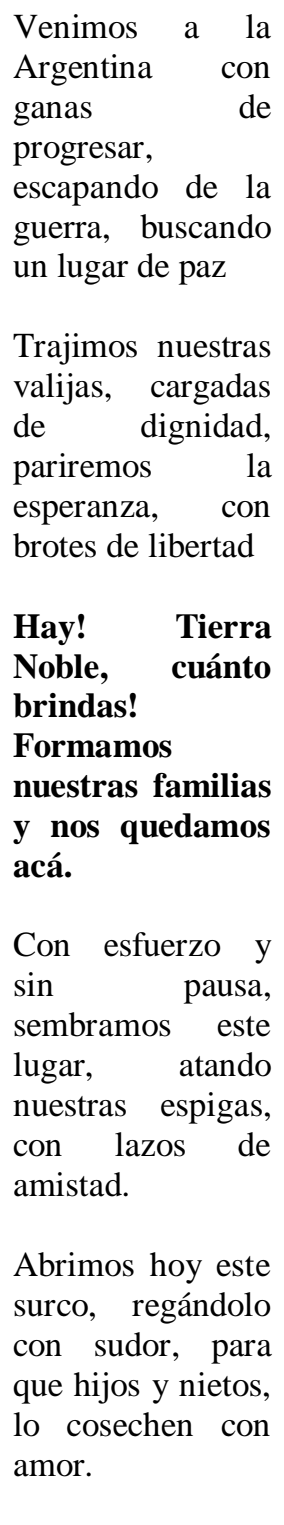 & $\begin{array}{l}\text { El día que yo } \\
\text { partí } \\
\text { Pensando en mi } \\
\text { porvenir } \\
\text { Subí con } \\
\text { nostalgia al tren } \\
\text { que se iba } \\
\text { Qué grande es la } \\
\text { ciudad! } \\
\text { El tranvía viene } \\
\text { y va Y nos lleva } \\
\text { a trabajar a la } \\
\text { industria } \\
\text { Me voy pero } \\
\text { volveré } \\
\text { Tu nunca dudes } \\
\text { de mi, así te lo } \\
\text { prometí } \\
\text { Sansinena } \\
\text { Pero el tiempo } \\
\text { pasó } \\
\text { Y mi acento } \\
\text { cambió } \\
\text { La piel se me } \\
\text { refinó } \\
\text { De repente } \\
\text { Allá me enamoré } \\
\text { Gran progreso } \\
\text { encontré } \\
\text { Y tengo } \\
\text { televisión } \\
\text { Blanco y negro. }\end{array}$ & $\begin{array}{l}\text { En } 1911 \text { la } \\
\text { Comisión de } \\
\text { Fomento, pedía } \\
\text { por los caminos } \\
\text { había mucho } \\
\text { descontento } \\
\text { Pasaron los } \\
\text { gobernantes } \\
\text { Y la ruta en la } \\
\text { nada, dijeron } \\
\text { que ya la hacían } \\
\text { pero viene } \\
\text { demorada. } \\
\text { Transitamos ya } \\
\text { 100 años aquí, } \\
\text { y la ruta no } \\
\text { aparece } \\
\text { Aunque sea un } \\
\text { mejorado } \\
\text { nomás, } \\
\text { este pueblo la } \\
\text { merece } \\
\text { Un pozo por allá } \\
\text { La zanja por acá } \\
\text { Que no llueva } \\
\text { Diosito, que no } \\
\text { puedo pasar. }\end{array}$ & $\begin{array}{l}\text { Entra agua por } \\
\text { acá! } \\
\text { Pongan bolsas } \\
\text { más allá! } \\
\text { El agua no nos va a } \\
\text { ganar, el agua no } \\
\text { nos va a ganar } \\
\text { Dicen que van a } \\
\text { evacuar, no lo } \\
\text { vamos a aceptar } \\
\text { La solución hay } \\
\text { que encontrar } \\
\text { La solución hay } \\
\text { que encontrar } \\
\text { No me quiero ir } \\
\text { hay que resistir } \\
\text { este es mi lugar } \\
\text { Vaya abuela es } \\
\text { por su bien, } \\
\text { pronto el agua va } \\
\text { a bajar } \\
\text { y aquí la vamos a } \\
\text { esperar, y aquí la } \\
\text { vamos a esperar } \\
\text { Somos pocos es } \\
\text { verdad, nadie nos } \\
\text { quiere escuchar } \\
\text { merecemos, } \\
\text { igualdad, } \\
\text { merecemos } \\
\text { igualdad. }\end{array}$ & $\begin{array}{l}\text { Son } 100 \text { años y este } \\
\text { pueblo se merecía, que } \\
\text { entre todos } \\
\text { construyamos este } \\
\text { camino } \\
\text { Es la esperanza la que } \\
\text { nos une este día y el } \\
\text { alma queda repleta de } \\
\text { sentimientos... } \\
\text { Hay que saber combatir } \\
\text { a la indiferencia con } \\
\text { alegría, memoria y } \\
\text { brazos dispuestos } \\
\text { la dignidad y el amor } \\
\text { serán nuestra herencia } \\
\text { el abrazo y la palabra } \\
\text { nuestro alimento } \\
\text { Sansinena, estamos } \\
\text { aquí } \\
\text { Todos juntos } \\
\text { luchando por ti. } \\
\text { Los recuerdos no nos } \\
\text { dejan ir } \\
\text { Y los sueños son el } \\
\text { porvenir } \\
\text { Gritemos bien fuerte en } \\
\text { este reencuentro } \\
\text { Sansinena existe y va a } \\
\text { existir... } \\
\text { Mientras haya muchos } \\
\text { que lo defiendan } \\
\text { Sansinena existe y va } \\
\text { existir }\end{array}$ \\
\hline
\end{tabular}

En las primeras escenas, la fundación del pueblo y la llegada de las familias, la inmigración fue el hecho indiscutido considerado como aquel que dio origen al pueblo $^{58}$, y que la obra de teatro presenta a modo de homenaje. Ese pasado nostálgico,

\footnotetext{
${ }^{58}$ Idem.
} 
romántico, idealizado (Candau, 2008), fue el que instauró las ideas representativas del trabajo, el esfuerzo, el sacrificio por las nuevas generaciones, con sus correspondientes virtudes resultantes: dignidad, esperanza y libertad. La idea del campo como matriz que permitió la génesis y el desarrollo del pueblo, está presente en la terminología que se utiliza en la canción, en donde se presenta la actividad agrícola de la cosecha y la siembra asociada a la construcción y el mantenimiento del pueblo recién creado. Finalmente surge allí el concepto de una comunidad sin conflictos, que desarrolla lazos de amistad, de familia y de amor.

Partiendo a Buenos Aires presenta otra época, en donde la idea del progreso comienza a estar asociada con lo externo (y opuesto) al pueblo, con la ciudad, con la industria. El desarraigo como emblema de angustia por dejar los propios pagos se va transformando en una reafirmación de la partida y el establecimiento definitivo en la ciudad. La canción representa las transformaciones producidas en la persona que se aleja del pueblo con una serie de signos que se materializan en el cuerpo: la piel (de repente se "refinó"), la forma de hablar (mi acento cambió), y el encuentro con el tan ansiado "progreso" (simbolizado con las nuevas tecnologías encarnadas en el televisor).

La canción de los caminos, estructurada sobre la base musical de "La pollera amarilla", creada por Tulio Enrique León e interpretada por Gladys Nelly del Carmen Jiménez (la "Bomba" tucumana), exhibe el reclamo histórico por el mejorado de los caminos de un modo lúdico y en tono humorístico. Tanto la canción de los caminos como la de las inundaciones expresan el reclamo desde una postura asociada a la legitimidad del pedido ("lo merecemos"), no como un derecho, sino como algo de lo que hay que "hacerse digno" o "hacer méritos". Si bien en la canción de los caminos aparece una figura hacia la que se formula el reclamo ("los gobernantes"), en el caso de las inundaciones hay una voz no identificada hacia la cual se presenta una oposición (“dicen que van a evacuar"). A las imágenes más traumáticas que quedaron en la memoria de los vecinos - como la construcción del canal de contención y la evacuación de mayores y niños - se les agrega un sentido de resistencia frente a la adversidad y la desaparición. Aparece solapado aquí un reclamo de igualdad, enraizado en el "nadie nos quiere escuchar", y fortalecido en el parlamento de la última canción, en donde claramente aparecen las ideas más fuertes de toda la obra. Por un lado, la 
conmemoración del centenario como momento histórico clave o bisagra para la concreción y formulación de proyectos; por otro lado la lucha contra la indiferencia; también una convocatoria a la unión para la defensa del pueblo y su permanencia, construidas en base al pasado (los recuerdos), y el futuro (el porvenir).

\section{Sobre obras de autor y obras de autor/es}

"La novedad está ahora asociada a nuevas versiones del pasado más que del futuro" (Huyssen en Cuesta Bustillo, 1998:131)

\footnotetext{
“Te sentís más cómodo con las cosas que viviste"59

"Es totalmente distinto hacer una obra escrita que hacer algo que la escriben tus amigos, tus familiares, porque lo primero lo hacés como un loro, y lo comunitario lo hacés pensando. Lo haces como un loro porque no es una emoción que te va a dar, porque no la viviste ni la vas a vivir",60
}

\section{"Haciendo Por los caminos de mi pueblo yo me sentí más tranquila, era como que estaba en mi casa haciendo algo" 61 .}

Responder a la pregunta por el "quién" significa contar la historia de una vida. En ese sentido es la puesta a distancia del pasado lo que permite reconstruirlo para hacer de él una combinación compleja de historia y ficción, de verdad factual y de verdad estética. La particularidad de la narrativa que construye el teatro comunitario está en el carácter de verdad que adquiere para los vecinos que la generan, ya que, si bien operan en ella restituciones, agregados, invenciones, modificaciones, olvidos, censuras, resistencias, simplificaciones, esquematizaciones, represiones, interpretaciones, (Candau, 2008) etc., el hecho de haber experimentado las vivencias que se relatan, le otorga una legitimidad indiscutible a la representación.

La construcción de la narrativa se convierte así en un acto de memoria, que le permite al narrador colectivo reapropiarse de ese pasado, imprimiéndole su huella en función de los rasgos significativos que constituyen su perfil identitario presente. En ocasiones ese relato se transforma en una historia bella que refleja el modo en que el narrador intenta

\footnotetext{
${ }^{59}$ Vecino de González Moreno nacido en Sansinena., que participó de la construcción y la representación de la obra Por los caminos de mi pueblo (47 años).

${ }^{60}$ Vecina de Sansinena y parte del grupo de teatro (50 años).

${ }^{61}$ Vecina de Sansinena y parte del grupo de teatro (53 años).
} 
ser percibido desde el exterior, lo que llamamos una versión idealizada del pasado, que no excluye los capítulos traumáticos de la historia, sino que los presenta desde su costado más romántico o mítico.

El registro obtenido de las entrevistas a los vecinos, presenta una distinción entre la percepción del proceso de creación colectiva de la obra Por los caminos de mi pueblo (2009) respecto de De pie como un árbol (2006), - la adaptación de Los árboles mueren de Pie, de Alejandro Casona, que fue la primera obra representada-. Estas distinciones están vinculadas a diversos factores como la existencia de experiencia previa o no de los vecinos en actividades teatrales y discusiones del orden de lo estético en las obras de teatro comunitario. En cuanto al primer punto, vemos que la organización, el funcionamiento, y los objetivos del Grupo de Teatro Popular de Sansinena fueron transformándose; en un primer momento se aspiraba a reflotar la actividad teatral y cultural comenzada por Abelardo Moure en la década de 1950 y continuada por Osvaldo de la Iglesia en los años '80, a través de la conformación de un grupo de teatro vocacional, cuyas características remitían a un grupo de teatro independiente. Si bien el acceso al grupo de teatro vocacional era abierto para todo aquel que quisiera participar, la convocatoria fue respondida en su mayoría por personas que ya habían tenido contacto con las experiencias teatrales previas. Luego del año 2008, con la invitación dirigida a la construcción de una obra que cuente la historia del pueblo, la cantidad de gente que se acercó fue mucho mayor, entre las que se encontraban personas que no sólo no habían participado nunca de una actividad teatral, sino que además nunca habían asistido como público a una obra.

Aquellas personas que contaban con experiencias previas en actividades teatrales o culturales - un pequeño grupo en su mayoría ligados al teatro impulsado por Osvaldo de la Iglesia - evocaron un recuerdo de connotación más positiva sobre la construcción de la obra de Casona que por la de creación colectiva. Fueron destacadas ciertas características propias de ésta última como "perjudiciales" para el producto teatral, como la cantidad numerosa de personas que participan (lo que entorpecería la actividad por factores ligados a la responsabilidad, el compromiso, la puntualidad, entre otros), la falta de rigurosidad en cuestiones de técnica actoral y puesta en escena y la facilidad en 
la interpretación de los personajes (punto que fue planteado de manera ambigua como negativo y positivo).

El segundo punto que planteamos es la cuestión estética y la puesta en escena de las obras de teatro comunitario. El debate instaurado dentro del ámbito teatral comunitario, radica en la discusión de las producciones teatrales comunitarias como productos que priorizan en su organización y producción la apertura e integración de un gran número de personas, en desmedro de una mejora en su calidad artística (técnica actoral, canto, entrenamiento) (Scher, 2011). Esta discusión presenta opiniones opuestas dentro de los grupos, que se debaten entre la existencia de una posible funcionalidad social del teatro comunitario como experiencia de contención social, productora de nuevas subjetividades que deben generar un compromiso con la comunidad, y la práctica como espacio individual de valorización de la autoestima y motivador de la creatividad. Si bien ambas posturas pueden combinarse, cada director se posicionará más a favor de una u otra, y en base a ello definirá los objetivos, planteará propuestas de trabajo, tiempos de ensayo y actividades a desarrollar.

En el caso del grupo de Sansinena, las prioridades están al servicio de la participación y la integración. Si bien las puestas en escena son trabajadas y cuidadas, se privilegia la inclusión de más vecinos -a pesar de que ello conlleve desajustes en la representaciónantes que las cuestiones técnicas en la actuación o el canto. Esta postura es fuertemente defendida por María Emilia, para quien el proceso social de la construcción colectiva adquiere mayor valorización que el despliegue de aptitudes actorales.

\section{8. "La voz del pasado no solo hechiza, ordena",62}

Luis Villoro (1998) identifica dos modalidades para investigar reflexivamente las identidades de un pueblo, en las cuáles se intenta formar una imagen del mismo con la cual podamos identificarnos: la vía de la singularidad y la vía de la autenticidad. Si bien el autor las está pensando como elecciones teóricas del investigador, quizá puedan resultarnos esclarecedoras para pensar ciertas elecciones y selecciones dentro del

\footnotetext{
${ }^{62}$ Villoro, Luis (1998: 63)
} 
proceso creativo de la obra de teatro, con el fin de comprender un poco más sobre las representaciones identitarias que allí se ponen en juego.

Por vía de la singularidad, se tiende a reproducir los rasgos que caracterizan a la comunidad, mirando el futuro a la luz de la historia; es decir, que se singulariza a los rasgos culturales del pueblo con el fin de develar un conjunto de creencias y actitudes colectivas, "que expresarían una forma de sentir y comprender al mundo" (Villoro: 1998:62). Por la vía de la autenticidad, el reconocimiento del pueblo viene de la mano de la identificación de sus necesidades reales, y el perfil identitario sería una representación imaginaria de un ideal. A la abstracción de la primera vía, se le opondría la concreción de la segunda, en donde la identidad no sería un relato, sino un proyecto (Villoro, 1998). Mientras la primera se queda en "distinguir" cuáles son los rasgos del grupo en base a sus valores y creencias desde una imagen anclada en el pasado, la segunda complementa la idea del quienes somos con la de "quiénes queremos ser", lo que implica un proyecto en pos de la concreción de ese ideal, anclado en las necesidades del presente pero pensando en un proyecto a futuro.

A la luz de estas reflexiones, se pueden observar dos tendencias que Villoro las plantea como opuestas, pero que no necesariamente deben/pueden estarlo. En el caso del Grupo de Teatro Popular de Sansinena, si bien hay preeminencia de la singularización, en tanto se apela al futuro en función de la historia y se exacerban los rasgos culturales que caracterizan a la cotidianidad de la vida del pueblo, el relato contiene elementos que intentan construir una imagen utópica e ideal de lo que el pueblo debería ser y a pesar de que están presentes ciertas problemáticas actuales (como la de los caminos), estos reclamos están ligados a la legitimidad que les brinda su carácter e histórico.

Reconstruimos un recorrido cronológico por las experiencias teatrales del pueblo de Sansinena, e identificamos allí la presencia de experiencias previas en la actividad teatral, y la huella dejada por el grupo de teatro vocacional de Osvaldo de la Iglesia, que estuvo presente en los recuerdos evocados por muchos de los vecinos. Los procesos de anamnesis (Yerushalmi, 1989), de transmisión de memorias (Hassoun, 1996), olvidos, censuras e interpretaciones (Candau, 2008) que atravesaron la creación colectiva de Por los caminos de mi pueblo, nos devolvieron una narrativa nostálgica, romántica, en donde el conflicto y las tensiones que escasamente impregnan el relato, son presentadas 
a través de géneros que generan una interpelación humorística y donde lo emotivo y lo experiencial son fundamentales. La tradición y la conservación de un orden, en donde todo siga igual, es una idea fuerte que está presente tanto en el guión, como en las canciones, y fundamentalmente en el juramento.

Sin embargo, en ciertas canciones se presentó un discurso en donde se manifestaba una desigualdad, una indiferencia (aún no sabemos de quien), y un reclamo de visibilidad frente al abandono, elaborado a través de consignas de resistencia y lucha colectiva. En este sentido, el hecho de que el Grupo de Teatro Popular de Sansinena sea la primera organización social que existe en el pueblo y de que elabore producciones teatrales que contienen estos pequeños sesgos inconformistas, puede significar una reconfiguración, quizá escasamente identificada, de ciertos parámetros y sentidos tradicionales construidos por los vecinos, que comienzan a experimentarse desde otras perspectivas.

En el capítulo siguiente analizaremos las prácticas del grupo de teatro como organización social, performativa del espacio entendido como territorio, pero además como constructo generador de relaciones y marcos de sociabilidad específicos. 


\section{Capítulo III}

\section{El espacio en cuestión}

\section{Nuevas tramas relacionales, subversión y reproducción de roles}

"A lo mejor hay que contar una historia para generar mundos en común",63

Maurice Halbwachs (1968) reflexionó sobre los vínculos existentes entre el ejercicio de la memoria colectiva y el espacio en tanto territorio atravesado por sentidos construidos socialmente. Resaltó la importancia del espacio físico como ambiente en donde se encuentran los objetos de la vida cotidiana; allí será el lugar donde el grupo se forme una imagen de sí mismo y desde donde resista el cambio de los hábitos, porque "esta resistencia es el mejor indicador del grado en el cual la memoria colectiva de estos grupos se basa en imágenes espaciales" (Halbwachs, 1980: 16). Con esta idea, el autor destaca la importancia de la conservación del territorio, como una forma de resistir el paso del tiempo y las transformaciones que el grupo atraviesa en ese proceso.

Dentro de esta misma línea, en donde consideramos al espacio en relación con su existencia física, Candau (2008) hace referencia tanto a la memoria como a la identidad concentradas en lugares destacados, que siempre tienen nombre y que atraviesan la historia del grupo. Se distinguen de los lugares de memoria (Nora, 1998) en tanto estos últimos pueden ser objetos, símbolos, canciones, banderas, donde se puede ver cómo el pasado se cristalizó en el presente e identificar las huellas de las disputas que surgieron para la emergencia de ese lugar.

Dentro del amplio abanico de posibilidades que se abren a la hora de incorporar el concepto de espacio y la relación dialéctica con la/s memoria/s y la/s identidad/es que ese espacio construye en la actividad teatral comunitaria, identificamos diversas prácticas que podrían ser analizadas a la luz de esta heterogeneidad de relaciones posibles: la construcción del espacio de representación escénica, las prácticas cotidianas del grupo de teatro como espacio creativo/ organizativo (y las relaciones que se

\footnotetext{
${ }^{63}$ Rabotnikof, Nora.
} 
construyen tanto hacia el interior del grupo como hacia el afuera) y las relaciones que establece el grupo con el espacio físico (su utilización, reapropiación). Éste último aspecto ha sido el más desarrollado en trabajos académicos (Bidegain Marcela, 2007; Proaño Gómez, 2006), pues la utilización del espacio público que realizan los grupos de teatro comunitario para sus actuaciones (calles, plazas), despertó interés en los investigadores que abordaron el tema en cuanto a las transformaciones de los sentidos del espacio, la discusión sobre la accesibilidad al espectáculo y la subversión de las relaciones entre público y espectador establecidas originariamente por las teatralizaciones tradicionales (con escenario a la italiana).

Por otro lado, es pertinente marcar una diferenciación en cuanto a qué entendemos por espacio y por territorio, ya que numerosos autores han reflexionado desde diversas perspectivas sobre ambas categorías, otorgándole a cada una de ellas un corpus de significaciones diferentes. Siguiendo a Giménez (1999), comprendemos que el territorio es el espacio apropiado y valorizado simbólicamente por los grupos humanos, pero fundamentalmente es el espacio en donde se inscribe la cultura. Desde esta perspectiva la construcción y reapropiación del espacio por parte de un colectivo adquiere relevancia pues se instituye como rasgo fundamental del sentido de pertenencia y constitución de las identidades, a la vez que configura un espacio de inscripción del pasado grupal y funciona como marco espacial de la memoria colectiva.

En el caso de Sansinena, se trata de un pueblo aislado por falta de rutas, marcado por la lucha de que el pueblo sea un espacio habitable, y donde los vecinos se enorgullecen de sus edificios e instituciones -que funcionan como "termómetros" de progreso-. El Grupo de Teatro Popular de Sansinena promueve la recuperación de ciertos espacios abandonados o inutilizados para el desarrollo de sus actividades, como la estación de tren del pueblo, o las calles y plazas de parajes en ruinas, como el pueblo de San Mauricio $^{64}$. Lo hace a través de la utilización no convencional de esos espacios y la construcción de nuevos sentidos creados a partir de la misma. En esta línea, Proaño Gómez (2006) trabajó con la recuperación de la estación ferroviaria del pueblo de

\footnotetext{
${ }^{64}$ San Mauricio es un pueblo de la localidad de Rivadavia en donde actualmente residen cerca de veinte personas. Consta de una plaza y edificios semidestruidos que la rodean.
} 
Patricios $^{65}$, por parte del grupo de teatro comunitario Patricios Unidos de Pie. La autora destaca que la intervención de los vecinos en ese espacio significó poner "en escena" las tensiones, las alianzas de los diferentes sectores y la renegociación de un nuevo sentido asociado a la vida y no a la muerte, y que su uso no convencional hace aparecer "lo contingente", lo que se considera como naturalmente dado, en cuanto se convierte en un lugar de encuentro, se actualiza la memoria, surgen nuevas reglas y normas y una nueva lógica de relaciones fundada en una jerarquía de valores opuesta a la del régimen neoliberal.

En el caso del grupo de Sansinena, observamos que la estación del ferrocarril fue y sigue siendo objeto de tensiones y disputas, ya que a partir de una iniciativa de Edith Bello, habitante de Sansinena y coordinadora del grupo de teatro, se comenzaron las gestiones para la recuperación de las tierras en donde se encuentra la estación del ferrocarril con el fin de instalar allí un museo, que fue inaugurado oficialmente en el año 2010 durante los festejos del Centenario del pueblo. El edificio de la estación, que quedó inutilizado con la desaparición del tren, estuvo a merced de las decisiones tomadas por los delegados municipales, y las necesidades de algunos vecinos y vecinas del pueblo que necesitaban un lugar en donde vivir y la adoptaron como hogar. Las sucesivas ocupaciones constituyeron materia de conflicto ya que ponían en jaque el carácter público del edificio, que seguía perteneciendo legalmente a la empresa Ferroexpreso Pampeano, al mismo tiempo que era adoptado como propiedad privada por los inquilinos del momento.

Las disputas por este espacio alcanzaron a la actividad teatral, en tanto se presentaron tensiones entre las personas que vivían en las habitaciones más grandes del edificio ferroviario, y el grupo de teatro que utilizaba los alrededores del andén y algunas salas del museo para ensayar y representar Por los caminos de mi pueblo. Si bien se usaron las instalaciones como vestuarios, la estación no llegó a constituirse en un lugar de referencia exclusivo para los miembros del teatro. Por el contrario, los sentidos construidos en torno a la estación se encuentran vinculados más estrechamente con los "buenos tiempos" en los que pasaba el tren, la prosperidad, el transporte accesible y los

\footnotetext{
${ }^{65}$ El pueblo de Patricios está ubicado en el Partido de Nueve de Julio, Provincia de Buenos Aires.
} 
encuentros sociales, que a la actividad teatral. Sin embargo el solo hecho de que los andenes se convirtieran en escenario, generó una reapropiación no sólo instrumentalfuncional del espacio, sino también simbólica expresiva, en tanto objeto de apego afectivo y lugar de inscripción del pasado histórico (Giménez, 1999).

\section{Incursionando espacios posibles}

Si hablamos de espacios "recuperados" por la práctica teatral comunitaria, la escasa literatura que aborda esta cuestión (Proaño Gómez, 2006; Bidegain, 2007, Borba, 2008) presenta una dicotomía entre el espacio público y privado, identificando las acciones teatrales como actividades culturales performativas del espacio público, que ponen en jaque los sentidos de lo privado en un nivel simbólico. Pues bien, no existe una sola vía desde la cual concebir a estas dos categorías, y consideramos, junto con Rabotnikof (2005), que sería interesante abordar la cuestión realizando una primera problematización: el carácter dicotómico entre espacio público y privado.

Fue con el comienzo de la modernidad cuando comenzó a delinearse la dicotomía entre lo público y privado, en tanto el Estado llevó adelante diversas políticas con el fin de hacer homogéneo y legible el espacio, en donde los límites que separan el adentro y el afuera estén bien marcados. Allí la constitución del adentro se logró por la contraposición-diferenciación con el afuera.

Desde el siglo XVII el Estado pondrá a disposición de la familia instrumentos para lograr la interiorización de los límites a través de prácticas disciplinarias (...) el Estado se constituyó en un instrumento fundamental para la construcción del orden al interior de la familia y con ello la configuración de lo privado como lugar de interiorización de límites (Murillo, 2005: 38).

Lo público suele contraponerse a lo privado fundamentalmente en tres sentidos: lo público como lo que es común a todos, que atañe al colectivo o comunidad toda -en contraposición con lo singular y personal de lo privado-; lo manifiesto, accesible a la mirada de todos -frente a lo oculto o secreto-; y lo accesible a todos, abierto -en oposición a lo restringido- (Rabotnikof, 2005) ${ }^{66}$. Pero aquí es cuando este pensamiento

\footnotetext{
${ }^{66}$ Para Hugo Quiroga (2006), los tres significados de lo público coinciden con la caracterización de Rabotnikof, en la medida que identifica tres sentidos de lo público como estatal (que tiene interés
} 
dicotómico entra en conflicto, ya que muchas veces lo que se manifiesta a la luz del día puede no ser accesible a todos, y la supuesta visibilidad se combina con algún tipo de clausura, opacando ciertos rasgos que serían propios de lo público. En esta línea, el entrecruzamiento y desdibujamiento de las fronteras creado por la superposición de características entre ambos espacios, nos presenta la existencia de ciertos "grises" que será necesario examinar.

Si bien el trabajo de Rabotnikof está centrado en trabajar teóricamente con la categoría del espacio público en relación a los sistemas políticos democráticos (Rabotnikof, 1995), esta mirada podrá resultar enriquecedora en tanto nos aleja de una idea del espacio entendida como territorio, que hemos esbozado con anterioridad, para adentrarnos en un análisis que abordará al espacio atravesado por relaciones del orden de lo social y político. ¿Qué tipo de espacio construye el teatro comunitario de Sansinena? ¿Cómo se entrecruzan allí las nociones de público y privado? ¿Qué tipo de relaciones atraviesan los procesos de constitución de ese espacio y cómo juegan las identidades y la memoria colectiva en ellos?

\section{Algo en común / lo público}

"La publicidad de la esfera pública es la que puede absorber y hacer brillar a través de siglos cualquier cosa que los hombres quieren salvar de la natural ruina del tiempo" (Arendt, 2005:64)

Proaño Gómez (2006) considera la utilización del espacio público en la práctica teatral comunitaria del grupo de Patricios, como una intervención que genera una transformación de lo político, en tanto demuestra la contingencia del orden neoliberal y propone valores opuestos al mismo, inaugurando el ejercicio de la libertad al problematizar la lógica de identificación y de lo que se ha considerado apropiado en ese espacio. Las prácticas de reapropiación del espacio estudiadas por la autora se centran en un accionar sobre el espacio físico que será modificado y re instituido a través de las mismas y en el surgimiento de una lógica que pone en jaque la lógica neoliberal. En nuestro caso, la pregunta se centra en las relaciones que se dan dentro del espacio del 
grupo como organización, que lo constituyen como tal y construyen determinados parámetros de lo público y lo privado no ya considerados en una relación dicotómica, sino articulados en un mismo proceso.

El primer sentido de lo público esbozado por Rabotnikof (2005) como lo común a todos, se convierte en la práctica del grupo sansinense en un elemento de cohesión fundamental, cuando en el proceso de creación se apela al pasado compartido para la selección de los hechos de la historia a contar. Justamente aquello que es común a todos es lo que se hace visible en el espacio de la representación, perteneciente a lo público también en el tercer sentido de Rabotnikof (es accesible para todos).

Es interesante al respecto retomar la idea de Arendt (2005), para quien el ámbito público y el privado estarían vinculados con el campo político, en el primer caso, y con el familiar, en el segundo. La autora está pensando en la polis griega; allí el ámbito de lo público es donde se desarrolla la libertad, porque reina la igualdad entre los hombres y nadie manda sobre nadie, ya que se está entre pares. Sería en el mundo moderno en donde los dos campos (público y privado) fluirían uno sobre otro, con la emergencia de lo social como parte del ámbito pública. En este espacio público asociativo "se alude a un campo de deliberación y actuación colectiva que no es el Estado" (Quiroga, 2006: 128).

Aparece nuevamente en el planteo de Arendt lo público ligado a lo común y lo visible, pero incluye el elemento de la apariencia: será con la aparición pública cuando se transformarán las fuerzas de la vida íntima. En ese sentido, "nuestra sensación de la realidad depende por entero de la apariencia" (Arendt, 2005:60), y aquello inapropiado se convierte en un asunto privado, íntimo. La representación teatral, como puesta en escena adquiere relevancia en el espacio público, dejando al descubierto sólo aquello que debe ser recordado como lo común, lo que genera sentimiento de cohesión y estructura la vida comunitaria, lo que debe trascender, quedar conservado. Lo inapropiado será, por el contrario, oculto, callado, reservado para el ámbito no público. La idea de hacer público algo (ponerlo en común) con el fin de conservar aquello que debe mantenerse para la posteridad, puede vincularse con el afán conservador que hallamos en los postulados de la construcción de una memoria colectiva, que busca 
sintetizar los hechos vividos en una experiencia común, con el fin de preservar lo que la comunidad ha sido en el pasado, y crear una imagen idealizada de la misma.

La ruptura de un pensamiento dicotómico nos llevaría a comprender de modo más acabado la articulación entre lo público y lo privado en el espacio construido por el grupo como organización colectiva. Pero volvamos a la distinción que Arendt realiza en un primer momento sobre el espacio público y privado. El primer entrecruzamiento que identificamos en relación a esta cuestión salta a la vista en tanto el relato de la obra se nutre principalmente de testimonios e información biográfica de los autores. Allí, el plano de lo personal, íntimo, privado, deja de serlo al ser expuesto como materia prima de la producción teatral, en primer lugar, y como parlamento arriba del escenario, por el otro. Pero ¿qué rol adquiere "lo inapropiado"? ¿De qué modo logra permanecer oculto a pesar de su exposición? Encontramos que en el caso de la obra de teatro, se exponen públicamente elementos que pertenecerían al ámbito de lo privado, pero sólo de aquellos personajes, situaciones o acontecimientos apropiados de ser contados como parte de una memoria compartida.

Según Arendt, la estructura de la vida comunitaria se modeló a partir de las relaciones entre los miembros de una familia, ya que "se sabía que éstas eran no políticas e incluso antipolíticas" (2005:63). Desde esta perspectiva lo familiar está ligado al ámbito privado y alejado del conflicto de la arena política, ya que si bien la autora no niega el conflicto entre pares, lo que le interesa es mostrar la pluralidad del mundo en común. En este marco, la función de contar historias del grupo de teatro no está ligada a generar un consenso, sino a ganar convocatoria. Es este mundo de la vida el que genera la continuidad temporal asentada en la construcción de la memoria colectiva o memoria fuerte (Candau, 2008), la apelación a rasgos identitarios ligados al pueblo, y la exposición pública que la hace trascender para la posteridad.

Dentro de las dinámicas que observamos en las lógicas de funcionamiento del grupo de teatro se encuentra la reproducción de ciertos valores instaurados desde el punto de vista ético-normativo que son los que sostienen, para los vecinos, la estructura de la vida comunitaria del pueblo: solidaridad, responsabilidad, lazos afectivos, pero principalmente, la idea de familia como núcleo de convivencia cotidiana y contención. 
Las representaciones que tienen los vecinos sobre las prácticas del grupo de teatro, son análogas con las que mantienen respecto al pueblo: la idea de la gran familia se convierte en el sostén que matiza las diferencias, que armoniza la pluralidad, y que, en última instancia, los aleja del conflicto. Tanto el grupo de teatro como el pueblo son una "gran familia", en donde todos se conocen. Ese mundo en común adquiere mayor relevancia en la representación teatral, anclada en las tradiciones que mantienen el imaginario de una comunidad que parecería no cambiar. Tal como afirman Grondona y Romero (2005: 259), "la familia es un anclaje que permite a los sujetos narrarse en un relato lineal, evolutivo y continuo (...) es un espacio desde el cual proyectar el futuro a partir de los ideales heredados en los que nos han socializado".

La percepción de la familia en un tiempo lineal y evolutivo se combina con una percepción circular del tiempo, ahistórica, basada en su carácter de sagrado. Existe una propuesta evolutiva en el relato lineal que se combina con un tiempo circular, opuesto al cambio, que tiende a la conservación. La idea de rebaño está presente en tanto aparece una dimensión moral que remite al valor de la comunidad, una colectividad que reviste las mismas características de la familia invernadero. Registramos en los testimonios de las vecinas del pueblo un discurso que da cuenta de la conformación de un tipo de familia de este tipo -invernadero- donde en la estructura de roles al interior de la familia la madre será la encargada del cuidado cotidiano, del orden de la casa, de "llevar adelante el hogar" (Grondona y Romero, 2005).

Hago la limpieza de mi casa. Mi tarea es hacer la comidita, esperar los dos nietos que vienen a comer, después me llevo el nieto más chiquito al jardín y a las cinco y media, cinco y cuarto salgo a buscarlo, que para mí eso es vida ${ }^{67}$.

Hago lo que hace cualquier mujer (risas)... las cosas de la casa, entré en esto de teatro, porque a mí me gusta estar en actividad, salir (...) Y después lo común de una mujer en la casa ${ }^{68}$

Mi día es súper aburrido, no cambia. Mientras caliento mi desayuno voy y le doy de comer a mis pajaritos, y mientras desayuno acá los veo comer a ellos. Después entro a la casa a ordenar, después la comida, y siempre lo mismo. Lo único que corta un poco la rutina mía son las manualidades (...) a mí me gusta vivir así, lógico no es que nadie me obliga, me he acostumbrado mucho a estar en casa, soy medio solitaria ${ }^{69}$.

\footnotetext{
${ }^{67}$ Vecina de Sansinena y miembro del grupo (66 años).

${ }^{68}$ Idem (66 años).

${ }^{69}$ Vecina de Sansinena (56 años).
} 
Me dedico acá al negocio, a los quehaceres domésticos de una mujer de la casa ${ }^{70}$.

El rol femenino de ama de casa instaurado por un tipo de familia invernadero, establece determinados roles y espacios de sociabilidad para los hombres y las mujeres. En los apartados siguientes, veremos los procesos por medio de los cuales la práctica teatral comunitaria reproduce o genera una ruptura con los roles instituidos por este modelo familiar.

\section{Prácticas que construyen espacios}

"Había dos necesidades: una de María Emilia y un grupo de locos de hacer algo distinto, y otra de un montón de gente de ver algo que los sorprenda, sobre todo en los pueblos chicos",71

Las prácticas que realiza cotidianamente un colectivo artístico dan cuenta del carácter del espacio construido, a través de las significaciones que las mismas generan en sus miembros, las acciones concretas que llevan a cabo, y las relaciones que se establecen hacia el interior del grupo y con el afuera.

Dentro de las prácticas cotidianas del grupo, como son los ensayos y las reuniones, el vínculo entre los miembros es de informalidad y familiaridad, en tanto se reproducen prácticas del orden de lo privado de un grupo familiar: las reuniones para tomar mate, el festejo de los cumpleaños, las relaciones de solidaridad entre vecinos cuando alguno presenta un problema, etc. Incluso Ratier (2009) identifica rasgos similares que se establecen en las relaciones laborales, donde las formas patriarcales se ven acompañadas con formas de reciprocidad donde el intercambio de favores es central. Estos lazos se ven profundizados debido a las características de vínculos que se establecen específicamente entre los vecinos de Sansinena; allí predominan las

\footnotetext{
${ }^{70}$ Vecina de Sansinena y miembro del grupo (72 años).

${ }^{71}$ Delegada municipal de Sansinena (33 años).
} 
relaciones de parentesco, el conocimiento y reconocimiento de todas las familias que componen la historia fundacional del pueblo.

La interpelación que realizan los vecinos a través de la obra tiene gran efectividad en cuanto logra generar procesos de identificación con los mismos habitantes, pero no en clave de confrontación, sino de integración, anclados en el pasado común compartido. La construcción del espacio teatral como organización está aferrada a la búsqueda de la pluralidad, y la convivencia de una heterogeneidad de situaciones sociales y posturas políticas. Es por eso que siempre se resalta que en el teatro comunitario lo político partidario juega un rol secundario en pos de una integración mayor (Bidegain, 2007).

"Acá todos tenemos diferentes niveles sociales, desde gente que es analfabeta hasta gente egresada de la universidad, tenemos radicales, peronistas, conservadores, de lo que ande dando vueltas. Y lo sabemos, porque somos consientes (...) En las últimas elecciones, hubo gente que hizo campaña para un partido y otros para otro, y lo sabemos. Pero al momento de sentarnos a debatir las diferencias se olvidan porque somos todos compañeros del grupo de teatro, y uno lo dice pero parece mentira. Hay veces que te dan ganas de agarrarte de los pelos, pero lo discutimos y queda ahí adentro, la discusión se resuelve antes de irnos, por eso el grupo permanece y no se desgasta y no se disuelve" ${ }^{, 72}$.

"Las diferencias que aparecen son cosas que se charlan y se pulen. Porque ninguno tiene la misma versión, si se trata de un hecho político, si vos naciste en una casa con una ideología política el otro la va a contar distinta porque la vio desde otro ángulo, como se la contaron en su casa. Pero eso no implica para nada la buena relación del grupo. Por ejemplo mis compañeros de armado de obra son totalmente opuestos a mis ideas, entonces en vez de generar roces hace que nos unamos y quede la idea en la mitad, se busca que no sea hiriente para nadie, es lo que se ha tratado de hacer, tampoco burlarse de un personaje. Siempre se busca la beta cómica". ${ }^{73}$

El tipo de acciones que el grupo de teatro realiza no son confrontativas, y están arraigadas en un compromiso ligado más al objetivo de fomentar un despertar cultural que a la creación de un colectivo disruptivo combativo. La apelación a una memoria colectiva fuerte y al sentimiento de pertenencia que nutre parte de los perfiles identitarios, se convierte en estrategia frente al proceso llamado de desaparición de pueblos (Ratier, 2009). En este sentido, las prácticas que el grupo realiza tanto dentro del pueblo como en sus viajes a otras localidades, portan un componente que es

\footnotetext{
${ }^{72}$ Coordinador del Grupo de Teatro de Sansinena (25 años).

${ }^{73}$ Coordinadora del Grupo de Teatro de Sansinena (62 años).
} 
claramente visible en las canciones y en el guión teatral: la lucha por la resistencia frente a la desaparición, y la conservación de las tradiciones.

En cuanto a las relaciones que el grupo entabla con las instituciones, debe tenerse en cuenta que estas últimas:

"parecen tener una lógica propia, producto de las condiciones locales que tiñe en forma particular la vida social lugareña, distorsionando las funciones establecidas para dichas instituciones (...) todas ellas tienen peso político y se relacionan con la toma de decisiones" (Ratier, 2009:77).

En este sentido, las instituciones -constituidas como redes asociativas que concentran núcleos de poder- se articularon en varias oportunidades con el grupo de teatro para realizar actividades conjuntas. Se organizaron funciones donde la ganancia que se cobró de acceso al espectáculo fue fraccionada en beneficio de la escuela, del cuartel de bomberos, y demás instituciones.

Las relaciones que el grupo de teatro mantiene con las instituciones no estuvieron desprovistas de conflictos y tensiones. Como afirma Ratier (2009), las redes asociativas que desarrollan actividades comunitarias en las instituciones del pueblo, parecerían presentar un sesgo apolítico, en tanto se vinculan a través de intercambios informales y de familiaridad; sin embargo es por medio de ellas que las autoridades municipales se comunican con la comunidad, y es allí en donde se concentran núcleos de poder de mayor intensidad, debido a que la poca participación de los vecinos en las comisiones genera una reiterada presencia de las mismas personas cumpliendo esas funciones.

Dichas tensiones se manifestaron fundamentalmente con representantes de las comisiones directivas, las que giraron en torno al pago o la gratuidad del Centro Recreativo Sansinena para su utilización por parte del grupo de teatro. En este sentido, las negociaciones son parte fundamental de la actividad del grupo, que busca conseguir recursos, lugares de ensayo y financiación de modo autónomo. A través de negociaciones frecuentes con los centros de poder, con la clausura o la presión sobre los intereses de las autoridades y la visibilizacion de la masividad del movimiento para dar cuenta del poder movilizador, es María Emilia de la Iglesia quien fundamentalmente asume el rol de representante del colectivo frente a las autoridades. 
El vínculo de interacción permanente con la figura que concentra el poder de máxima jerarquía en la región -el intendente radical Sergio Buil ${ }^{74}$ - asumió relevancia en cuanto se estableció entre él y los coordinadores del grupo (María Emilia, Edith Bello y Darío Fernández), un lazo de negociación continua. El mismo se configuró en ocasiones como una demanda de recursos (iluminación, sonido, gradas), y en otras encarnó una lucha de legitimidad y reconocimiento del colectivo por parte del poder político, expresada en la visibilidad a través de programas o anuncios públicos ${ }^{75}$. El reconocimiento del poder político se fue ganando progresivamente, a medida que iba aumentando la participación de la gente en el grupo. Como hemos apuntado anteriormente, los procesos por los que atravesó el grupo desde su constitución hasta la actualidad construyeron nuevas representaciones de los vecinos sobre la misma actividad, en una relación dialéctica de mutua transformación. Las mismas estuvieron ligadas a un cambio en la percepción del reconocimiento desde el exterior, en tanto Sansinena adquirió visibilidad en los medios de comunicación (a nivel nacional y local) ${ }^{76}$ y en las localidades cercanas, a través de la difusión de la actividad teatral. Recordemos que la visibilizacion resulta un factor fundamental para las personas que viven en geografías marginales (Ratier, 2009) en donde el aislamiento y las reducidas dimensiones de sus parajes generan situaciones de desigualdad.

El espacio que constituyó el grupo de teatro comunitario de Sansinena adquirió para los vecinos muchas veces el carácter de entretenimiento, una práctica cultural que vino a llenar el vacío de una actividad de esparcimiento, utilizada muchas veces como terapia o como lugar de catarsis para sus miembros. Frente a la monotonía de la vida del pueblo, el teatro aparece como un espacio lúdico, cargado de referencias que acentúan en su accionar la idea de qué lindo es vivir allí, a la importancia del lugar de origen y las virtudes del pueblo frente a la ciudad. Es interesante tener presente, que la percepción

\footnotetext{
${ }^{74}$ Sergio Buil es el Intendente de Rivadavia, que inició en diciembre del 2011 su cuarto mandato en el cargo. Pertenece al partido Generación para un Encuentro Nacional (GEN).

${ }^{75}$ En ocasiones de festividades, como por ejemplo el Centenario del Partido de Rivadavia, en donde el grupo de teatro tenía pautada una función dentro de la programación de los festejos, los folletos de difusión priorizaban visualmente las visitas de cantantes o desfiles tradicionales, y excluían o relegaban la información de la obra de teatro.

${ }^{76}$ Ver ANEXO 1
} 
por parte de los vecinos del espacio teatral como lugar de entretenimiento es la más difundida. Son pocos los que han reflexionado sobre la misma como un espacio alternativo de construcción política, de disputa por sentidos o derechos; y los que lo hicieron fueron principalmente los coordinadores o el círculo de personas más cercanas a ellos.

\begin{abstract}
"Aparte de ser un lugar de dispersión el grupo es un lugar en donde uno comparte cosas, no sólo lo de teatro sino las vivencias de cada uno, las necesidades de cada uno. Porque este grupo es como una familia, te conoces entre todos. Más allá del grupo de teatro compartimos nuestras necesidades, nuestras vivencias, nuestras alegrías, todo. Y tratamos de ayudarnos, cómo hacemos para ir a los lugares, es más que un grupo de teatro, es una familia...."77
\end{abstract}

El registro que realizamos aportó ciertos datos en cuanto a las significaciones que el espacio teatral adquiere para los vecinos que participan en él, en donde se destaca la idea de que es una actividad con la que "se sale más", "se ocupa la cabeza", "el pueblo tiene algo más", "el teatro trae gente al pueblo y por eso se pone más lindo"78.

\title{
3. La creación, motor de la acción
}

Desde el año 2009 -en que se representó por primera vez Por los caminos de mi pueblohasta la actualidad, el número de integrantes que componen el grupo disminuyó significativamente. Si entendemos la creación como motor de la acción, ésta viene a interrumpir la rutina de la vida cotidiana, -de allí la ruptura con la monotonía que muchos vecinos alegan en relación al teatro- generando espacios de encuentro y sociabilidad intergeneracionales; allí las relaciones de orden cotidiano adquieren un plus, que se encuentra justamente en el desarrollo de una actividad artística. La misma cotidianeidad se entabla con el correr del tiempo en la práctica teatral, a través de la regularidad de ensayos y reuniones, donde lo novedoso vuelve a concentrarse en el

\footnotetext{
${ }^{77}$ Vecina de Sansinena y miembro del grupo de teatro (40 años).

${ }^{78}$ Testimonios de los vecinos que conforman el Grupo de Teatro Popular de Sansinena.
} 
momento de producción y en la diversidad de edades que convergen en el mismo espacio.

"El grupo aumenta cuando hay construcción (...) porque si no hay construcción, sino se cambia la rutina... y yo creo que justamente el teatro comunitario viene a romper con la rutina. Entonces si rutinizamos también los ensayos, la gente deja de venir a los ensayos, aunque no deja de pertenecer al grupo"

La ruptura que genera la práctica teatral en la rutina diaria de los vecinos que participan, adquiere más notoriedad en el caso de las mujeres, en tanto trastoca la distribución de roles tradicional que señalamos en las familias de tipo invernadero. Las figuras femeninas y masculinas ven desdibujados los rígidos límites que marcaron su rutina diaria como amas de casa/ ámbito doméstico/ espacio privado -para las mujeres- y trabajador/ proveedor de alimentos/ espacio público- para los hombres. Si bien se conservan ciertas prácticas ligadas al ámbito familiar -como el encuentro para tomar mate, la celebración de los cumpleaños, los lazos de colaboración y solidaridad-, el espacio teatral subvierte esos roles, en donde todos se encargan de todo independientemente de si se es mujer u hombre; de hecho, de las tres personas que coordinan el grupo dos son mujeres, y son las encargadas de llevar a cabo las tareas más difíciles (negociaciones con autoridades, gestión de recursos).

Reconocemos en el espacio teatral la institución de un nuevo tipo de relación intergeneracional que atraviesa las prácticas cotidianas del grupo, donde a la vez convergen vecinos peones con sus patrones, estudiantes universitarios y analfabetos, profesionales de las diversas ramas, militantes peronistas con radicales y conservadores. En el momento de creación se observan en el grupo relaciones de tipo familiar, y el mismo se convierte en novedad desde su estructura porque configura un espacio que articula posturas políticas, modos de concebir el mundo, expectativas a futuro, intereses y modos de actuar muy diferentes. Todo ello en un contexto que le otorga un gran valor a las tradiciones, la conservación de las costumbres y los valores morales y religiosos. Dentro de las dinámicas inscriptas en las prácticas del grupo, las relaciones de poder, el juego de legitimidades y las trayectorias individuales adquieren relevancia a la hora de

\footnotetext{
${ }^{79}$ Coordinador del grupo de teatro de Sansinena.
} 
la construcción colectiva. La comprensión de estas tramas relacionales, en su mayoría omitidas o poco visibilizadas en los testimonios de los vecinos, nos ayudarán a entender la configuración del espacio teatral y los procesos que allí tienen lugar, los roles establecidos y las disputas de poder. 


\section{Capítulo IV}

\section{De equipos y personalidades. Tensiones de liderazgo, dificultades y potencialidades de la acción}

En toda práctica que se construye colectivamente podemos encontrar diferentes niveles de participación, relaciones de poder, estrategias de organización, vínculos con instituciones y autoridades; el desarrollo de estas dinámicas será particular en cada grupo. En el caso del Grupo de Teatro Popular de Sansinena, se adoptó un modo organizativo en donde la toma de decisiones sobre las acciones a seguir se realiza a través de asambleas. Los testimonios afirman que las decisiones se toman entre todos y que no existen restricciones en cuanto a la participación. Las actividades son propuestas por los vecinos durante los ensayos, en donde se plantean posturas y se debaten diversos puntos de vista, con el objetivo de llegar a un consenso. Esta misma metodología de trabajo se estableció durante la construcción de la obra, momento en el cual se intercambiaron experiencias y anécdotas para el armado teatral.

Frente a la idea de que la práctica teatral comunitaria asume un perfil horizontal, autogestivo y reflexivo (Bidegain, 2007), nos preguntamos qué sucede dentro de la organización teatral con las diferentes legitimidades que se construyen sobre los directores, de qué modo inciden las trayectorias que los mismos vivieron en experiencias anteriores, los grados de participación de los vecinos y la construcción de liderazgos hacia adentro del grupo. De igual modo es fundamental analizar la implicancia que estos elementos tuvieron en la determinación de las negociaciones por la búsqueda de recursos, el establecimiento de redes asociativas y la creación de otras prácticas culturales a raíz de la actividad teatral. 


\section{1. “Tener a Edith y a María Emilia juntas es como tener a Messi y a Maradona en el mismo equipo",80}

En los registros que tomamos encontramos reiteradas referencias a María Emilia de la Iglesia, Edith Bello y Darío Fernández, quienes son referenciados por los miembros del grupo como los portadores de las capacidades y saberes necesarios para llevar adelante el grupo de teatro. Pero difícilmente pueden igualarse en esas referencias las percepciones que los vecinos-actores tienen sobre cada uno de ellos, ya que las experiencias, trayectorias e ideas de los tres coordinadores se diferencian.

María Emilia tiene 29 años y es oriunda de Sansinena. El primer contacto que tomó con el teatro fue a través de su padre -Osvaldo de la Iglesia- quien dirigió por varios años un grupo vocacional en el pueblo. Cuando ingresó a la escuela secundaria en General Villegas $^{81}$ se vinculó con profesores de teatro, participó en diversas obras y a los diecisiete años escribió notas de actualidad para diarios locales ${ }^{82}$. Un año después viajó a la ciudad de La Plata para estudiar comunicación social y actuación; allí participó de programas de radio y grupos de teatro independiente. Con la idea de dictar talleres de teatro en Sansinena presentó un proyecto a la Municipalidad de Rivadavia, y en año 2006 comenzó a viajar al pueblo todos los fines de semana, convocando vecinos para la conformación del Grupo de Teatro Popular de Sansinena.

La idea era volver a tomar el ritual del teatro en el pueblo, porque había sido muy importante, y una muestra de eso son los clubes que tienen un escenario a la italiana, que son muy grandes, donde la gente se juntaba y hacía un montón de actividades teatrales (...) había una herencia de eso, en la memoria de la gente estaba el tema del teatro pero hacía, en el caso de Sansinena, 17 años que no se hacía teatro. Mi viejo había sido el último director de teatro en Sansinena, entonces lo primero que hice fue, además de hacer una convocatoria general, convocar especialmente a los últimos actores que habían actuado con mi viejo. Eso era teatro vocacional, porque empezamos con Los Árboles mueren de pie, una obra tradicional de Casona (...) Yo estaba viviendo en La Plata, primero empecé viniendo una vez al mes, después ya cada quince días y después una vez por semana (...) al principio como venía una vez al mes, no fue mi figura de directora como lo más importante, pero lo que se trató siempre de hacer es de generar coordinadores locales en cada lugar. En el caso de Sansinena la coordinadora natural era mi vieja, porque ella siempre había acompañado la experiencia de mi viejo desde la escenografía, el vestuario, no había actuado nunca, pero tenía como esa cosa mamada del teatro. Después decantó también Darío, que es una persona

\footnotetext{
${ }^{80}$ Vecino actor del grupo de Sansinena (47 años).

${ }^{81}$ Ciudad cabecera del Partido de General Villegas, al noroeste de la Provincia de Buenos Aires.

${ }^{82}$ Ver ANEXO 2
} 
maravillosa, muy joven de 23 años, que tiene pilas bárbaras. Son los dos coordinadores locales de Sansinena ${ }^{83}$.

Edith Bello es la madre de María Emilia, tiene 62 años y es oriunda de Sansinena. Su padre era músico y participó de la orquesta de los hermanos Bello, de gran popularidad en el pueblo. Luego de contraer matrimonio con Osvaldo de la Iglesia participó como asistente de vestuario, maquilladora, escenógrafa, peluquera y actriz en el grupo de teatro vocacional que dirigía su esposo, y con la conformación del grupo de teatro comunitario, pasó a formar parte de la dirección del mismo, junto con María Emilia y Darío Fernández.

Darío Fernández, de 25 años de edad, nació en Sansinena. Participó de varias actividades culturales que se desarrollaron en el pueblo, como la radio FM Sansinena que funcionó hasta el año 2001, y actualmente es docente en la escuela del pueblo, ya que estudió Ciencias de la Educación. Recientemente se mudó al pueblo de América, pero sigue coordinando el grupo de Sansinena junto con Edith Bello.

La evocación de la figura de Osvaldo de la Iglesia es significativa, en tanto se convierte en un acto de memoria, no sólo porque es una huella ${ }^{84}$ (Jelin, 2002) que María Emilia retomó para su labor, sino que además fue una herramienta que abrió el proceso de legitimidad para que ella se convirtiera en la directora del grupo. Las operaciones memorialísticas ancladas en el recuerdo se activaron para dar paso a la reconstrucción de la experiencia iniciada por Osvaldo. De esta forma se vinculó en los recuerdos de los vecinos, la existencia de aquel teatro como un don, un talento que se lleva en la sangre, y que María Emilia habría heredado de su padre.

En otra oportunidad hice también con el papá de María Emilia, la obra cuando recién nació la nena, hicimos un cuadro de distintas colectividades y bailé una jota sola en el escenario (...) María Emilia ha nacido para eso. Muy bohemia, las cosas que dice por ahí 'ésta de dónde salió', es la vida de teatro esa, de ser así. ${ }^{85}$.

\footnotetext{
${ }^{83}$ María Emilia de la Iglesia, coordinadora del grupo de Sansinena (29 años).

${ }^{84}$ Para Jelin (2002: 11), "lo que el pasado deja son huellas, en las ruinas y marcas materiales, en las huellas «mnésicas» del sistema neurológico humano, en la dinámica psíquica de las personas, en el mundo simbólico. Pero esas huellas, en sí mismas, no constituyen «memoria» a menos que sean evocadas y ubicadas en un marco que les dé sentido".

${ }^{85}$ Vecina actriz del grupo de Sansinena, docente (50 años).
} 
Yo con el asunto del teatro anduve siempre, se hacían fogones criollos con el papá de María Emilia, que hacíamos pericón, recitado, se bailaban danzas. Tendría 16 años cuando empecé con los pericones ${ }^{86}$.

Yo siempre fui como de la familia de los De la Iglesia, y el esposo de ella (Edith) era un hombre que siempre era de teatro, muy fino, yo cuando nos casamos nos arregló la capilla, muy detallista, y murió pobrecito joven, y yo estoy con una satisfacción de que la hija logró lo que él quería hacer (...) Osvaldo era buenísimo, era un amor (...) Emilia quedó chiquita cuando murió el padre, como un don que le dio para que siguiera. Porque es una pulguita que no se queda quieta, hace de todo. Está en todo ${ }^{87}$.

Y se ve que le gusta muchísimo, ella lo trae del padre, y de Edith, lo trae en la sangre $^{88}$.

En Sansinena también había actividad teatral, con los fogones, era muy natural, tuve oportunidad de conocer al papá de María Emilia, de que nos dirigiera y estar en grupos de teatro con maestras jardineras de Sansinena ${ }^{89}$.

Había un gran impulsador que era el marido de Edith...cuando faltó Osvaldo hizo un quiebre todo ${ }^{90}$.

Teníamos una gran amistad con Osvaldo, con Edith, pasaba horas charlando con Osvaldo. Y me iba a meter en el teatro porque me gustaba (...) hoy yo creo que hay una persona que la menciono siempre que es la mamá de María Emilia, Edith. Creo que es el alma, porque María Emilia no puedo decir nada, es una tromba se lleva todo por delante, pero tiene a Edith que es tener a Maradona y a Messi en el mismo equipo. Además ella (Edith) siempre estuvo con Osvaldo, siempre tuvo un rol secundario, era la que en las obras se ocupaba de dar el último toque. Venía, te pintaba, pero era lo único que hacía. Hasta que empezó e hizo una obra, la primera, que para mí fue la mejor que hizo Edith, que se dio cuenta de que también podía trabajar (...) y después lo que la ves trabajar, está todo el día, es una hormiguita, salís a las ocho de la mañana y anda buscando cosas, y son las nueve de la noche y anda acarreando gente. $\mathrm{O}$ sea, creo que Edith tiene una parte fundamental, después tenés otra gente, Darío Fernández, Beba Felleti, son incondicionales ${ }^{91}$.

El lazo parental de Osvaldo con María Emilia generó la primera instancia de legitimación, que se vio reforzada por diferentes "aptitudes" de la joven para liderar el grupo, que fueron continuamente remarcadas por los vecinos. De igual manera, los conocimientos adquiridos en el manejo de herramientas del lenguaje académico e institucional, facilitaron la construcción de la imagen de María Emilia como la líder del grupo. Pero ¿cómo puede comprenderse el proceso de asignación de roles? ¿Qué

\footnotetext{
${ }^{86}$ Vecino actor del grupo de Sansinena, músico (58 años).

${ }^{87}$ Vecina actriz del grupo de Sansinena, ama de casa (66 años).

${ }^{88}$ Vecina actriz del grupo de Sansinena, jubilada en enfermería (66 años).

${ }^{89}$ Vecino actor y coordinador del grupo de González Moreno, periodista (47 años).

${ }^{90}$ Vecina de Sansinena, ama de casa (54 años).

${ }^{91}$ Vecino actor del grupo de Sansinena, farmacéutico (47 años).
} 
características adquiere la figura de María Emilia y por qué? ¿Qué implicancias tiene este proceso en el grado de participación y la toma de decisiones?

\section{Legitimidad adquirida, legitimidad otorgada}

\section{Dependencias e interdependencias}

Encontramos en la figura de la directora una legitimidad otorgada por los vecinos en base a conductas, trayectorias, experiencias y conocimientos aportados por María Emilia; simultáneamente, ella construye los rasgos que definen su rol en un proceso de aprendizaje constante. Los elementos aportados por los estudios de actuación cursados en La Plata son, en primera instancia, los que la ubican como la portadora del conocimiento en materia teatral. Pero veremos en los testimonios de los vecinos, que no son esos atributos los que exclusivamente contribuyen a la construcción de la figura de liderazgo, sino que además son valoradas positivamente las capacidades para gestionar recursos frente a las autoridades, hacer reclamos, conseguir subsidios, organizar actividades y trabajar incansablemente en pos del proyecto teatral. Son reiteradamente puestos de relieve los esfuerzos que María Emilia realiza diariamente para que las representaciones cuenten con la infraestructura necesaria, se tengan en manos los materiales de la puesta en escena, se ensayen las canciones, las actuaciones y se cuente con el vestuario adecuado. A este esfuerzo se le suma el acompañamiento de Edith, quien suplió en muchos casos la presencia de María Emilia cuando se inició el proyecto de la conformación del grupo de todo el Partido de Rivadavia, momento a partir del cual la directora permaneció menos tiempo en Sansinena.

Sin palabras, porque es tan amorosa. Tengo muchas cosas para decir pero no sé cual sería más linda para decir, porque es muy buena, tiene mucho talento, es completa $^{92}$.

Hay que tener pasta, porque una cosa es que estés en tu pueblito dirigiendo un grupo, pero ya tener seis grupos... tenés que tener ganas, capacidad y sentir amor por la profesión que tenés. Emilia lo hace bastante bien ${ }^{93}$.

María Emilia es muy agradable, lucha para que todos podamos llegar a entender. Para que tengamos toda la confianza. Ella te hace entender las cosas, es bárbara,

\footnotetext{
${ }^{92}$ Vecina actriz del grupo de Sansinena, ama de casa (66 años).

${ }^{93}$ Vecina actriz del grupo de Sansinena, modista (40 años).
} 
manejar más de doscientas personas...llega al corazón de todos porque es muy buena piba. A veces la sacamos de las casillas, pero vuelve enseguida...cuando ella no está no es lo mismo que cuando está. Te sentís más seguro... ella es especial, porque el padre de ella era un hombre que no había estudiado y sin embargo había teatro... Podés preguntarle a cualquiera, que si no está María Emilia no es lo mismo...si falta ella a nosotros nos falta algo, y cuando aparece nos pone contentos. Ella es la cabeza. Te sentís cómodo, es querible ${ }^{94}$.

El énfasis de los vecinos al resaltar las virtudes de María Emilia como directora ponen de manifiesto la construcción de un liderazgo fuerte, compacto, erigido sobre las bases de una legitimidad que tiene sus raíces en la figura de Osvaldo de la Iglesia, y que se fue edificando sobre las experiencias en las que María Emilia se destacó. Ella fue la que "trajo el teatro al pueblo", al igual que su padre, pero se diferenció de él en la medida en que su figura trascendió el territorio sansinense, constituyéndose en un referente para todo el Partido. El hecho de haber participado en actividades relacionadas a la comunicación desde la adolescencia y el desarrollo de prácticas radiales y periodísticas, fueron labrando su carácter de líder indiscutido. Hemos sido testigos de situaciones en las cuáles María Emilia debió negociar cara a cara con el Intendente, presentar proyectos, constituyéndose en la representante de doscientos vecinos.

Por otra parte, no sólo registramos en las prácticas cotidianas del grupo (como los ensayos) una necesidad de la presencia de María Emilia, sino también la institución de su figura como autoridad, aquella que debe tener la última palabra en las decisiones del grupo, porque es la portadora del saber y quien sabrá "qué es lo que hay que hacer". Surgen entonces las preguntas sobre una dependencia por el fuerte liderazgo, además de las dificultades propias de un exceso de actividades centrados en un solo responsable. ¿Qué sucedería, entonces, si María Emilia dejara el teatro?

Yo creo que no hay otra Emilia, en el pueblo no hay, conozco la gente, y nadie va a ir a buscar a nadie. No hay otra persona que haga el camino de hormiga. Creo que se termina. ${ }^{95}$

A mí me parece que mientras esté Edith y María Emilia esto se mantiene. Porque las teatreras verdaderas son ellas dos. Darío también trabaja muy bien, pero tiene sus ocupaciones en otro lado. Salvo que venga otra generación de otro chico que

\footnotetext{
${ }^{94}$ Vecino actor del grupo de Sansinena, jubilado (66 años)

${ }^{95}$ Vecina actriz del grupo de Sansinena, docente (50 años).
} 
como María Emilia que estudio y volvió a su pueblo, que podría no haberlo hecho. Ella levantó todo esto que la acompañamos un montón de gente. Pero si ellas dos dejan esto el teatro muere. Porque asimismo a ellas les cuesta juntarlos a todos, Edith golpeando las puertas, es muy constante. Hay algunos que hay que volverles a repetir. Y sería una lástima ${ }^{96}$.

Si no estuviese María Emilia dudo que alguien quisiera tomarse semejante responsabilidad. Porque no es Sansinena solo, somos varios formando el partido. Y tenés que tener amor, vocación de servicio, para sacar de tu tiempo personal para dárselo a otras personas, y no cualquiera lo puede hacer. Y también pelear por las necesidades. No es solamente el venir y darnos la clase de teatro. Implica mucho más, el pelear por lo que necesitamos, las luces, el equipo de sonido, cómo trasladarnos $^{97}$.

Muchos autores le atribuyeron a la práctica comunitaria una dinámica basada en la búsqueda de horizontalidad (Proaño Gómez, 2006; Bidegain, 2007; Rosemberg, 2008), la que podríamos poner en cuestión en el caso de Sansinena, en cuanto surge la pregunta por la dependencia de este fuerte liderazgo que presenta la cuestión de la delegación como operación fundamental.

\section{Transformar sin irrumpir, construir sin confrontar}

Diversos autores que analizaron experiencias colectivas de organización y movimientos artísticos surgidos luego de la crisis del año 2001 (Palomino, Altamirano, Méndez y Libchaber, 2003; Svampa, 2005; Pérez, Armelino y Rossi, 2006; Rodriguez Blanco, 2006; entre otros), consideraron al contexto de movilización social y la crisis de representación política que el país estaba atravesando, como el caldo de cultivo para la constitución de diversas manifestaciones populares que proponían una mayor intervención de los distintos sectores sociales (fundamentalmente de la clase media) en las decisiones políticas. Encontramos dentro de estas manifestaciones las experiencias de las asambleas vecinales, cuyo análisis también ha sido abordado por diferentes cientistas sociales que encontraron allí nuevas formas de participación política (Rodríguez Blanco, 2006). La emergencia de las asambleas barriales, conformadas por un gran porcentaje de vecinos de clase media, es frecuentemente evocada como un

\footnotetext{
${ }^{96}$ Vecina actriz del grupo de Sansinena, jubilada en enfermería (66 años).

${ }^{97}$ Vecina actriz del grupo de Sansinena, modista (40 años)..
} 
fenómeno que se vincula con el teatro comunitario, en la medida en que ambas experiencias surgen (asambleas) o se multiplican (teatro comunitario), durante los años inmediatamente posteriores al 2001. Se destacan, además, ciertas estrategias de funcionamiento y de organización que dichas asambleas desplegaron, en donde se intentaba construir un espacio de horizontalidad, en donde todos puedan opinar y los vecinos sean parte de un proceso colectivo de toma de decisiones, no desprovisto, igualmente, de conflictos y relaciones de poder (Di Marco, Palomino, Altamirano, Méndez, Libchaber, 2003, Pérez, Armelino y Rossi, 2005; Dri, 2006).

Algunos investigadores de teatro comunitario establecen cierto paralelismo entre la práctica teatral comunitaria y los movimientos sociales, en tanto expresarían y visibilizarían la voluntad de sectores marginados y excluidos que, a través de mecanismos colectivos presentan demandas al Estado y reivindican la consigna del poder popular (Proaño Gómez, 2007, Bidegain, 2007). Pero los interrogantes en torno a la debilidad de las afirmaciones que homogenizan estas prácticas es evidente, pues los contextos específicos difieren, al igual que los proyectos que los colectivos están pensando para el futuro y las formas de llevar a cabo la práctica. También podemos hallar similitudes, pero será necesario analizarlas detenidamente.

Hay un elemento que se manifiesta en el horizonte ideal de la práctica asamblearia, piquetera y teatral comunitaria: la horizontalidad. En relación a las dos primeras experiencias, Rodríguez Blanco (2006) afirma que el principio de horizontalidad no es novedoso (porque ya se había desarrollado en otras ocasiones de cortes de ruta y protestas en el interior del país), pero acompaña la premisa de la autogestión; allí habría, para la autora, una fuerte crítica a las formas más tradicionales de representación política (la política partidaria, la política sindical y la política estatal). Estos elementos de horizontalidad y autogestión que destacan los análisis de los movimientos sociales, piqueteros y asamblearios, se encuentran en el caso de la práctica del grupo de Sansinena atravesados por lógicas alejadas de una necesidad ${ }^{98}$

\footnotetext{
98 Coincidimos con Pinedo en afirmar que si bien la necesidad es para algunos investigadores de organizaciones piqueteras el "motor de la acción", "las acciones colectivas no brotan naturalmente de las necesidades y las carencias que se sufren en el barrio, ni de la cultura política que se gesta en los habitantes del barrio, sino de estrategias de representación y regulación de consensos y disensos entre
} 
material que el colectivo podría suplir, lo que marca una particularidad en torno a la participación y compromiso de los vecinos con el grupo. La participación no estaría vinculada con la adquisición de un Plan que permita la supervivencia del grupo familiar, sino con factores ligados a la pertenencia territorial e identitaria de conservación de la tradición sansinense, conjugados en una práctica lúdica de vinculación intergeneracional que construye nuevos lazos de sociabilidad desde la cotidianidad.

El grado de representación que adquiere la figura de María Emilia frente a los vecinos tiene incidencia en las formas en las que el grupo toma decisiones, porque su legitimidad indiscutida de líder del grupo obstruye la idea de que se pueda continuar haciendo teatro sin su presencia. Las aptitudes de la directora son bien conocidas por los vecinos, quienes acatan su conocimiento de manera axiomática. Los registros que recabamos dan cuenta de una gran unanimidad en cuento de la aceptación de las decisiones de María Emilia; sin embargo, todos los vecinos manifestaron que el espacio teatral está abierto a la presentación de reflexiones, percepciones personales, las cuales son motivadas por la directora luego de cada ensayo, para que los vecinos presenten dudas, comentarios, críticas o propuestas sobre el trabajo realizado. La "toma de decisiones", manifestaron los vecinos, es entre todos, pero la última palabra la tiene María Emilia, que es "la que sabe". En este sentido, la autoridad de los referentes es fundamental, y se presenta dentro de la práctica a través de modos de actuar que erigen a determinadas personas como aquellas que promueven la actividad. Tal como afirmó Darío Fernández, coordinador del grupo: "la legitimidad de quién va a coordinar la reunión te la va dando el grupo, porque no es necesario que alguien te asigne: 'vos sos el coordinador', simplemente sos el que te acordas cómo era la letra”.

El desarrollo de la práctica, más los conocimientos previos, configuraron las legitimidades que establecieron las relaciones de liderazgo dentro del colectivo, ya que, al igual que en la práctica del grupo de Sansinena, los referentes de los movimientos asamblearios y piqueteros han tenido por lo general una experiencia política de militancia previa, no así la mayoría de los miembros del grupo. De esta manera:

actores que en numerosas ocasiones no comparten un mismo clivaje social, ni este se presenta como estrictamente territorial" (2009: 90). 
"generalmente hacen uso de la palabra aquellos que cuentan con mayores recursos, o bien son más locuaces, o disponen de mayor facilidad oratoria y retórica para argumentar y desarrollar una idea (...) a menudo el saber experto o la experiencia militante inciden en la toma de decisiones" (Rodríguez Blanco, 2006: 325).

La conformación del Grupo de Teatro Comunitario de Rivadavia, compuesto por seis pueblos del Partido, incluido Sansinena, significó una notable ausencia de María Emilia en el pueblo y en los ensayos, suplida por el trabajo de los coordinadores Edith y Darío. A pesar de las referencias positivas que los vecinos hacían de la labor de los coordinadores, la ausencia de María Emilia coincidió con una disminución importante en la cantidad de personas que participan del grupo, a lo cual se le sumó el ensayo reiterado de las mismas escenas que venían representando desde hacía tres años. Paralelamente, debieron gestionarse recursos para el transporte, elementos de escenografía e infraestructura, con menor presencia de la directora, que en años anteriores era la encargada de realizar esa labor.

Registramos un proceso de aprendizaje en la delegación de tareas, desde María Emilia hacia los coordinadores, que se extendió al resto de los vecinos del grupo a través de los encuentros distritales y la conformación de la Cooperativa La Comunitaria ${ }^{99}$.

Cuando se construyó la obra de Sansinena todo pasaba por ella, de lo primero hasta el último. Todos decidíamos pero todo tenía que tener en visto bueno de Emilia. Era: la cooperativa eléctrica no había traído los tapones y saltaron los tapones, a nadie se le ocurría decir "yo voy a la cooperativa a solucionarlo". Hoy sí lo hacemos" $" 100$.

¿Qué implica, entonces, el acto de delegación? ¿En qué medida hay un aprendizaje real de los vecinos para solucionar los problemas que se presentan, y hasta donde no se convierte en otra forma de representación de la autoridad que debe cumplir las normativas de aquella? Al respecto, la opinión de un joven de quince años miembro del grupo, difiere de la presentada por Darío:

\footnotetext{
${ }^{99}$ La Cooperativa La Comunitaria se conformó con la idea de promover, gestionar y apoyar actividades culturales que fomenten la vida cultural del Partido de Rivadavia, además de para conformar una figura que permita la gestión de recursos para ese fin. Está conformada por integrantes de todos los pueblos que conforman el Grupo de Teatro Comunitario de Rivadavia. Comenzó a funcionar en septiembre del 2011.

${ }^{100}$ Coordinador del grupo de Sansinena.
} 
Si en algún momento a María Emilia se le ocurriese dejar el teatro (que me parece algo muy ilógico, pero bueno) se viene todo abajo. Porque te lo decía antes, somos constantes, compañeros, todo lo que vos quieras, pero nos tienen que estar arriando para que nos organicemos. Y entonces empezarían los roces, que uno quiere mandar más que el otro, mucho cacique y poco indio, y ahí se iba a armar, y bueno, terminaríamos con el trabajo de tantos años.

La autoridad de María Emilia es para este joven algo más que un conocimiento de experta en cuestiones teatrales; adquiere una significación de poder sobre el colectivo, capaz de hacer convivir la pluralidad que, no exenta de conflictos, puede sin embargo confluir en un proyecto común. Pero el factor de la dependencia continúa prevaleciendo en su testimonio. Para Darío "nadie es imprescindible, porque el grupo funciona en sí mismo, esté o no esté María Emilia, esté o no esté él mismo", y la muestra es visible porque el grupo siguió a pesar de las ausencias de María Emilia. Darío vincula la idea de cooperativismo, en donde los lazos de solidaridad entre los miembros es fundamental, con la actividad cotidiana del grupo sansinense: "si Emilia no viene te aseguro que la obra se da, que entre todos vamos a solucionar todos los problemas que se presenten".

La consigna de "todos tiramos para el mismo lado, porque se trata de mostrar quiénes somos, cuál es nuestra historia, y que estamos orgullosos de nuestro pueblo", es la que articula el sentimiento de pertenencia, y es aquella que María Emilia utiliza constantemente para motivar y fortalecer el compromiso colectivo. Esta consigna se convierte en el bastión señalado por el joven en su testimonio, una herramienta que se personaliza en la medida en que la unicidad del liderazgo de María Emilia se fortalece. Si bien es innegable que el grupo adquirió ya una trayectoria de seis años de existencia, no perdemos de vista que las oscilaciones en el grado de participación estuvieron ligadas a la presencia /ausencia de la directora, y que su legitimidad, construida sobre las bases de la idea de un "talento heredado", aumenta a medida que María Emilia encabeza nuevas actividades, proyectos cada vez más ambiciosos en cuanto a la masividad de vecinos que participan, gestiona recursos y se vincula con las máximas autoridades del distrito, y su visibilidad se hace más notoria en los medios de comunicación locales y nacionales. 


\section{Sobre representantes y representaciones}

Con la introducción de la pregunta por la horizontalidad y la autogestión, surge el interrogante por las características del espacio teatral como organización social. Como hemos visto, la figura de los referentes es primordial en el funcionamiento del grupo, y más aun en el vínculo que el colectivo establece con las autoridades del distrito (representantes del poder estatal). Al introducirnos en los mecanismos de representación que instaura el grupo de Sansinena frente al poder nos preguntamos: ¿podemos ver allí elementos que señalen la existencia de un espacio de carácter político?

Los grupos de teatro comunitario son experiencias culturales diferenciales entre $\mathbf{s i ́}^{101}$, cuyo origen proviene de diversos frentes (incluso el Gobierno de la Ciudad de Buenos Aires tiene gran implicancia en su multiplicación post $2001^{102}$ ), pero el pueblo de Sansinena configura un contexto que se diferencia radicalmente de los sitios urbanos. La organización jerárquica de las relaciones de poder, la ausencia de experiencias previas de lucha colectiva, la cercanía en los lazos familiares y afectivos entre los pobladores, el atraso en la instalación de infraestructura básica como el agua potable y el gas, generan un marco diferente al de las ciudades, en donde el surgimiento del grupo de teatro adquiere relevancia.

En primer lugar, el grupo de teatro generó un movimiento inusitado, que permitió que Sansinena se convierta en una de las sedes del Noveno Encuentro Nacional de Teatro Comunitario 2011 (primer encuentro nacional en la historia del Partido). Suplió el vació cultural que sufría el pueblo desde hacía más de quince años, generando un nuevo

\footnotetext{
101 Ya que existen diferencias sustanciales entre los grupos (cantidad de participantes, recursos, estrategias de negociación, visibilidad, entre otros).

${ }^{102}$ En el año 2002 los grupos pioneros de teatro comunitario Catalinas Sur y el Circuito Cultural Barras, realizaron en el marco de un proyecto cultural del Gobierno de la Ciudad llamado Programa Cultural en Barrios, una Carpa Cultural Itinerante que llevaba la función de Catalinas Sur, Venimos de muy lejos, a diferentes barrios de la ciudad con el fin de que se generen nuevos grupos. Ésta iniciativa estaba acompañada de una charla con los vecinos, posterior a la función y guiada por Talento y Bianchi, a lo que se le sumaba el apoyo de diferentes centros culturales del Programa Cultural en Barrios, que difundieron la actividad. Varios grupos surgieron de este proyecto itinerante.
} 
espacio de participación que convocó a los vecinos para que puedan ser narradores de su propia historia, buscando integrar diversidades. Constituyó un espacio de intercambio de experiencias y fortaleció los lazos de solidaridad entre los vecinos, a través del encuentro intergeneracional que se da en los ensayos y las presentaciones del grupo en localidades cercanas. Adquirió visibilidad en los medios, y dejó de ser "un lugar perdido en el mapa", erigiéndose como el pueblo pionero de la experiencia teatral que habría de expandirse a todo el Partido de Rivadavia.

Como líneas que atraviesan trasversalmente estos procesos, no encontramos que se hayan desarrollado nuevas pautas de acción de los vecinos frente a los representantes del poder. Si bien continúan funcionando ciertos vínculos de poder jerarquizado, en donde la autoridad se sigue depositando en un solo responsable (María Emilia), la experiencia de la conformación del Grupo de Teatro Comunitario de Rivadavia implicó un progresivo proceso de aprendizaje en la delegación de tareas, -constantemente tensionado- en donde los coordinadores fueron construyendo liderazgos locales en cada pueblo. Los procesos de negociación para conseguir los recursos continúan presentando dificultades para los vecinos que no están acostumbrados a exigir o demandar, como tampoco a generar tensiones con las autoridades.

Las motivaciones individuales en torno a las cuales se construye la participación de los vecinos (espacio de catarsis, de entretenimiento, lugar de crecimiento individual en donde se "pone de manifiesto" el amor por el pueblo), su perfil no confrontativo sino más bien integrador, y la recuperación de la visibilidad del pueblo a través del teatro, dan cuenta de que la organización social que los vecinos han conformado accionó un modo de construcción colectiva desligado de la disputa política que acude a los mecanismos tradicionales de confrontación ${ }^{103}$, no sólo porque no cuenta en su historia con experiencias de luchas colectivas anteriores, sino también porque -como vimos en capítulos anteriores- existe un miedo a la política y al conflicto con las autoridades. Uno de los vecinos que participó de la construcción de la obra y fue uno de los iniciadores del grupo de teatro comunitario de González Moreno comentó:

\footnotetext{
${ }^{103}$ Nos referimos tanto a los mecanismos que se manejan dentro del sistema de la política (administrativa-institucional), como aquellos implementados por los grupos disruptivos, que por fuera de los marcos institucionales buscan reivindicar sus derechos.
} 
Los que iniciamos, tenemos que estar muy atentos a ser cuidadosos en cómo planteamos determinados temas, para que la gente no sospeche, y tenés que ser todo lo transparente que tenés que ser. Mostrar todo tal como eso, para que la gente no vea que estás ocultando nada, y tenés que tener un discurso muy transparente, y tenés que dejar de lado algunas cuestiones de lo ideológico de uno... porque el teatro comunitario es inclusivo, incluye a todo tipo de gente, entonces es un ejercicio fenomenal de tolerancia. Porque hay gente diametralmente opuesta a vos, cosas por las cuales te cagarías a trompadas en otras circunstancias, pero cuando haces teatro están junto con vos. Tenés que ser cuidadoso, porque sino no construís nada, y destruir es facilísimo Por eso digo que las transformaciones son lentas, porque si apurás destruís eso ${ }^{104}$.

Si bien, como dice el testimonio, las transformaciones son lentas, el grupo de teatro comunitario generó nuevas estrategias de acción que significaron un aprendizaje para los miembros del grupo, vecinos que nunca habían participado de un espacio de intercambio con sus pares, en donde reinaron muchas diferencias de pensamiento y de edad. El grupo lleva más de seis años de existencia, y si bien su composición ha fluctuado, continúan generando actividades y produciendo teatro.

La experiencia del teatro comunitario se constituyó como referente en Sansinena, por ser la primera práctica colectiva de actividades culturales/ teatrales, por fuera de un marco institucional, con una participación masiva de los vecinos. Veamos los vínculos que el grupo desarrolla con las autoridades y las estrategias de gestión, en donde se redefinen cuestiones ligadas a la autonomía y se delinean más claramente los liderazgos.

\section{Ecos de voces que no callan}

\section{Lógicas de negociación y potencialidades de la acción}

"Nosotros no nos casamos ni acostamos con el Intendente, pero sí estamos de novios. Eso lo entiende la gente, si le decís que es negociación, no. $" 105$

\footnotetext{
${ }^{104}$ Vecino oriundo de Sansinena, que participó en Por los caminos de mi pueblo y actualmente vive en González Moreno, en donde coordina el grupo de teatro de ese pueblo (47 años).

${ }^{105}$ Vecino actor del Grupo de Teatro Comunitario de Rivadavia y coordinador del grupo de González Moreno, agrónomo (33 años).
} 
Un aspecto fundamental en el estudio del Grupo de Sansinena como organización social radica en las estrategias de financiación adoptadas para llevar adelante sus actividades, y los criterios por los cuales se definen diversos grados de autonomía. Veremos que no hay posturas unívocas en torno al vínculo que los grupos deben mantener con el Estado $^{106}$ para lograr la obtención de recursos y que el grupo de Sansinena construyó un lazo de reciprocidad particular con las autoridades, en donde la búsqueda de cierta autonomía es un punto neurálgico que se tensiona en la práctica.

Los estudios de teatro comunitario han definido a la experiencia como autogestiva (Proaño Gómez, 2006, 2007; Bidegain, 2007; Greco, 2008), porque si bien los grupos no fueron el resultado de una inversión financiera o un proyecto artístico comercial, con el paso del tiempo se necesitaron recursos para acceder a los elementos necesarios para la actividad teatral como el vestuario, el maquillaje, la utilería, etc. En ese tránsito de la autogestión por medio del paso de la gorra hacia otros mecanismos más complejos de financiación, algunos grupos conformaron una Asociación Civil, figura legal que les permitió acceder a subsidios o ayudas de diversas instituciones, otros optaron por contribuir con el grupo todos los meses, aportando una pequeña cuota societaria para gastos generales, y otros grupos construyeron estrategias de articulación con otras instituciones para generar intercambios de recursos.

Edith Scher (2010) califica al tema "gestión" como un tema tabú para el teatro comunitario, e intenta establecer ciertas etapas por las cuales los grupos de teatro comunitario van atravesando, en donde a medida que el grupo va creciendo en cantidad, producción y reconocimiento, la gestión de recursos representa un desafío cada vez mayor. Muchas de las problemáticas que dan forma a ese desafío tienen que ver con los criterios adoptados en cuanto a la selección de quiénes serán los que otorguen el

${ }^{106}$ El Estado siempre ha estado presente en la dinámica de la obtención de recursos. En los inicios de la actividad del teatro comunitario, propiciando la actividad a través de la Carpa Cultural Itinerante, el Programa Cultural en Barrios (iniciativas del gobierno de la Ciudad de Buenos Aires, año 2002) y el Proyecto Escenarios (impulsado por el Instituto Cultural de la Provincia de Buenos Aires y el Instituto Nacional del Teatro). Durante el final del año 2010 y principios del 2011, el Consejo Provincial de Teatro Independiente otorgó una serie de subsidios a través de los cuáles muchos de los grupos de teatro comunitario se vieron beneficiados y el Instituto Nacional de Teatro financió la publicación de material bibliográfico sobre el tema. 
beneficio (ya sea un subsidio, una ayuda económica, etc.) y quiénes serán los destinatarios del mismo. Cada grupo escoge una estrategia que estará ligada a su capacidad de gestión, recursos humanos, vínculos con otras instituciones, etc.

Si bien autores como Greco (2008), afirman que la estructura organizativa autónoma con la que nacieron los grupos de teatro comunitario no facilitó al desarrollo de actividades de autofinanciamiento, y por eso fue necesaria una transformación funcional de la organización ${ }^{107}$, existen grupos que han optado por modos alternativos de autofinanciamiento, más cercanas a la construcción de cooperativas de trabajos y microemprendimientos, como en el caso del grupo Patricios Unidos de Pie (del pueblo de Patricios).

En el caso del Grupo de Teatro Popular de Sansinena distinguimos una serie de características propias de las lógicas políticas de los pueblos pequeños, que, como hemos apuntado, están impregnadas de un fuerte centralismo en la figura de la autoridad máxima del Partido (Intendente), un trato cara a cara entre él y los vecinos de los pueblos y un extendido conocimiento interpersonal entre los miembros de la comunidad que facilita el desarrollo de un vínculo más cercano. El grupo de teatro comunitario, a través del paso del tiempo, fue ganándose el reconocimiento en la práctica por parte de las autoridades y de otras instituciones desde diversos frentes, para que la actividad cultural (encarnada en el teatro) sea reconocida. La desconfianza de muchos de los vecinos del pueblo y del municipio señalada por los entrevistados como rasgo destacado en los inicios de la actividad teatral, comenzó a disiparse con el aumento progresivo de miembros que se fueron sumando, y la masiva recepción que tuvo el primer espectáculo $^{108}$.

\footnotetext{
${ }^{107}$ Tal como lo hizo el Grupo Catalinas Sur, el primer grupo de teatro comunitario del país. Comenzó a funcionar en el año 1983 en el barrio porteño de La Boca, y hoy, con sus más de 26 años de existencia se ha convertido no sólo en uno de los referentes y transmisores de la experiencia hacia grupos que están comenzando, sino que además cuenta con más de 300 vecinos actores, un galpón propio en donde realiza funciones todos los fines de semana, dictado de talleres de diversas disciplinas artísticas, y varios premios nacionales e internacionales. (www.catalinasur.com.ar).

${ }^{108}$ Ver ANEXO 1
} 
En esta lenta trayectoria, las negociaciones fueron complejizándose, los interlocutores fueron cambiando y se sumaron nuevos actores dentro del "entramado de la gestión". El inicio de la actividad comenzó a ser gestionada con el proyecto presentado por la directora a la Municipalidad, que le permitió viajar todas las semanas al pueblo desde La Plata para dictar los talleres. Con la conformación del grupo y las primeras funciones, fueron necesarias las luces, la escenografía, el vestuario, el maquillaje, y diversos elementos presentes en la representación, como la pantalla para pasar las diapositivas. Por los caminos de mi pueblo marcó el inicio de un vínculo entre María Emilia y las autoridades municipales (en ocasiones el delegado municipal, en ocasiones directamente el Intendente), y las instituciones del pueblo: la cooperativa eléctrica (que colaboró con la iluminación), el cuartel de bomberos, la escuela, la Casa de la Cultura, entre otras.

La concentración de actividades desplegada en torno a la figura de María Emilia era inevitable, en tanto las gestiones estaban concentradas en su persona, y era "a ella a quien escuchaban". Con la génesis del proyecto que nucleaba a vecinos de todo el Partido $^{109}$, esta concentración en la gestión fue haciéndose más evidente y más dificultosa de sobrellevar. Ya no se trataba de organizar un grupo de setenta personas de un solo pueblo, sino unas doscientas personas, provenientes de seis pueblos distintos. Las dificultades técnicas eran mayores, ya que la representación de la obra del Partido La historia de entreteje desde abajo y se cambia desde la comunidad, sería puesta en escena en San Mauricio, un pueblo semi abandonado, ubicado en el centro del Partido, en donde viven quince personas ${ }^{110}$.

Con el comienzo de este nuevo proyecto fue necesaria la articulación con los referentes (delegados), las instituciones y los vecinos de cada pueblo. La financiación por parte de diversos organismos que quisieran colaborar era ineludible, pues los gastos de

\footnotetext{
${ }^{109}$ El Grupo de Teatro Comunitario de Rivadavia buscaba incluir a todo el Partido. Participaron vecinos de los pueblos de Sansinena, González Moreno, América, Roosevelt, Fortín Olavarría y San Mauricio.

${ }^{110}$ San Mauricio es un pueblo ubicado en el centro del Partido de Rivadavia, que en algún momento fue pensado como cabecera del Partido por su ubicación estratégica. Según testimonios de los vecinos, llegó a albergar más de dos mil personas, se hacían allí grandes bailes y celebraciones populares. Por acción de las lluvias y la incomunicación provocada por la ausencia de transporte -no pasaba por allí el tren-el pueblo fue despoblándose, sus edificios destruidos y saqueados.
} 
infraestructura, transporte y herramientas propias de la puesta en escena eran altísimos y no podrían ser costeados por el pequeño fondo con el que contaba el teatro. La Municipalidad de Rivadavia, reacia en sus comienzos a prestar colaboración, accedió a los pedidos de financiación a partir de corroborar la masiva participación de los vecinos, la cantidad de instituciones involucradas y el compromiso que iban adquiriendo cada vez más vecinos con la actividad teatral. Dentro de las disputas que presenciamos durante los días previos al estreno de la obra del Partido, no faltaron tensiones internas dentro de las instituciones que habían decidido colaborar, con diversos representantes del poder municipal, quienes constantemente suspendían la ayuda, volvían a otorgarla, o generaban obstáculos administrativos. En esta vorágine de llamados, mensajes, incomunicaciones, malentendidos y negligencias, la cuestión de la delegación de responsabilidades adquirió una relevancia inevitable en tanto la directora concentraba la mayor cantidad de decisiones. Si bien ya había comenzado una lenta práctica de delegación hacia los coordinadores locales de cada pueblo, resultó dificultoso que los diversos actores involucrados no acudan directamente a María Emilia para hacer consultas, dar informaciones o negociar. Actualmente, estas dificultades devinieron en aprendizajes, a partir de las cuales surgieron nuevos referentes locales que nuclean las responsabilidades de cada pueblo, y funcionan como voceros de la voz colectiva de los vecinos, descomprimiendo la concentración de actividades sobre María Emilia.

Conjuntamente con la financiación, el reconocimiento de las autoridades le otorgó el grupo visibilidad y legitimidad como actividad cultural. El grupo de Sansinena como los de los otros pueblos del Partido, articularon una red de colaboraciones a través de gestiones de tono localista, que generaron presiones y tensiones en las autoridades, pero tuvieron gran efectividad por el trato "cara a cara" que se establece entre los coordinadores y las autoridades $^{111}$.

La organización del Noveno Encuentro Nacional de Teatro Comunitario que se llevó a cabo en el Partido de Rivadavia durante los días 8, 9 y 10 de octubre de 2011, significó una reconfiguración de los parámetros de negociación, los cuales se complejizaron,

\footnotetext{
${ }^{111}$ También colaboraron otros organismos estatales como el Instituto Nacional del Teatro y el Consejo Provincial de Teatro Independiente.
} 
adquirieron nuevas formas e involucraron nuevos actores ${ }^{112}$. En el caso de la participación del grupo de Sansinena en dicho evento, se observa un movimiento inverso al del resto de los pueblos: habiéndose convertido en el "pueblo pionero" en donde comenzó la experiencia teatral comunitaria, la expansión del fenómeno generó una merma en la participación de las instituciones del pueblo, de las cuales muy pocas colaboraron con el evento. Si bien existió un apoyo fuerte desde la delegación municipal, el entusiasmo de los vecinos y el apoyo de las instituciones fueron mucho menores a los experimentados durante los primeros años del grupo (2006-2009) ${ }^{113}$. Para María Emilia, "el entusiasmo es menor porque ahora la obra del centenario no es de ellos solos - solamente un pedacito -, y por eso están más entusiasmados los nuevos". Esta opinión coincide con lo que afirma una vecina de Sansinena, que participa del grupo:

Si le hubieran agregado otra cosa a los inmigrantes llevás más gente, pero la gente está cansada de los inmigrantes. Si hubieras mezclado otra obra... pero hacer lo mismo no me lleva. Entonces no puedo hacer algo que no me llama. Yo sentí que cuando hicieron la obra en San Mauricio, es que los demás hicieron algo nuevo y nosotros seguimos haciendo lo mismo. Como para que digan: no pudieron armar otra obra. Para que nos entusiasmáramos porque íbamos a hacer algo nuevo. Pienso que a la gente la están dejando, que si pusiera (María Emilia) algo más de granito acá y las pilas en Sansinena habría entusiasmado más a la gente. Hay muchos que no entraron, y si ella hubiese puesto algo nuevo se enganchaban. Yo para ir y aburrirme me quedo en mi casa.

Observamos nuevamente que los momentos creativos funcionan como motores de la acción, ya que los vecinos participan más en los momentos de producción de nuevas escenas u obras. Por otro lado, en este testimonio es clara la importancia que adquiere la vista de afuera", en tanto aquello para mostrar por medio de la representación teatral es la carta de presentación del grupo, e incluso del pueblo, hacia los visitantes.

La organización del Encuentro Nacional significó pautar reuniones periódicas de los coordinadores en los distintos pueblos, coordinar la logística para el recibimiento de los treinta grupos que acudieron al encuentro, la organización de las comidas y el

\footnotetext{
${ }^{112} \mathrm{El}$ análisis de estas lógicas comportaría el inicio de un estudio aparte.

${ }^{113}$ Se observa una merma en la participación de los vecinos en el grupo (en el año 2006 eran 70, en el 2010 eran 30), y en la colaboración de las instituciones del pueblo.
} 
alojamiento durante tres días, los transportes ${ }^{114}$, la financiación, y el trabajo que implicó la puesta en escena de la obra del Grupo de Teatro Comunitario de Rivadavia en San Mauricio. Durante más de un año, el proceso de aprendizaje de nuevas estrategias para lograr estos objetivos significó activar una red de acciones colectivas, articuladas con instituciones, organismos, sectores de poder, empresas y nuevos actores en un proyecto conjunto. Una experiencia inédita que fue lográndose desde aquellos primeros años en los que el grupo tuvo que luchar para lograr legitimidad entre los mismos pobladores, hasta la actualidad en que el Partido adquirió una visibilidad inusitada en los medios de comunicación locales y nacionales ${ }^{115}$ y en la Red Nacional de Teatro Comunitario.

Dentro de las negociaciones que tuvieron lugar para gestionar los recursos del encuentro, el vínculo con la Municipalidad se fue construyendo a través de diversos representantes del poder estatal; algunos de ellos eran los referentes para las consultas de orden político, y otros para las consultas sobre gestión. El trabajo articulado que fueron adquiriendo los coordinadores (con María Emilia a la cabeza) con estos representantes fue tal, que llegada la fecha del Encuentro con un estado climático desfavorable que impedía la entrada a muchos de los pueblos ${ }^{116}$, María Emilia se reunió con el Intendente y su gabinete completo en la Municipalidad de Rivadavia para debatir sobre la postergación del Encuentro para unos días más adelante. ¿Podemos pensar que el trayecto experiencial atravesado por el grupo generó progresivamente una politización de la práctica? ¿Puede el vínculo cada vez más estrecho con los mecanismos de la política -mecanismos institucionales de la política tradicionalgenerar un perfil más confrontativo en la práctica teatral, a través del aprendizaje de ciertas estrategias de negociación?

Identificar un sesgo confrontativo en la práctica teatral comportaría un desafío, ya que explícitamente se busca un alejamiento de la confrontación, por lo cual se adopta un lenguaje burlesco, y se utilizan los géneros que se valen de estereotipos y exageraciones. Si bien encontramos críticas que ponen de relieve inconformidades tales

\footnotetext{
${ }^{114}$ El Encuentro se desarrolló simultáneamente en seis sedes distintas, (en cada pueblo del Partido).

${ }^{115}$ Ver ANEXO 1

${ }^{116}$ Sansinena, Roosevelt y San Mauricio no tienen asfalto.
} 
como la falta de caminos, o la pregunta pendiente por la propiedad de las tierras, la representación teatral es, fundamentalmente, un homenaje y una reivindicación al pueblo sansinense, de tono emotivo. La falta de otros servicios básicos como el agua potable y el gas natural, o falencias en materia de salud o educación, podrían haber sido construidas en la obra como demandas al sistema estatal. Si bien en el ejercicio memoralístico que atravesó la producción de la obra estas cuestiones se discutieron entre los vecinos, no formaron parte del relato teatral.

Como experiencia colectiva el grupo de teatro amalgamó prácticas que, si bien puede parecer novedosas en las grandes ciudades, no lo son tanto en Sansinena: las reuniones regulares entre vecinos, el fortalecimiento de los lazos de solidaridad, el afianzamiento del sentido de pertenencia, entre otros. Inauguró, sin embargo, una forma de socialización intergeneracional e integradora, configuró un nosotros particular (nosotros los teatristas), caracterizado por ser comprometido con el pueblo, por el amor a él, el exacerbamiento de los rasgos rurales frente a los citadinos (los que eran caratulados como "pitucos", "agrandados"), y la abierta oposición a los discursos que declaman la desaparición de los pequeños pueblos. Como consigna primigenia, "Sansinena existe" concentra la demanda por la visibilización, frente a la negligencia, el aislamiento, y la condena "a la desaparición".

Si nos adentramos en las dimensiones de la acción llevada a cabo por el colectivo, identificamos una práctica que no se recluye en el espacio privado, sino que se reapropia del espacio público, tomando plazas, estaciones y calles. Cuando analizamos las relaciones que atraviesan ese espacio como organización social, vimos que predomina la matriz de la idea de familia, con un horizonte en el cual se dibuja la comunidad armónica, sin conflicto, que es idealizada en el "juramento" de la última escena de la obra. La toma de decisiones colectiva no está exenta del liderazgo de la directora, lo que genera fuertes dependencias en la praxis. La reflexión sobre estas tensiones y dificultades de la práctica no son abordadas por los miembros del grupo, sino que permanecen en mayor medida circunscriptas al grupo coordinador. Las acciones en territorio no irrumpen con el fin de convertir esta irrupción en un repertorio de acción (Tilly, 1995), sino que se construyen modos de participación y de trabajo 
articulados con instituciones, dependencias estatales y otros organismos. Un vecinoactor afirmó que:

En el ámbito cultural de aquí uno está trabajando sobre mucho terreno baldío, y eso está buenísimo, porque siempre estás comenzando a construir cosas. En las ciudades pasa más desapercibido, porque están todos construyendo en todos lados, y para que te perciban necesitas un gran edificio. Acá enseguida sos visible ${ }^{117}$.

Los desafíos que el grupo le presenta al poder político están, por un lado, en la masividad que adquirió el fenómeno en el Partido, (ya que la gran cantidad de vecinos que participan impide que la movilización generada por el teatro pase desapercibida, lo que tensiona a las autoridades a colaborar con el mismo) y la conformación de nuevas estructuras organizativas de tono colectivo, como la Cooperativa La Comunitaria. Esta dinámica encontraría más dificultades para reproducirse en las grandes ciudades, donde los colectivos culturales pueden ser más fácilmente ignorados por el poder político.

\section{5. “No importa lo que tengas, ni de qué pueblito vengas, siempre es mejor sumar...", 118}

El proyecto que comenzó en el año 2006 con el surgimiento del grupo de Sansinena ya no es el mismo. La experiencia de Sansinena ahora es parte de algo mucho mayor, en donde las relaciones se complejizaron por la suma de nuevos actores políticos, instituciones, vecinos y territorios, que deben negociar y conciliar intereses. Las tensiones se multiplican y las diferencias salen a la luz. Para María Emilia:

Esto es una herramienta contrahegemónica, y si bien uno está luchando con un montón de otras interpelaciones, esta es una. No sé si es lo suficientemente fuerte como para transformar a las personas. Creo que es una, por eso tiene que haber más de una forma, sino te quedás en una sola. El teatro no lo resuelve, si hay medios alternativos, si hay obreros organizados, si hay cultura comunitaria, entonces son interpelaciones más fuertes, y esto abona eso, pero por sí mismo no. No porque una persona participe del teatro comunitario le va a cambiar la vida, porque tampoco importa si le cambia la vida a nivel personal a él solo. Tenés gente que va porque se siente bien, pero la apuesta es por algo más grande, y para eso se necesita más de uno. La particularidad de esta interpelación es que integra muchas

\footnotetext{
${ }^{117}$ Vecino actor y coordinador del grupo de González Moreno (47 años).

${ }^{118}$ Fragmento de la canción final de La historia se entreteje desde abajo y se cambia desde la comunidad.
} 
cosas, integra el cuerpo, la música, la organización, la escenografía, la prensa, pero no es la única ${ }^{119}$.

Si comprendemos con Benjamin Arditi (1995) que nada es político pero todo es politizable, los ecos del teatro comunitario se extendieron hacia los territorios de la política, insertando su práctica dentro de la "agenda" de las autoridades. Hoy, María Emilia, convertida en referente, asume un rol que dista mucho de ser el de tallerista, con el cual comenzó la actividad en Sansinena. Como interpelación cultural, la construcción de la obra La historia se entreteje desde abajo y se cambia desde la comunidad dio paso a la constitución de áreas de trabajo en los seis pueblos que conforman el grupo, en donde se desarrollaron acciones que, si bien surgieron por la organización iniciada por el teatro, instituyeron proyectos laborales ${ }^{120}$ y culturales ${ }^{121}$ que intentaron dar respuesta a problemáticas sociales de los pueblos, como la desocupación o la ausencia de espacios culturales.

\footnotetext{
${ }^{119}$ María Emilia De la Iglesia, directora general del Grupo de Teatro Comunitario de Rivadavia.

${ }^{120}$ Como la conformación de la Cooperativa La Comunitaria. También en el pueblo de González Moreno, simultáneamente mientras se realizaba esta tesis, algunos de los vecinos que formaban parte del grupo de teatro presentaron un proyecto en el Presupuesto Participativo de la localidad y luego de una intensa "campaña política" lograron el apoyo de instituciones y vecinos y ganaron el proyecto, que consistía en la instalación de tres talleres de oficio (herrería, carpintería y textil) abiertos a la comunidad.

${ }^{121}$ El edificio de la antigua estación del ferrocarril de González Moreno, fue cedida a los vecinos y se abrió allí un centro cultural llamado "Sobrerrieles marcha la cultura", en donde se realizan diversas actividades culturales abiertas y gratuitas.
} 


\title{
Reflexiones finales
}

\begin{abstract}
"Parece como si la sociedad recurriera al teatro cada vez que quiere afirmar su existencia o realizar un acto decisivo que la consolide; como si la "praxis" fuera primeramente un acto colectivo de creación en el escenario de la historia" (Jean Duvignaud, 1966:11)
\end{abstract}

Esta tesis intentó dar cuenta de la complejidad de las relaciones que se tejen en la práctica comunitaria, donde se tensan ideas y acciones movilizantes para los habitantes del pueblo, con la búsqueda de la conservación de las tradiciones. Situamos la mirada desde la producción de esas actividades, con el fin de complejizarlas a la luz de dimensiones de análisis específicas.

Ubicándonos en el primer capítulo, esbozamos un mapa contextual desde donde observar esas prácticas, delineando ciertas características propias de los ámbitos de la ruralidad pampeana en donde el teatro hunde sus raíces. En esa dirección, en el Capítulo dos abordamos el análisis de dos procesos que consideramos imbricados, inseparables, y en constante y mutua redefinición, como son las operaciones de la memoria colectiva y la constitución de identidades. Indagamos en el proceso de creación colectiva de la obra, momento fundacional, a nuestro entender, de la reflexión sobre el "quiénes somos" del colectivo. En el capítulo tres, observamos que la transformación física y simbólica del espacio público, la disputa por la utilización y reapropiación de un territorio marcado por la lucha de "figurar en el mapa", configuró un espacio teatral atravesado por lógicas que buscaban integrar a los vecinos bajo la idea de familia, en pos de una oposición al discurso de la desaparición de los pueblos y la lucha por resistir.

En el último capítulo nos centramos en el análisis de las relaciones específicas que estructuran la actividad teatral, en su vínculo con el "afuera" y hacia "adentro" del mismo grupo. Como parte de un ejercicio intelectual de poner en cuestión la horizontalidad de las decisiones y la igualdad de opiniones, acudimos a la reconstrucción y posterior interrogación de las situaciones de negociación que establece el grupo con autoridades, el delineamiento de las legitimidades que tiñen las percepciones de los vecinos sobre quienes tienen la autoridad y el conocimiento para decidir y gestionar. 
Lo que en una primera instancia detectamos como una tensión, -tanto en los procesos de memoria y configuración de los perfiles identitarios como en las relaciones que se tejen "en" y "desde" el grupo- fue la constante búsqueda de conservación de las tradiciones y el pasado, en un proceso que constantemente está transformando las relaciones entre los vecinos que conforman el grupo entre sí, y con los sectores de poder. Esa relación entre la conservación y transformación parecía tensarse en la práctica teatral, sin embargo, encontramos que ambas se imbrican y complementan en el mismo proceso, porque es la apelación a ese pasado mitificado e idealizado, donde se construye la consigna que interpela las identificaciones para la acción. Asimismo, la tensión entre lo nuevo y lo viejo, condensada en la oposición campo-ciudad, atraviesa la producción teatral y en particular la definición de un nosotros "comunidad sansinense". Se construye una nueva subjetividad anclada en esta oposición, que necesita de la profundización de las diferenciaciones y la exaltación de los valores compartidos por la comunidad, para visibilizar la legitimidad del reclamo de visibilizacion del pueblo.

Cuando insistimos en la complejidad que reviste el fenómeno del teatro comunitario en Sansinena, hacemos referencia a la heterogeneidad de tramas relaciones que instituye, en tanto inaugura nuevos espacios de sociabilidad en donde se subvierten los roles tradicionalmente otorgados a la mujer y al hombre, se producen intercambios intergeneracionales que no se dan en otros ámbitos y se conforman nuevas estrategias y vínculos con el poder (autoridades, instituciones). En este sentido, el grupo se constituyó a través de sus actividades y trayectoria, en un nuevo actor capaz de tener voz y voto en la toma de decisiones de la vida cultural del pueblo, construir agenda y participar de eventos oficiales (en gran parte debido a la masividad de espectadores que convoca). A partir de estructuras de legitimidad que fueron lográndose a partir del vínculo concreto con las instituciones de la comunidad, la incidencia en procesos de visibilizacion del pueblo y sus problemáticas, ha logrado permanecer y ser reconocido por las autoridades.

Las estructuras de poder, relaciones asociativas y laborales que Ratier (2009) identifica en los pueblos rurales bonaerenses presentan un mapa de situación de la comunidad sansinense, que nos permite reconocer disrupciones y continuidades a partir de la actividad teatral, fundamentalmente en cuanto a nuevos modos de organización 
colectiva y subversión de roles de género. Si bien encontramos una tendencia hacia el desarrollo de relaciones de poder jerárquicas, afianzadas en el liderazgo de la directora, -rasgo que no despertó inquietudes en la mayoría de los vecinos pero sí en la coordinación- se buscó generar nuevos vínculos delegativos y procesos de aprendizaje de los coordinadores de los otros pueblos para superar la concentración de responsabilidades y decisiones. La conformación del Grupo de Teatro Comunitario de Rivadavia, la organización del Encuentro Nacional y las diversas actividades conjuntas entre los pueblos, funcionaron como dispositivos pedagógicos en este sentido.

Como actividad cultural, el Grupo de Teatro Popular de Sansinena es, por un lado, un teatro libertario, tal como De la Rosa (2008) caracterizó al teatro ácrata de las décadas de 1910-1930. Comparten una concepción del arte ligada indisolublemente a lo social, construyen con la idea de transmitir valores, desligarse de los acartonamientos y las ataduras de la profesionalización, buscan una impronta realista y una trama de fácil comprensión; someten al público a un espectáculo concebido como herramienta de cambio, de fuerte componente ético. Por otro lado, a pesar de esta analogía, el grupo de Sansinena no tiene como objetivo utilizar al teatro como arma de denuncia y "educar" al público $^{122}$; no encontramos que los vecinos conciban su práctica teatral como arma ideológica o política, de hecho, la mayoría encuentra en él un espacio lúdico, de catarsis o entretenimiento frente a la monotonía del pueblo y la ausencia de propuestas culturales. La fotografía de la realidad que intentaba expresar en sus obras el teatro ácrata (De la Rosa, 2008; Verzero, 2010), estaba centrada en una imagen del presente, en dar cuenta de las injusticias de clase y la desigualdad social. El teatro de Sansinena, presenta esa fotografía pero la toma del pasado, reconstruye lo que fue para presentar una promesa al futuro (Juramento), en donde el ideal se presenta en una comunidad sin conflictos.

En palabras de Eduardo Rinesi ${ }^{123}$ "la pregunta por la identidad es la pregunta por lo que queda, mientras todo cambia, por la continuidad de algo que, en sí mismo, no es más

\footnotetext{
${ }^{122}$ Para el anarquista, el teatro debe ser espejo de las costumbres y de la moral de los pueblos (...) mostrar las contradicciones de los mundos sociales distintos (De la Rosa, 2008: 92).

${ }^{123}$ Rinesi, Eduardo (2004). Identidad, construcción social y subjetiva. Primer coloquio interdisciplinario de Abuelas de Plaza de Mayo. Buenos Aires: Ed. Abel Madariaga.
} 
que movimiento". Movimiento y continuidad, lo que se conserva y lo que se transforma, quienes consideramos que somos y quienes queremos ser, el pasado, el presente y el futuro, conectados por una acción que nos define. La representación teatral puso en juego mecanismos de interrogación sobre el "quienes somos" frente a las preguntas: ¿Qué queremos contarle a los demás sobre nosotros mismos? ¿Qué imagen queremos construir? ¿Cómo nos reconocemos, de quién/ es nos diferenciamos? Estos interrogantes, eminentemente identitarios, instituyeron nuevos procesos de construcción colectiva, que si bien resultaron novedosos en cuanto a la instauración de acciones en común que configuraron modos organizativos inéditos, no se tradujeron en materiales teatrales que profundizaran sobre las tramas de los procesos históricos, ni que generen reflexiones ni autocríticas sobre estos hechos.

Hemos visto que la idea de comunidad idealizada y el temor a los conflictos obstruyeron una reflexión más profunda que indague en la identificación de actores y causas involucrados en los acontecimientos narrados. Sin embargo, la conformación del espacio teatral y la difusión de la práctica hacia pueblos cercanos, significó la extensión de la experiencia hacia territorios desprovistos de organizaciones colectivas y propuestas culturales integradoras, y cuya consigna apunte a reconstruir la memoria colectiva y repensar la identidad. En este sentido, la conformación del Grupo de Teatro de Rivadavia da cuenta de las potencialidades que el grupo de Sansinena posee, en tanto colectivo que genera acción y produce nuevas visiones identitarias.

Si no existe una identidad plena (Laclau y Mouffe, 1987), sino varias identidades conviven y fluctúan en tensión, la práctica comunitaria genera una apertura, a la posibilidad de "pensarse" como otro, reconstruyendo una historia que permite una ruptura con los parámetros identitarios colectivos tradicionales. Para una comunidad carente de experiencias de construcción colectiva, las prácticas instituidas por el grupo de teatro comunitario introducen nuevas preguntas, expectativas y pensamientos que atraviesan el hacer cotidiano de los vecinos que constituyen el grupo. Pero es cuando aparece la posibilidad de narrar esa historia, el momento en el que se ponen en cuestión las concepciones naturalizadas, los perfiles que consideramos definen nuestra identidad, y las disputas por cómo interpretar un pasado compartido. El ejercicio de la narración de sí, conlleva instancias de auto reflexión y autoconciencia que, en 
diferentes niveles de profundidad, significan una re interpretación de los parámetros que delimitan los roles y conductas que estructuran la vida social. El teatro comunitario, una práctica que en el relato teatral reproduce la imagen idealizada de la comunidad, de horizonte sin conflictos, anclada en la reivindicaciones de las tradiciones y el homenaje al pasado, redefinió en su acción organizativa la noción de pueblo, resquebrajando y fisurando sus propios miedos y limitaciones; cuestionó así las propias nociones de lo político de los vecinos, permitiendo su participación en procesos de construcción colectiva.

A pesar de lo pequeño que pueden resultar los aportes de estas páginas a la hora de dar un salto en el análisis, y tratar de comprender estos procesos en experiencias de mayor magnitud -como lo es el caso del Grupo de Teatro Comunitario de Rivadavia (conformado por seis pueblos del Partido y más de doscientos vecinos)- el presente análisis nos permite, al menos, abrir el abanico a nuevas preguntas. Entre ellas, las indagaciones sobre la capacidad subversiva del acto estético, el estatuto instituyente de la narración de sí y la construcción específica de la noción de pueblo en una actividad de multi pertenencia, podrían ser algunos de los interrogantes futuros que aporten a un análisis más complejo y exhaustivo sobre la experiencia teatral comunitaria. 


\section{Agradecimientos}

Mi primer gran agradecimiento es a Raúl, a quien dedico esta tesis por todo el aguante que tuvo durante estos años, su predisposición y ayuda en los momentos más difíciles. Sin él a mi lado, el camino recorrido en esta tesis hubiese sido arduo y oscuro. Agradezco a mi familia toda -los que están y los que acompañan desde algún otro lugar-, a mis amigos y amigas, porque son parte de mi sostén diario y debieron resistir mis múltiples estadios tesísticos.

Un profundo gracias a Lola y a Martín, quienes cada uno a su manera y desde sus saberes, me acompañaron en un proceso de conocimiento académico y personal, en el trabajo cotidiano que conlleva una tarea intelectual, pero que involucra también sentimientos y sensaciones. A ellos toda mi gratitud por escucharme, enseñarme y construir conmigo un modo de pensar las ciencias sociales sin desconocer a la persona que está detrás.

Gracias infinitas a quienes no sólo son protagonistas de este trabajo sino también los que me permitieron ser parte de una gran familia por varios días: los vecinos y vecinas del pueblo de Sansinena, quienes siempre me recibieron con los brazos abiertos y me brindaron su calidez. Fundamentalmente a María Emilia y Manuel, junto a quienes viví momentos angustiantes y emocionantes; a Edith Bello y Marta Cuello, cuyos hogares me cobijaron y extendieron sobre mí una hospitalidad extraordinaria; a Oscar y Diego por hacerme conocer historias y lugares fantásticos. Gracias a todos los que formaron parte de las experiencias reflejadas en estas páginas, habitantes de González Moreno, América, Fortín Olavarría, Roosevelt y San Mauricio.

A mis compañeros y compañeras del CISH, muchos de los cuáles fueron testigos de mis ataques dubitativos y prestaron su oído y conocimiento para ayudarme. A Jerónimo Pinedo y a Daniel Badenes, quienes, quizá sin saberlo, fueron parte de este proceso de tesis en sus diferentes instancias.

Gracias al CONICET, que al darme una beca me permitió trabajar en investigación y a la Facultad de Humanidades y sus puertas abiertas, por donde pude ingresar y permanecer. 


\section{BIBLIOGRAFIA}

*Ameghino Azcuy, Eduardo (2004). Trincheras en la historia argentina. Buenos Aires: Ediciones Imagno Mundi.

*Arditi, Benjamin (1995). Rastreando lo político, en Revista de Estudios Políticos, No. 87, Madrid, enero-marzo, pp. 333-351.

http://www.cepc.es/rap/Publicaciones/Revistas/3/REPNE_087_334.pdf

*Arendt, Hannah (2005). La condición humana. Buenos Aires: Paidós.

*Armelino, M., Perez, G. y Rossi, F. (2005). Entre el autgobierno y la representación. La experiencia de las asambleas en la Argentina, en Schuster, Naishtat, Nardacchione y Pereyra (Comp.) (2005). Tomar la palabra. Estudios sobre protesta social y acción colectiva en la Argentina contemporánea. Buenos Aires: Prometeo

*Bellelli, G.y Leone, G. (1999). Emoción y memoria colectiva, el recuerdo de acontecimientos públicos. En Psicología Política, $\mathrm{n}^{\circ} 18$, Universidad de Bali, Italia.

*Bello, Edith \& de la Iglesia, M. Emilia.(2009). Sansinena existe. Retazos de memoria. Tejidos de futuro. Buenos Aires: Municipalidad de Rivadavia.

*Berbeglia, A, De Paola, Effron, P., Maula A. (2005), Teatro comunitario: una herramienta de intervención en pueblos con riesgos de desaparición. Análisis de una intervención mediante Teatro Comunitario en el pueblo de Patricios", Partido de Nueve de Julio, Provincia de Buenos Aires. Carrera de especialización en psicología y psicoanálisis de los vínculos. Modulo Metodología de la investigación.

*Bidegain, Marcela (2007).Teatro comunitario, resistencia y transformación social. Buenos Aires: Atuel.

*Bidegain, M., Guain, P. \& Marianetti, M. (2008). Teatro comunitario. Vecinos al rescate de la memoria olvidada. Catalinas Sur, Patricios Unidos de Pie, Los Dardos de Rocha y Los Okupas del Andén, Buenos Aires: Artes Escénicas.

*Bogado, Andrea (2011). Construcción de ciudadanía en el grupo de teatro comunitario Murga de la Estación. Tesina de grado de Licenciatura en Trabajo Social. Facultad de Humanidades y Ciencias Sociales de la Universidad Nacional de Misiones.

*Borba, Juliano (2010). El teatro comunitario en Argentina: la celebración de la memoria. Artea online.

*Candau, Jöel (2008). Memoria e identidad. Buenos Aires: serie antropológica, Ediciones del Sol.

*Cheresky, Isidoro (2006). Ciudadanía, sociedad civil y participación política. Buenos Aires: Miño y Dávila Editores.

*Craviotti, Clara (2008). Empleo agrario y ruralidad ampliada. Revista Geograficando, Vol. 4, n 4, pp. 99-116.

*Cuesta Bustillo, Josefina (1998). "Memoria e historia, un estado de la cuestión", en Cuesta Bustillo, J. Memoria e historia. Madrid: Marcial Pans Librero.

*Di Marco, G.; Palomino, H.; Altamirano, R., Méndez, S. y Libchaber de Palomino, M. (2003). Movimientos sociales en la Argentina. Asambleas: la politización de la sociedad civil. Buenos Aires: Jorge Baudino Ed.

*Dri, Ruben (2006). La revolución de las asambleas. Buenos Aires: Diaporías.

*Falzari, Gastón (2011). Un acercamiento al movimiento teatral comunitario. Reflexiones sobre memoria colectiva, Verdad (es) y experiencias. Tesina de grado de 
Licenciatura en Comunicación Social. Facultad de Ciencias Sociales. Ciencias de la comunicación. Universidad Nacional de Buenos Aires.

*Fernández, Clarisa (2011), Procesos de memoria en el teatro comunitario argentino, en Revista Palos y Piedras, Centro Cultural de la Cooperación. (ISSN 1851-3263). Número 11, año 4.

*------------(2011), La transmisión de la memoria en el teatro comunitario argentino. El caso del Grupo de Teatro Popular de Sansinena. Revista académica Question, Volumen 1, Número 31 de invierno (ISSN 1669-6581).

*Gallego, Julián y Miceli, Paola (2008). Habitar, producir, pensar el espacio rural. De la antigüedad al mundo moderno. Buenos Aires: Mino y Dávila editores.

*Giménez, Gilberto, (1997). Materiales para una teoría de las identidades sociales. En Revista Frontera Norte, Vol 9, $\mathrm{n}^{\circ} 18$.

*--.-- (1999). Territorio, cultura e identidades, la región socio cultural. en Estudios sobre culturas contemporáneas. Época II, Vol. V, Numero 9. Colima.

*---- La cultura como identidad y la identidad como cultura.

Conferencia en el Instituto de Investigaciones sociales de la UNAM.

*Grondona, Ana y Romero, Guadalupe (2005) Gracias a Dios tengo mi familia, en Murillo, Susana (coord) Contratiempos, espacios, tiempos y proyectos en Buenos Aires de hoy. Buenos Aires: Ed. Del Instituto movilizador de Fondos Cooperativos (CCC).

* Guber, R. (2001). Etnografía. Método, campo y reflexibilidad. Buenos Aires: Norma.

*Halbwachs, M. (1995). Memoria colectiva y memoria histórica, Reis: Revista española de investigaciones sociológicas, $N^{\circ}$ 69, pp. 209-222 (Traducción de un fragmento del Capítulo II de La mémoire collective, Paris, PUF, 1968).

*Halbwachs, M. (1991). Fragmentos de la memoria colectiva. Selección y traducción de Miguel Angel Aguilar. Revista de Cultura Psicológica, año 1, $\mathrm{N}^{\circ}$ 1, México, UNAM. *Hall, Stuart (2003). ¿Quién necesita identidad?, en Hall Stuart y P. Dugay (comp), "Cuestiones de identidad cultural". Buenos Aires: Amorrortu.

*Hobsbawm, Eric y Ranger, Terence (2002). La invención de la tradición. Barcelona: Crítica.

*Jelin, Elizabeth (2002). Los trabajos de la memoria. Madrid: Siglo Veintiuno.

*Laclau, Ernesto (1990) Nuevas Reflexiones sobre la revolución de nuestro tiempo, Nueva Visión, Buenos Aires. Pp. 19-102.

*Lattuada, M. y Neiman, G. (2005). El campo argentino, crecimiento con exclusión. Buenos Aires: Claves para todos.

*Lefebvre, Henri (1974). La producción del espacio social. Publicado en Papers, revista de sociología. $\mathrm{N}^{\circ}$ 3. Universidad Autónoma de Barcelona.

*Lindón Villoria, Alicia (2000). "Del campo de la vida cotidiana y su espacio temporalidad (una presentación) en Lindón (comp.) La vida cotidiana y su espaciotemporalidad. Barcelona: Anthropos/ Colegio Mexiquense/ CRIM-UNAM.

*Marradi, Archenti y Piovani (2007). Metodología de las ciencias sociales, Bs. As: Emecé.

*Mora, Martín (2002). La teoría de las representaciones sociales de Serge Moscovici. En revista Athenea Digital, $n^{\circ} 2$, otoño.

*Murillo, Susana (coord) (2005). Contratiempos, espacios, tiempos y proyectos en Buenos Aires de hoy. Buenos Aires: Ed. Del Instituto movilizador de Fondos Cooperativos (CCC). 
*Neiman, G; Quaranta, G. (2006). "Los estudios de caso en la investigación sociológica", en Vasilachis de Gialdino (comp.) Estrategias de investigación cualitativa, Buenos Aires: Gedisa

*Olich, Jeffrey K. (1998). "Memoria colectiva y diferenciación cronológica: historicidad y ámbito público", en Cuesta Bustillo, J. Memoria e historia. Madrid: Marcial Pans Librero.

*Orga, Alberto (2010). Por estas tierras...recorrido geográfico e histórico de la ocupación de territorios en el Partido Rivadavia desde 1876 a 1910. Buenos Aires.

*Pinedo, Jerónimo (2009). Hacer lo que otros, por el momento, no pueden hacer. Proyecto militante, prácticas de anclaje territorial, relaciones de interdependencia y noción de compromiso en un Movimiento de Trabajadores Desocupados. Tesis de Maestría en Ciencias Sociales. Facultad de Humanidades y Ciencias de la Educación de la UNLP.

*Pironio, A. (2010). Patricios Unidos de Pie: de la nostalgia a la Esperanza. Un proceso de intervención social desde el teatro comunitario, Universidad de Chile, Faculdad de Ciencias Sociales, Programa Magíster Psicología mención Psicología Comunitaria, Cuaderno de Trabajo, vol 8, p. 44-52.

*Proaño Gómez, L.(2002). Poética, política y ruptura. Argentina 1966-73. Teatro e identidad. Buenos Aires: Atuel.

(2007) Poéticas de la globalización en el teatro latinoamericano. Universidad de California, Irvine: Colecciones Gestos.

----(2007). Teatro comunitario: historias locales en la escena y la construcción de la memoria del futuro. La escena iberoamericana: Celcit 29 (www.celcit.org)

-(2006) Derechos humanos: La utopía ético-estética en el teatro argentino comunitario. Ideologías y literatura. Homenaje a Hernán Vidal. Instituto Internacional de Literatura Iberoamericana. Pittsburg: Mabel Moraña, Javier Campos, Eds.

-(2006). Estética social y la aparición de lo político. Teatro comunitario y espacio urbano en. Espacios de representación. Fundación Autor, Madrid, España: Ediciones Proaño-Gómez.

-- Teatro comunitario, belleza y utopía. Teatro memoria y ficción_(Ed. Osvaldo Pelletieri). Buenos Aires: Galerna.

----------------(2001). El 'fulgor' de la historia argentina en el teatro popular. Latin American Theatre Review 35/1. Fall 2001.

----------(2010). El desplazamiento de la política: teatro comunitario argentino, en Revista Afuera, $\mathrm{n}^{\circ}$ 9, disponible en http://www.revistaafuera.com/articulo.php?id=61\&nro=9.

*Quiroga, Hugo (2006). Déficit de ciudadanía y transformaciones del espacio público en Ciudadanía, sociedad civil y participación política, Isidoro Cheresky (Comp.) Buenos Aires: Miño y Dávila Editores.

*Rabotnikof, Nora, (1995). "El espacio público: variaciones en torno a un concepto", en Rabotnikof Nora, Velasco, Ambrosio e Yturbe Corina (comps.), La tenacidad de la política, México, UNAM, Instituto de Investigaciones Filosóficas.

*-------------------- (2005). En busca de un lugar común. El espacio publico en la teoría política contemporánea. UNAM, México. 
*Ramos, María del Carmen y Sanz, Sonia (2010). El teatro comunitario como estrategia de desarrollo social a nivel local. Área de desarrollo social, local y regional. Instituto de investigación en ciencias sociales. Universidad de El Salvador.

*Rasftopolo, Alexis (2009). Desde mover una mesa hasta cambiar el mundo. El teatro comunitario y sus posibilidades. Tesina de Licenciatura en Comunicación Social. Facultad de Humanidades y Ciencias Sociales, Universidad Nacional de Misiones.

* Ratier (2009). Poblados Bonarenses, vida y milagros. Buenos Aires: La Colmena.

*Rodriguez Blanco, Maricel (2006). Representación política, deliberación y acción colectiva. Piqueteros y asambleístas: dos figuras de la participación de la sociedad civil en Argentina, en Cheresky, Isidoro (comp). Ciudadanía, sociedad civil y participación política. Buenos Aires: Miño y Dávila Editores.

*Rodríguez, Javier (2005). El complejo lácteo argentino en tiempos de soja y devaluación, en Giarraca, Norma y Teubal, Miguel (comp). El campo argentino en la encrucijada. Estrategias y resistencias sociales, ecos en la ciudad. Buenos Aires: Alianza Editorial.

*Rosemberg, Diego. (2009) Teatro comunitario argentino. Buenos Aires: Emergentes editorial.

*Ruckman, Hanna (2008), Patricios Stands United (Patricios Unidos de Pie): impacts of a rural tourism community theatre project, Patricios, Argentina, 2008, Tesis presentada en el Departamento de antropología de la California State University, B.A, 2005, University of California, Santa Barbara, 162 p.

*Scher, Edith. (2011). Teatro de vecinos, de la comunidad para la comunidad. Buenos Aires: Colección Estudios Teatrales del Instituto Nacional del Teatro.

*Schindel, Estela (2006). Las pequeñas memorias y el paisaje cotidiano: cartografías del recuerdo en Buenos Aires y Berlín. En Macón, Cecilia (Coord.). Trabajos de la memoria. Arte y ciudad en la postdictadura argentina. Buenos Aires: Ladosur.

*Schuster, Naishtat, Nardacchione y Pereyra (comp.) (2005). Tomar la palabra. Estudios sobre protesta social y acción colectiva en la Argentina contemporánea. Buenos Aires: Prometeo.

*Svampa, Maristella (2005). La sociedad excluyente. La Argentina bajo el signo del neoliberalismo. Buenos Aires: Taurus.

*Teubal, Miguel (2006). Expansión del modelo sojero en la Argentina. De la producción de alimentos a los commodities, en revista Realidad económica, $\mathrm{N}^{\circ} 220$, Buenos Aires, Instituto Argentino para el Desarrollo Económico (IADE).

*Vasilachis de Gialdino, Irene. (2006). La investigación cualitativa, en Vasilachis de Gialdino, I., Estrategias de Investigación cualitativa. Barcelona: Gedisa.

*Villoro, Luis (1998). Sobre la identidad de los pueblos. Publicado en Estado Plural, pluralidad de las culturas, México, UNAM: Paidós.

*Yerushalmi, Y. (1989). Usos del olvido. Buenos Aires: Nueva Visión.

\section{Documentos}

Censo Nacional de Población, Hogares y Vivienda (2010), del Instituto Nacional de Estadísticas y Censo (INDEC).

Páginas Web: www.teatrocomunitario.com.ar 


\section{ANEXO METODOLÓGICO}

\section{- Visitas al pueblo de Sansinena y actividades realizadas}

Marzo 2010:

$\checkmark$ Estadía de cuatro días, donde se realizó el primer acercamiento al campo, conocimiento del pueblo, sus instituciones y personajes emblemáticos guiados por María Emilia De la Iglesia. Se realizaron cuatro entrevistas introductorias y se constituyó el primer archivo fotográfico del lugar. Tuvimos la oportunidad de presenciar la función de Por los caminos de mi pueblo, que se representó en Sansinena por segunda vez (la primera fue para el Centenario del pueblo en el año 2009) en las vías del ferrocarril. También se realizó el festejo típico por el aniversario 101 del pueblo. En esta oportunidad pudimos acompañar a María Emilia durante los días previos a la función, lo que nos permitió observar las dificultades con las que el grupo lidia diariamente en cuestiones de infraestructura y las expectativas construidas por los vecinos.

$\checkmark$ Participamos del Encuentro realizado en el pueblo de Patricios (Partido de Nueve de Julio), por el motivo de cumplirse un nuevo aniversario del pueblo. Viajamos junto al grupo de Sansinena y de González Moreno, que hicieron una representación de la obra Violeta y Jacinto.

$\checkmark$ Entrevistas realizadas: María Emilia De la Iglesia (27), Susana Gorosito (57 años), Darío Fernández (23 años) y Celia Amione (86 años).

Junio 2010:

$\checkmark$ Estadía de cinco días al pueblo de Sansinena. En esta oportunidad, contábamos con una delimitación previa del problema a investigar, y un corpus de preguntas que conformaban las entrevistas semi estructuradas. Al llegar al lugar ya se había comenzado con el trabajo de extender la práctica del teatro comunitario a pueblos vecinos para conformar el Grupo de Teatro Comunitario de Rivadavia, por lo cual nos alojamos en la casa de Edith Bello (madre de María Emilia).

$\checkmark$ Participamos de los ensayos de los grupos de América, y Fortín Olavarría.

$\checkmark$ Realizamos doce entrevistas personales y un relevamiento general de la percepción del grupo de teatro en los chicos y chicas del nivel primario y secundario de la escuela de Sansinena.

$\checkmark$ Participamos de un guiso comunitario en el pueblo de América, a donde asistió el Intendente Sergio Buil. 
Entrevistas realizadas: María Delia Albín (54 años), Elsa Chiatellino de Lenti (66 años), Osvaldo González (65 años), Mirta Fernández (56 años), Osvaldo Fernández (80 años), Olga Marengo (59 años), Arsenio Ghiorzi (47 años), Carmen Figueroa (65 años), Oscar De la Iglesia (72 años), Lilian Esther Vanegas (72 años), Yolanda González (76 años) e Ilsen González (80 años).

\section{Octubre 2010:}

$\checkmark$ Esta visita se realizó con dos objetivos previos: asistir al estreno de la obra del Partido de Rivadavia, La historia se entreteje desde abajo y se cambia desde la comunidad, y participar de las actividades previas y la organización del evento. Por cuestiones climáticas la obra se pospuso dos días, por lo que nuestra visita duró siete días. Durante el trascurso de estos siete días permanecimos junto a la directora compartiendo las reuniones de coordinadores, los ensayos, los preparativos, las negociaciones y tensiones suscitadas con autoridades e instituciones. Observamos las lógicas en la toma de decisiones y las nuevas estructuras de delegación que iban dificultosamente tratando de ganar terreno.

$\checkmark$ Participamos como integrantes del grupo de Sansinena en el desfile que los grupos de teatro realizaron durante los festejos del centenario del Partido de Rivadavia y de los festejos posteriores.

$\checkmark$ Presenciamos los debates de la directora con coordinadores, vecinos y autoridades sobre los pasos a seguir y los avatares climáticos, que anegaban los caminos de entrada de los pueblos de Sansinena, Roosevelt y San Mauricio.

$\checkmark$ Realizamos siete entrevistas, la mayoría de ellas a vecinos de González Moreno.

$\checkmark$ Participamos de la organización de la escenografía y utilería del estreno de la obra en el Partido de Rivadavia y en el canal de contención puesto por la policía para encauzar al público de más de 5000 personas que asistió al evento en el pueblo de San Mauricio.

$\checkmark$ Entrevistas realizadas: Marta Cuello (67 años), Manuel Martino (31 años), Oscar Giménez (46 años), Hugo Daniel Fritz (53 años), Nilda Scott (51 años), Diego Pallero (25 años) y Edith Bello (61 años).

\section{Septiembre/ octubre 2011:}

$\checkmark$ Estadía de catorce días en el pueblo de Sansinena, problema y objetivos de investigación más definidos, entrevistas semi estructuradas. Ademas de realizar las entrevistas, nuestro propósito era poder observar y participar de la organización del Noveno Encuentro Nacional de Teatro 
Comunitario, pautado para desarrollarse los días 8, 9 y 10 de Octubre en los diversos pueblos que conforman el Partido.

$\checkmark$ Esta visita constituyó el acercamiento más fructífero a los vecinos y vecinas de Sansinena, ya que convivimos varios días allí y realizamos actividades cotidianas.

$\checkmark$ Realizamos 25 entrevistas pautadas, y mantuvimos varias conversaciones informales con los vecinos.

$\checkmark$ Participamos de la organización del encuentro, principalmente en las reuniones de logística del grupo de Sansinena y en los últimos encuentros de coordinadores por pueblos. El día anterior al inicio del encuentro nos trasladamos al pueblo de América, en donde se centraba la organización.

$\checkmark$ Entrevistas realizadas: Arsenio Ghiorzi (48 años), Blanca Merlo (69 años), Marisa Muñoz (40 años), María Liliana Marcantonio (33 años), Beba Felleti (76 años), Araceli Paola Bustamante (40 años), María Susana Sosa (66 años), Juan Carlos Centioni (66 años), Cristian y Soraya Acuña (8 y 11 años respectivamente), Carmen Figueroa (66 años), Jonathan Salas (17 años), Olga Noemí Hofsetz (48 años), Ivana Pacifici (13 años), Edith Bello (63 años), María Angélica Pastor (52 años), Carlos Casa (58 años), Nicolás Morales (13 años), Tamara Muñoz (11 años), Agustina González (11 años), Mauricio Gómez (22 años), Darío Fernández (24 años), Mabel Micoli (54 años), Natalia Pacifici (10 años), Monica Adriana Ces (50 años) y Oscar Giménez (47 años).

\section{Material audiovisual consultado}

$\checkmark$ Cabanchik, Adolfo, 2006, "La utopía Teatral”, Largometraje Documental de experiencias de Teatro Comunitario.

$\checkmark$ Comisión Provincial por la Memoria y Universidad de Comunicación de La Plata, 2009, "La huella colectiva", Documental de los grupos de La Plata.

$\checkmark$ Zanzio, Jorge, 2010, "Contra viento y olvido", Largometraje Documental de experiencias de la Red de Teatro Comunitario Regional Sur de La Plata.

$\checkmark$ Dante Divoy, 2009, "Cien años de historia, cien años de vida. Sansinena 100 años, 1909-2009". Largometraje documental del pueblo de Sansinena. Municipalidad de Rivadavia.

\section{Material periodístico consultado}

-Diarios digitales:

$\checkmark$ Master News

$\checkmark$ Villegas Digital 
-Periódicos locales y nacionales (más detalles en el anexo 1):

$\checkmark$ Revista N del Diario Clarín

$\checkmark$ La Nueva Prensa

$\checkmark$ La Opinión

\section{Folletería y material institucional}

$\checkmark$ "Nacer, crecer y realizarnos. Rivadavia. 100 años de historias compartidas". Revista de la Municipalidad de Rivadavia por el Centenario del Partido (2009).

$\checkmark$ Programa institucional "Los 100 años de Rivadavia".

$\checkmark$ Programa del Noveno Encuentro Nacional de Teatro Comunitario. 


\title{
ANEXO 1
}

\author{
VISIBILIZACION DEL GRUPO DE TEATRO POPULAR DE SANSINENA EN LOS MEDIOS DE \\ COMUNICACIÓN
}

\section{PAGINA MASTER NEWS (Primer diario digital de Rivadavia) 02/07/2010}

http://www.masternews.com.ar/index.php?option=com_content\&view=article\&id=3516:lospueblos-se-comunican-a-traves-del-teatro-sansinena-presenta-su-obra-teatral-enroosevelt\&catid=42:el-distrito $\&$ Itemid $=66$

\section{Los pueblos se comunican a través del teatro: Sansinena presenta su obra teatral en Roosevelt}

Viernes, 02 de Julio de 2010 18:01

Este sábado 3 de julio a las 20:30 horas el grupo de teatro Popular de Sansinena presentará la obra "Por los caminos de mi pueblo", una obra de creación colectiva que relata las vivencias de los habitantes del pueblo durante los 101 años que llevan viviendo en ese lugar. Esta obra tuvo una gran repercusión en el público durante el centenario de Sansinena donde más de 700 personas pudieron disfrutarla, y este año en el festejo de los 101 años del pueblo donde se volvió a representar y nuevamente el número de espectadores duplicó la cantidad de habitantes del pueblo.

La entrada al espectáculo es totalmente gratuita. La obra se realizará en la escuela de la localidad de Roosevelt y la organización del evento estará a cargo de la Comisión de Fomento de este pueblo, quienes dispondrán de un esmerado servicio de cantina.

Más de 30 vecinos-actores que van de $\operatorname{los} 4$ a los 81 años se suben en escena para expresar a través del arte su historia a otro pueblo como el de Roosevelt que tiene similares características: pocos habitantes (350), calles y caminos de tierra, éxodo de sus jóvenes, pero al mismo tiempo: muchas ganas de salir adelante y no bajar los brazos, sumado a ese trato personal que marca la diferencia con cualquier gran ciudad, donde no sos un número, sino una vida importante que marca la existencia del pueblo.

Vale la pena pasar un sábado diferente, hacerse unos kilómetros y llegar a Roosevelt para disfrutar de una obra hecha por los propios vecinos de Sansinena y luego degustar unos ricos platos caseros hechos por la gente de la comisión de fomento de la localidad anfitriona y poco a poco contagiarse de esas ganas de gritar bien fuerte iiilos pueblos del Partido de Rivadavia existen, vengan y disfruten!!!

\section{PAGINA MASTER NEWS 18/05/2011}

http://www.masternews.com.ar/index.php?option=com_content\&view=article\&id=9383:lacultura-en-movimiento- \&catid=49: columnas \&Itemid $=94$

\section{La cultura en movimiento}

Miércoles, 18 de Mayo de 2011 07:02

\section{Por Federico Urrutia}

El domingo 15 de mayo se llevó a cabo el $2^{\circ}$ Encuentro Distrital del año del Grupo de Teatro Comunitario de Rivadavia en Sansinena, donde todos participaron en la planificación del IX Encuentro Nacional de Teatro Comunitario, que se realizará el 8, 9 y 10 de octubre de este año.

Recibidos por una cálida bienvenida, los mates y la torta hicieron apertura al encuentro. Luego, el espíritu comunitario ocupó su lugar, actuando, cantando, riendo y disfrutando del hermoso día al aire libre.

No faltó el debate y los grupos de trabajo, donde adultos, ancianos y jóvenes tenían la posibilidad de aportar su 
opinión. La diagramación de áreas de trabajo favoreció el trabajo en grupo, y dio lugar a la organización del Encuentro Nacional. Además, los niños se expresaron mediante dibujos, utilizando valores y frases grupales para encontrar la manera de invitar a sus amigos al grupo, e integrarlos a este hermoso espacio.

Sumado a estas actividades, y como una forma de enriquecer el encuentro, cada persona contó como había comenzado el año en referencia a los grupos de cada pueblo, y ayudarnos entre todos para poder sostenernos con el tiempo; incluir nuevos integrantes y poder difundir el arte.

Y la jornada no podía terminar de una mejor manera: a puro teatro, los integrantes del grupo de Teatro Popular de Sansinena, presentaron la Obra "Charlatanes", dirigida por María Emilia de la Iglesia , y actuada por los mismos vecinos de la localidad.

Un domingo diferente, donde el arte y el trabajo comunitario superaron sus objetivos, promoviendo la actuación, la libertad de expresión y reafirmando nuestra identidad cultural.

Luego de 6 años de vigencia del teatro en una comunidad de 400 habitantes, el público sigue participando y llenando la sala del Centro Recreativo Sansinena. La obra Charlatanes, dirigida por María Emilia de la Iglesia y actuada por los propios vecinos de la comunidad, fue presentada el domingo pasado a las 20:30 hs. en adhesión al 50 aniversario de la Unidad Sanitaria. Se congregaron unas 220 personas que pudieron disfrutar de un espectáculo de gran calidad. Luego todos pudieron degustar de una esmerada cantina realizada por la Comisión de la Unidad Sanitaria.

"Charlatanes" es una obra que habla del poder del dinero, de la codicia sin escrúpulos, de las apariencias, los engaños y del lugar de la salud y de los médicos en nuestra sociedad.

Este texto dramático escrito hace más de 60 años por Escobar, y adaptado por el grupo de teatro de Sansinena, tiene una vigencia reveladora, ya que indaga con humor y sencillez relaciones humanas atravesadas por el ser o el aparentar, el amar o el fingir, la ética o la charlatanería.

"Como las barrenderas que limpian esas hojas caídas, esas hojas de otoño que recuerdan las injusticias y tragedias que muchas veces no queremos ver como sociedad, el grupo de teatro popular de Sansinena les presenta esta obra", afirman en sus programas de mano.

\section{REVISTA Ñ DEL DIARIO CLARIN 26/01/2008}

\section{RESCATES / TEATRO INDEPENDIENTE}

\section{Cachetazo de campo}

250 personas asistieron al estreno de La Zapatera Prodigiosa en Sansinena, un pueblo de 400 habitantes. Ramal que para, teatro que abre...

\section{Por: PATRICIO FEMINIS}

EL SHOW DEBE CONTINUAR. Parte del elenco de La Zapatera Prodigiosa, primer estreno en 17 años en Sansinena, límite entre Buenos Aires y La Pampa.

A lo largo del país, experiencias de trabajo artístico hecho por vecinos: una puesta en acto de lo creativo, lejos del quehacer de especialistas, que rebate la idea de que sólo desde la butaca y el precio de una entrada se vive la cultura. Generar arte, pensarlo no en soledad, discutir, inventar a cada paso: animarse a crear colectivamente no es una frase vacía de contenido, sino una decisión vibrante, en pueblos bonaerenses como Sansinena o González Moreno, donde las llanuras adquieren un tono, un ritmo reposado, sólo interrumpido por el viento, difícil de llevar a las palabras.

Muy cerca de la Provincia de La Pampa, en ambos pueblos tiene lugar un proceso de teatro vocacional, a pura pasión, para no quedarse quietos y poder verse en los ojos del otro. Dos pueblos, o pequeños mundos de pasiones cotidianas y deseos pendientes, que los años noventa parecieron borrar, una vez que cerraron el ramal del tren y hubo éxodo, desocupación, olvido. Pero también resistencia, a través del teatro: ¿Cómo contarlo sin frases vagas, sin lugares comunes? Basta decir que en diciembre último más de 250 personas, allí en Sansinena -en donde viven entre 300 y 400 personas- asistieron al estreno de "La Zapatera Prodigiosa", una reelaboración colectiva de la obra de Federico García Lorca. Todos están involucrados en la obra, que en tono de farsa funde los desgarros del amor y la fantasía, con la Zapatera como imagen de lo que alguna vez fue el pueblo, pero podrá regresar. 
Cada tarde, los pobladores dejaban sus quehaceres para caminar las tablas. Más de 25 actores -entre escenógrafos, vestuaristas y apuntador- conforman el grupo de Teatro Popular de Sansinena, que va desde los 6 a los 81 años.

Y diciembre fue apenas el comienzo: a modo de cierre del año, el 29 de diciembre fue la segunda función en el Centro Recreativo Sansinena. Para la coordinadora de la experiencia, María Emilia de la Iglesia, una joven periodista recibida en La Plata y teatrista por herencia familiar, antes que un proyecto individual esta obra nació de los vecinos, ávidos de contarse arriba $\quad$ del escenario.

"Quisimos recuperar a Sansinena, darlo a conocer a través del teatro, y difundirlo en los pueblos y las ciudades aledañas. La cultura la hacemos todos y trabajamos con mucho respeto en esta versión de La Zapatera, con calidad y con el deseo de divertirnos actuando".

Este proceso, señala, apunta a reflotar espacios de teatro vocacional: desde los años 40 existieron grupos teatrales en Sansinena, pero "hacía 17 años que en el pueblo no se presentaba una obra: el último director había sido Osvaldo, mi padre. Esto es muy movilizador". Formada en la Escuela Provincial de Teatro de La Plata, algo de De la Iglesia ya estaba escrito desde hacía tiempo:a principios de 2006, presentó un proyecto a la Municipalidad de Rivadavia -al que pertenece Sansinena-: "Rearmar el Tejido de los Teatros del Pueblo". Luego de que se aprobara comenzaron las pruebas piloto, allí y en González Moreno, a pocos kilómetros, donde hoy trabaja el grupo Catarsis -también bajo su coordinación-, que llevó su obra "Juvenecia", basada en Venecia, de Jorge Accame, a diversas localidades: General Villegas, Trenque Lauquen y

"La respuesta fue inédita en ambos pueblos; lo que se vive en Sansinena, hoy, es muy especial. Es importante que en una comunidad de 400 habitantes la gente pueda reunirse una vez por semana para hacer teatro, no importa la especialización. La técnica se adquirió en el trabajo mismo, en los ensayos de ocho meses para poner en escena La Zapatera Prodigiosa. $\quad \mathrm{Y}$ todos participan".

Este año, dice, armarán "una gran movida cultural" en conmemoración de los cien años del pueblo.

\title{
VILLEGAS DIGITAL. EL PORTAL DE NOTICIAS DE LA CIUDAD DE GENERAL VILLEGAS 08/04/2010
}

http://www.villegasdigital.com.ar/index.php/qlos-101-anos-de-sansinenaq.html

\author{
"Los 101 años de Sansinena" \\ JUEVES, 08 DE ABRIL DE 2010 03:32 CLARISA FERNÁNDEZ
}

2010-04-08 1 En épocas de vertiginosidad y aceleración, se olvidan muchas veces las cosas más importantes, como el hecho de acordarnos de dónde venimos. Sansinena cumplió 101 años y lo festejó a lo grande. Sea bienvenido a la fiesta, y disfrute.

El olor a tierra mojada, las calles casi desiertas y las casas sencillas y bien cuidadas llaman la atención al visitante urbano. El paisaje habla con sus edificios muertos y aquellos que han sido revividos por una historia que late, que palpita en el aire, condensada en los testimonios y las miradas de sus habitantes.

Sansinena, un pueblo rural por excelencia que llegó a tener casi 3000 habitantes, hoy sólo cobija bajo su cielo colosal cerca de 350. Víctima, como muchos pueblos, del desmantelamiento del sistema ferroviario-fuente de vida y comercio-, de los vaivenes económicos que fueron aniquilando la vida industrial, y de las inundaciones, los pobladores del lugar no bajan los brazos, y bajo el grito de "Sansinena existe, venga y disfrute", resisten el olvido desde varios frentes.

Arriba el telón

El viernes 26 de marzo de 2010 Sansinena se preparaba para ser testigo de un evento especial que ya había presenciado el año anterior en el Centenario: la obra de teatro "Por los caminos de mi pueblo"...

Detrás de bambalinas

Respiraciones agitadas, saltitos de nerviosismo y espiadas detrás del telón componían el backstage de la obra que estaba por salir a escena. Mujeres, hombres y niños conformaban una conjunción de movimientos acelerados, expectativa y sudores que no podían esperar un minuto más; pañuelos negros, polleras largas, labios rojos y bombachas de gaucho eran parte del show. María Emilia de la Iglesia, la directora y entusiasmadora general del Grupo de Teatro Popular de Sansinena corría de un lado al otro tratando de solucionar las peripecias que 
inevitablemente se presentan en la producción de una obra teatral que se hace a pulmón. Pero afortunadamente, como esas cosas que siempre fluyen de modo natural, todo estaba listo para comenzar; infundiendo ánimos, guió a los actores en un breve calentamiento del cuerpo e instauró así el espíritu de trabajo que siempre ha caracterizado al grupo: la satisfacción de poder contar su propia historia.

El público ubicado frente a la estación del ex ferrocarril oeste que funcionaba de escenario, componía un tumulto respetuoso y heterogéneo que aglutinaba habitantes de Sansinena, como también de otros pueblos que habían venido especialmente a ver la función. Cerca de 800 personas que debajo de un cielo estrellado y mágico, rodeadas de campo, envueltas en una brisa templada, observaban el lienzo negro que escondía a los vecinos-actores y la pantalla para diapositivas que acompañaría con imágenes toda la obra.

\section{Aplausos, risas y llantos}

"Por los caminos de mi pueblo" es una obra de creación colectiva, por lo que las escenas están armadas en base a testimonios de vecinos que aportaron su experiencia y conocimiento. Allí se cuenta la historia del pueblo, con los momentos más importantes que marcaron el devenir del presente. Esos hechos fundamentales son los hilos que entretejen una memoria compartida, un pasado en común, un relato de vivencias que despiertan en el habitante de Sansinena un sentimiento fuerte de identificación, porque ésa es su historia, su vida, la de sus padres y abuelos.

La historia comienza con la repartija de tierras, la subasta de terrenos y el traspaso de unas manos a otras de lo que tiempo después sería Sansinena. La obra realiza un homenaje a los personajes del pueblo que hicieron historia, se sumerge en la problemática de los inmigrantes que llegaron a "hacerse la América", introduce situaciones cotidianas del pueblo como el cumpleaños de la abuela, el drama de las inundaciones del año 2001, y destaca las problemáticas históricas que sufre el pueblo, como el mejorado y tendido de caminos.

El efecto en el público fue impresionante, risas y llantos acompañaron toda la obra. En la escena de las inundaciones algunos lloraban como recordando ese momento trágico para el pueblo. La obra culminó con aplausos y felicitaciones; los actores, emocionados, saludaban y gritaban a coro “¡Sansinena, Sansinena!”... otra vez más, la magia del teatro logró convocar a personas de distintos pagos y reunirlas por medio del arte. Y en este caso, un arte que daba cuenta de sus historias como personas y como pueblo.

La fiesta

El 27 de marzo de 2010, en el cumpleaños número 101 de Sansinena, todo era bullicio y expectativa. Los vecinos iban y venían trayendo y llevando todo lo necesario para que esa noche sea perfecta. El mate daba vueltas siendo testigo de comentarios, charlas e ilusiones mezcladas en un todo compacto. Sin discreciones a la hora de colaborar, todo el pueblo era parte de esta fiesta en la que se incluía la inauguración del Museo Antonio Bertino -preparado especialmente por Edith Bello-, un despliegue de actuaciones de patinaje y baile, y una cantina bien dispuesta con choripán y papas fritas. El evento contó con la presencia del Intendente Sergio Omar Buil y otras autoridades del Partido, se leyeron saludos desde diversas partes de la Provincia y de más allá también.

La fiesta siguió con varios espectáculos de folklore; y la cena preparada por la gente del pueblo. Dos grupos musicales se hicieron presentes aportándole música y baile a la jornada. Luego se realizó un emotivo homenaje a algunos adultos mayores reconocidos del pueblo; se proyectó un video que mostraba imágenes de la vida de cada uno de ellos, contaba su historia y resaltaba su situación actual. Cada mención era acompañada por el público con ovaciones y cánticos. La noche se fue cerrando así, entre baile, mate y aplausos, debajo de un mar de estrellas. El cumpleaños de Sansinena estaba llegando a su fin, dejando detrás una estela de hermosos recuerdos, un día más en que este pueblo reafirmaba el sentimiento de amor y dedicación para con su pueblo querido.

\section{Por Clarisa Fernández}

*Lic. en Comunicación Social. Becaria del CONICET. 
NOTAS PERI ODI STI CAS EN DI ARI OS LOCALES: LA NUEVA PRENSA (AMÉRICA) Y LA OPI NI ON (TRENQUE LAUQUEN).
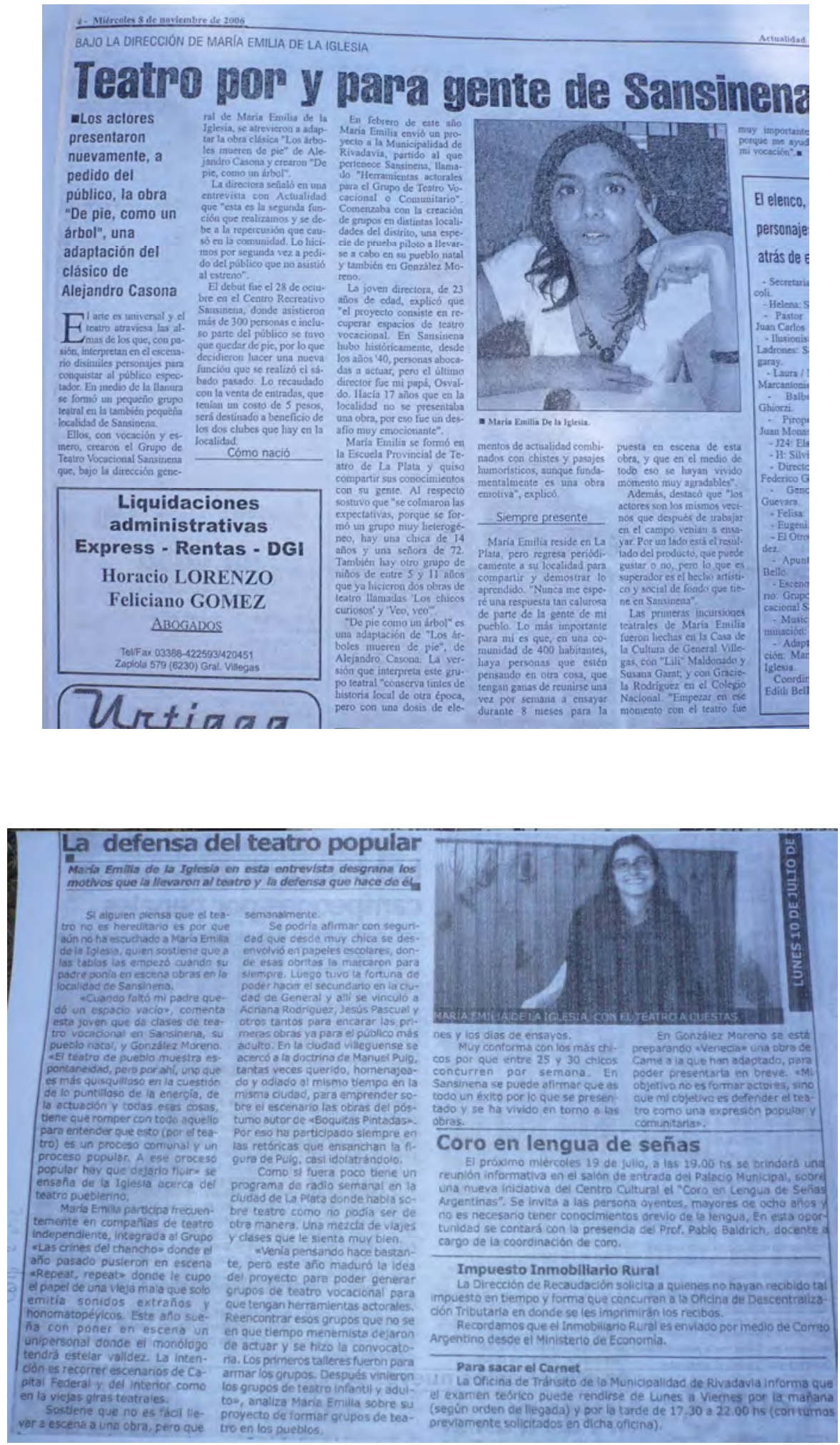

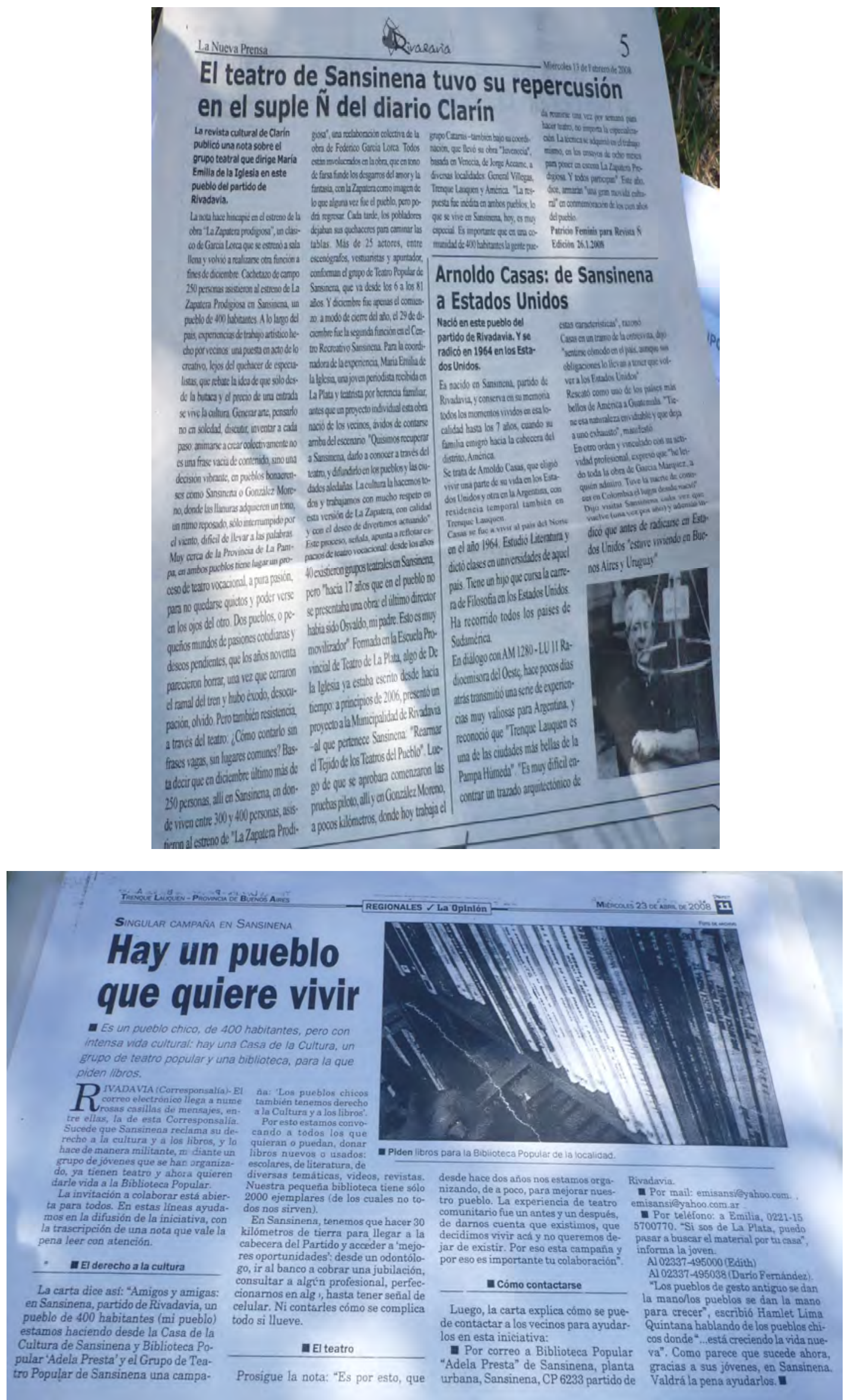


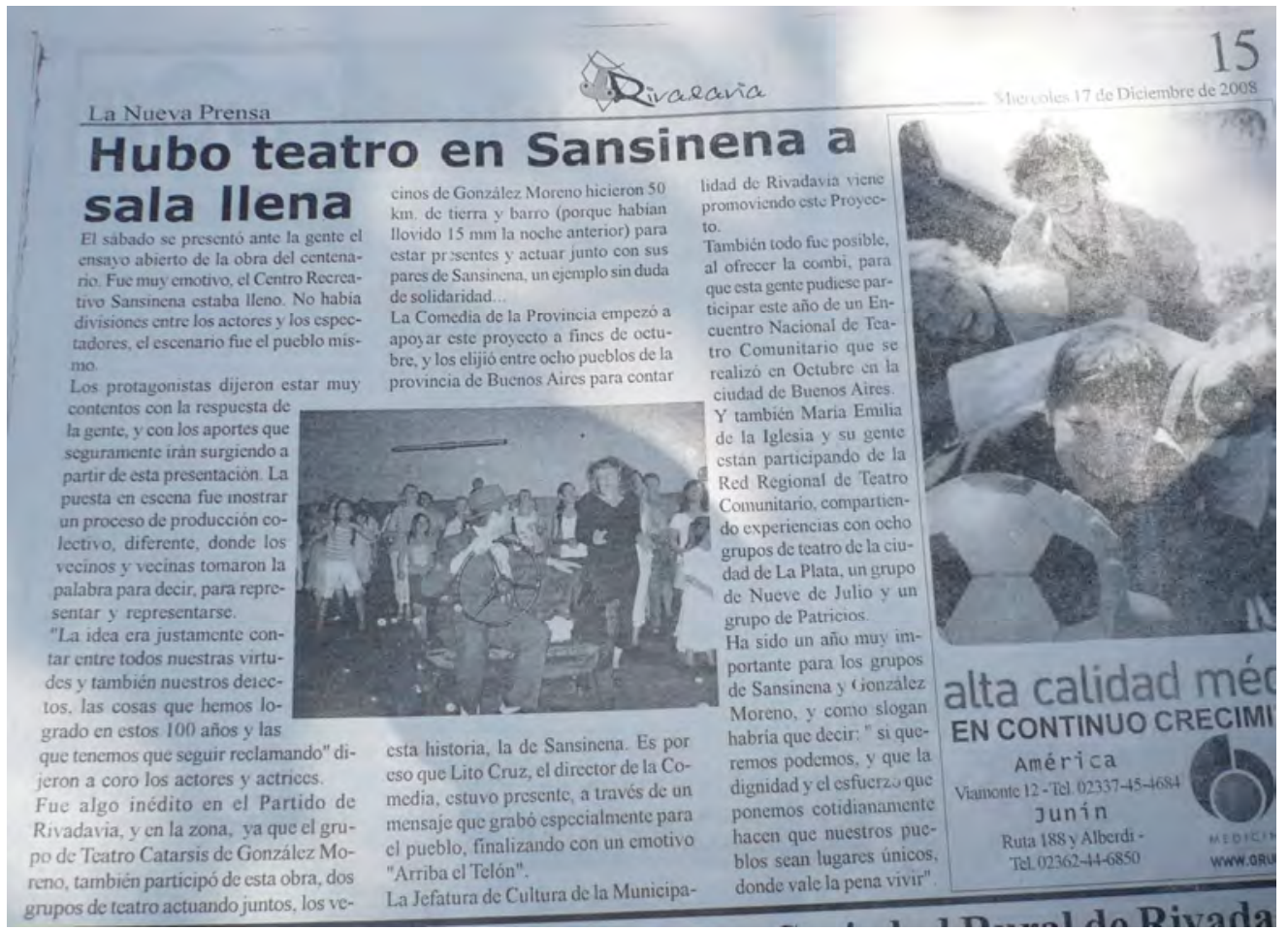

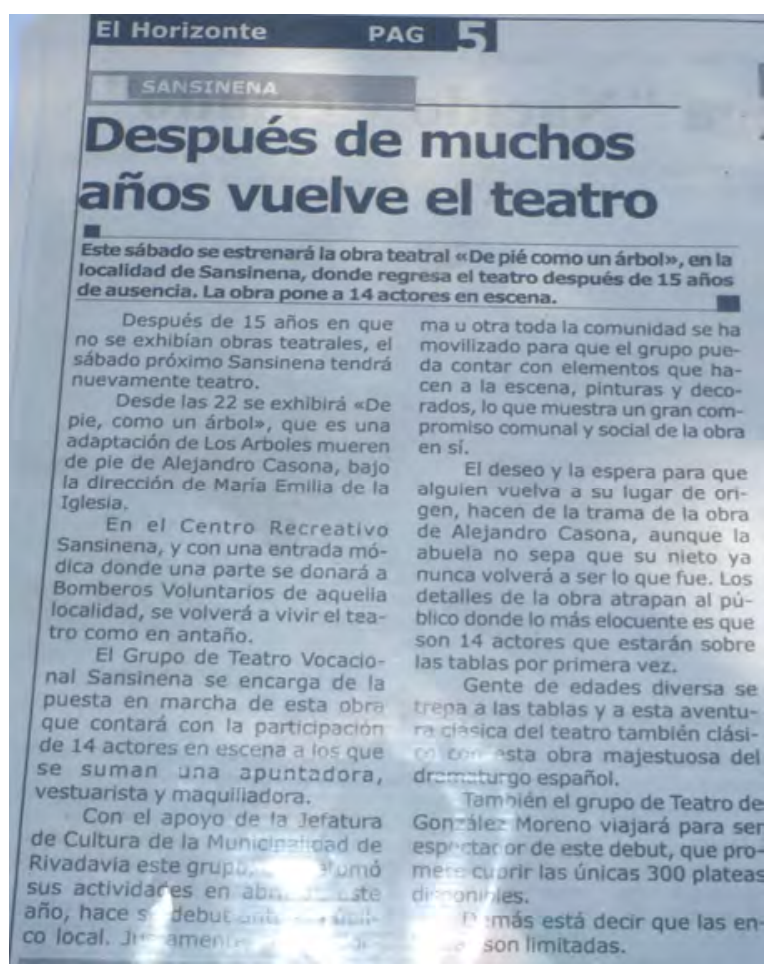

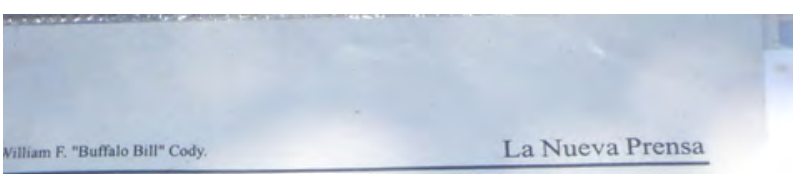

EI teatro también está en el pueblo

María Emilia De la Iglesia, estudió Teatro y Comunicación Social en la ciudad de La Plata, es oriunda de Sansinena y volvió a su tierra para devolverle algo de los que su pueblo le dio en su infancia.

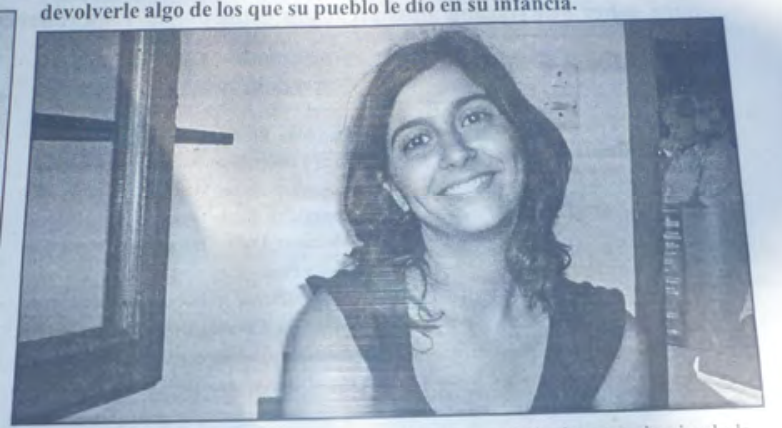

«En el 2006 el teatro estuvo presente en Sansinena y si Dios quiere durante el 2007 seguiremos con este proyectc. Estoy muy feliz de estar ejerciendo la docencia en estos lugares» dijo María Emilia de no más de 25 años. EChicos, grandes.... la verdad que el

Yo me fui a estudiar, pero mi cabeza siempre se quedó también en mi pueblo. A demás también armamos un etapa fue fabuloso. Esto me incentiva grupo fabuloso en González Moreno a seguir con muchas ganas" 

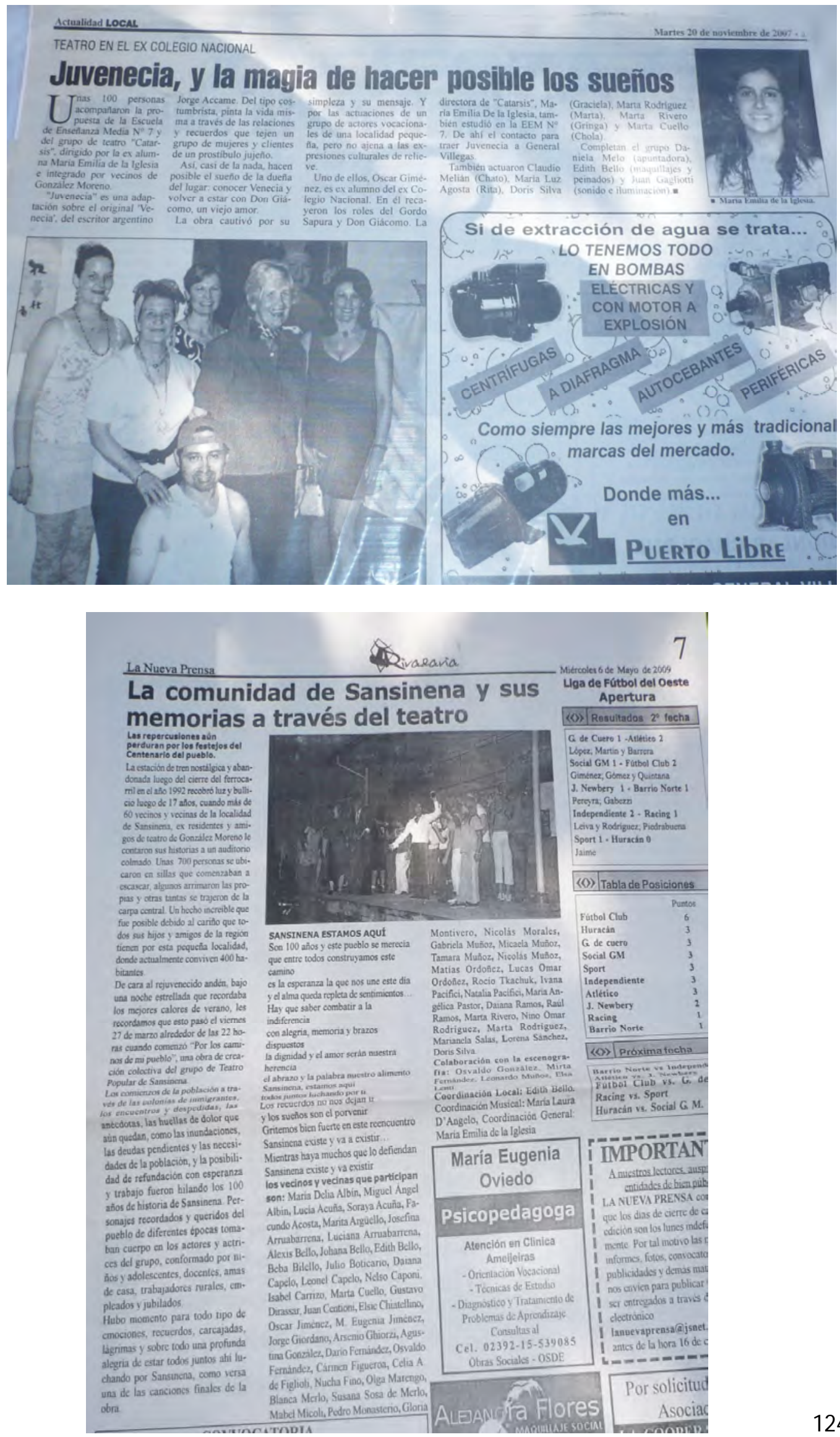

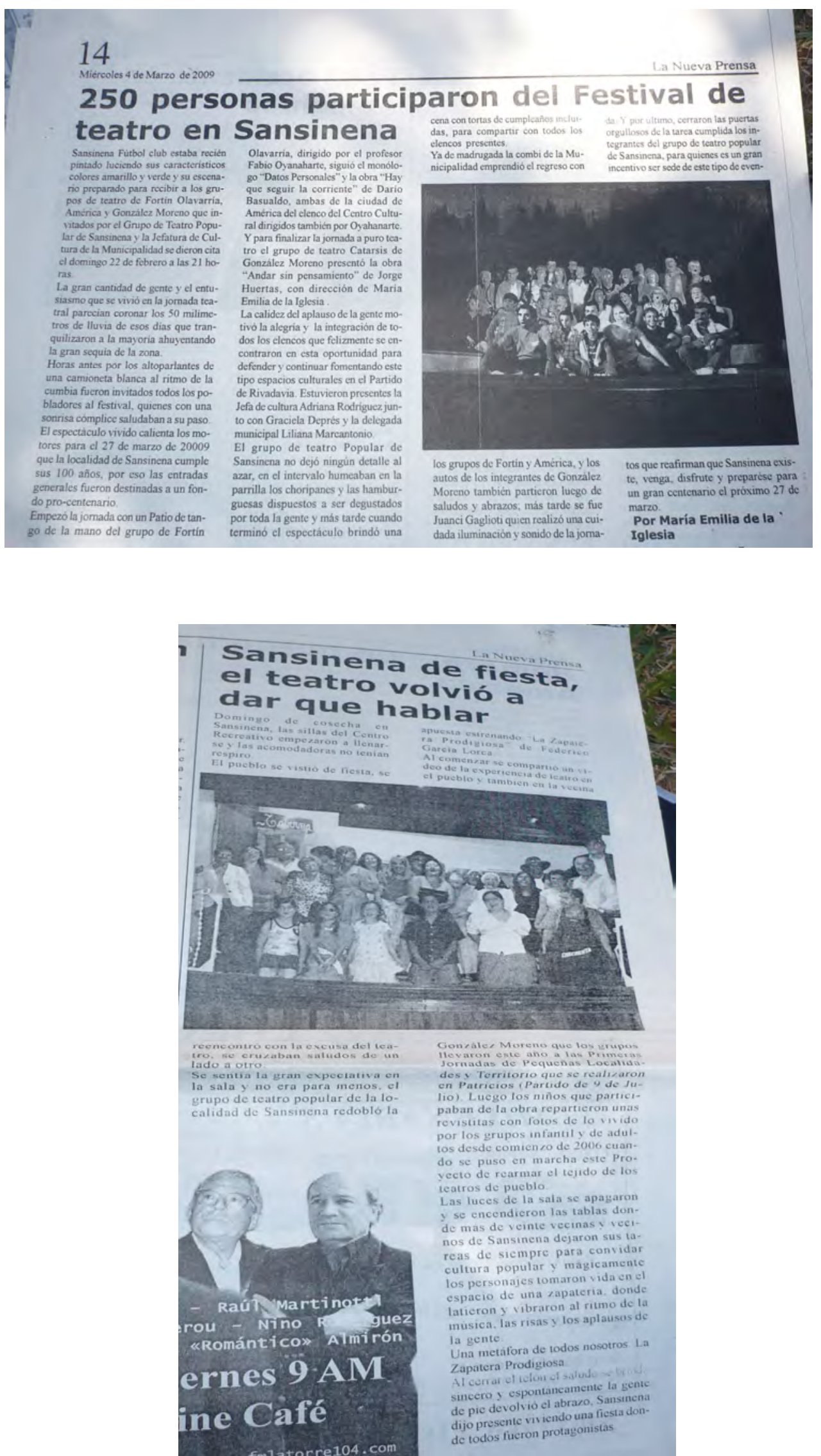


\section{ANEXO 2}

\section{Notas publicadas por María Emilia De la I glesia, en diarios locales}

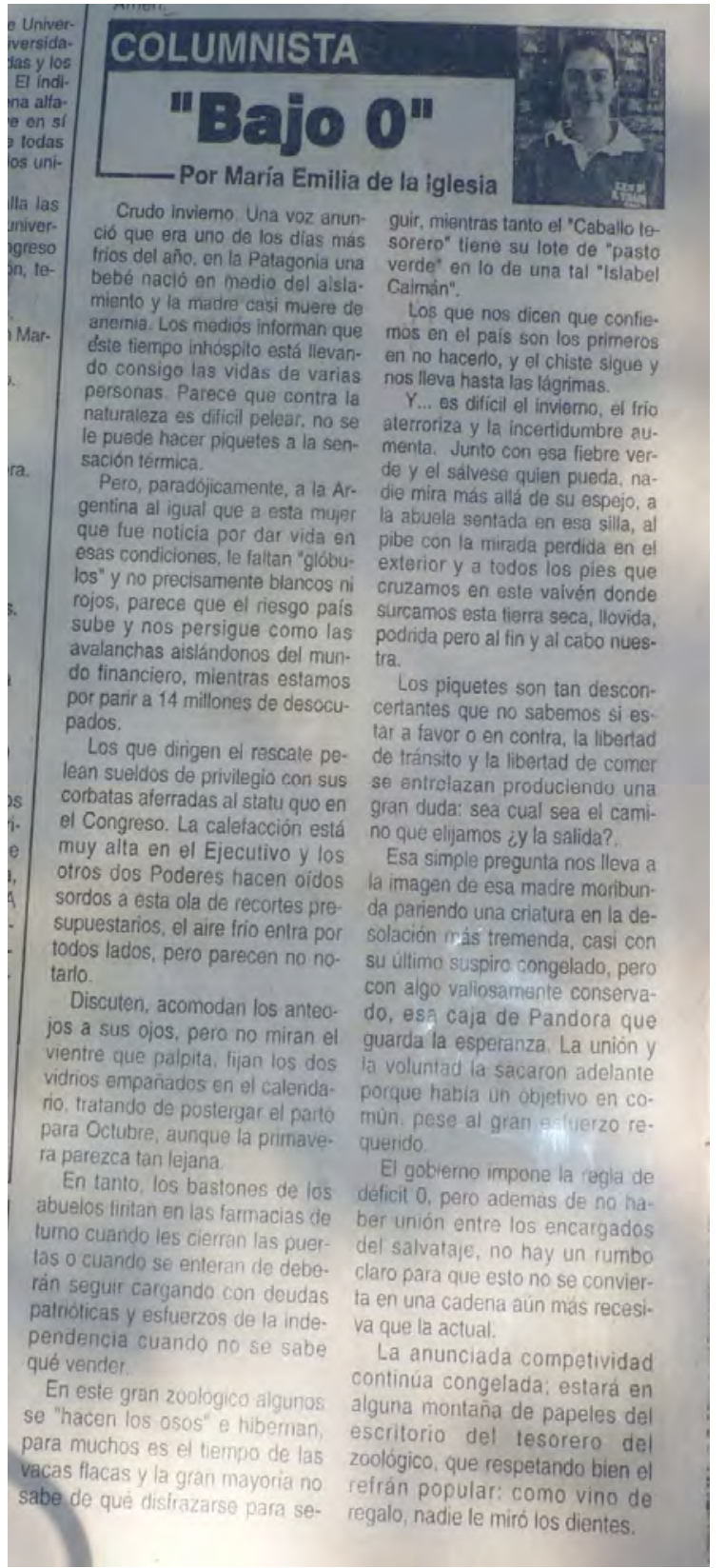

\section{SANSINENA}

\section{El día después}

Se fueron los camiones del ejército, se callaron los medios nacionales la exención de impuestos no corre hasta que den la orden, nos movimos, nos Cosperamos y hasta nos peleamo

Cómo cambia la historia el dia despuès, ahí es donde hay que ver con opes resignados los difundidos estudios topográficos y los eminentes ingenierosproyectando canales que ni ellos saben si terminarán.

El dia que se acaba el show pero el agua no, ese es el día después, la etapa del comienzo de una lucha por producir lo imposible, de trabajar tierras que no se pueden sembrar, de vivir con la ambigũedad de tener lotes llenos de agua y al lado otros muriendo de sequia, de vender dos latas de tomate que nadie compra, de educar a chicos con padres sin trabajo.

"Nuestro único propósito es salvar al pueblo...", pero yo me pregunto: ¿salvar a un pueblo que de qué vive señores?

Mientras tanto nos seguimos echando culpas y hablamos por lo bajo como queriendo esconder un disgusto que crece y se ahonda con el tiempo, porque no es sólo el dia después sino los años después que nos costará volver a construir lo que veniamos cuidando con ' nto sacrificio.

Pero acá no hay ricos ni pobres, porque todos nos sacrificamos para cultivar lo que tenemos y solamente juntos, algo muy dificil de hacer entender, es de la única manera que tendríamos que haber empezado y finalizado esta triste situación que nos afecta en definitiva a todos.

Ya que esos antiguos decires populares que nos cansamos de repetir son los que menos practicamos porque la unión hace la fuerza, o "los hermanos sean unidos..." son lemas que parecen olvidados.

El dia después nos sirve para diferenciar las realidades de los espejos de colores que nos"han querido vender y para proponernos como en cada comienzo hacer las cosas bien.

El dia después es ese en el que te mirás al espejo y te palmeas con las manos ásperas las mejillas y con un fuerte suspiro te proponés seguir adelante. 


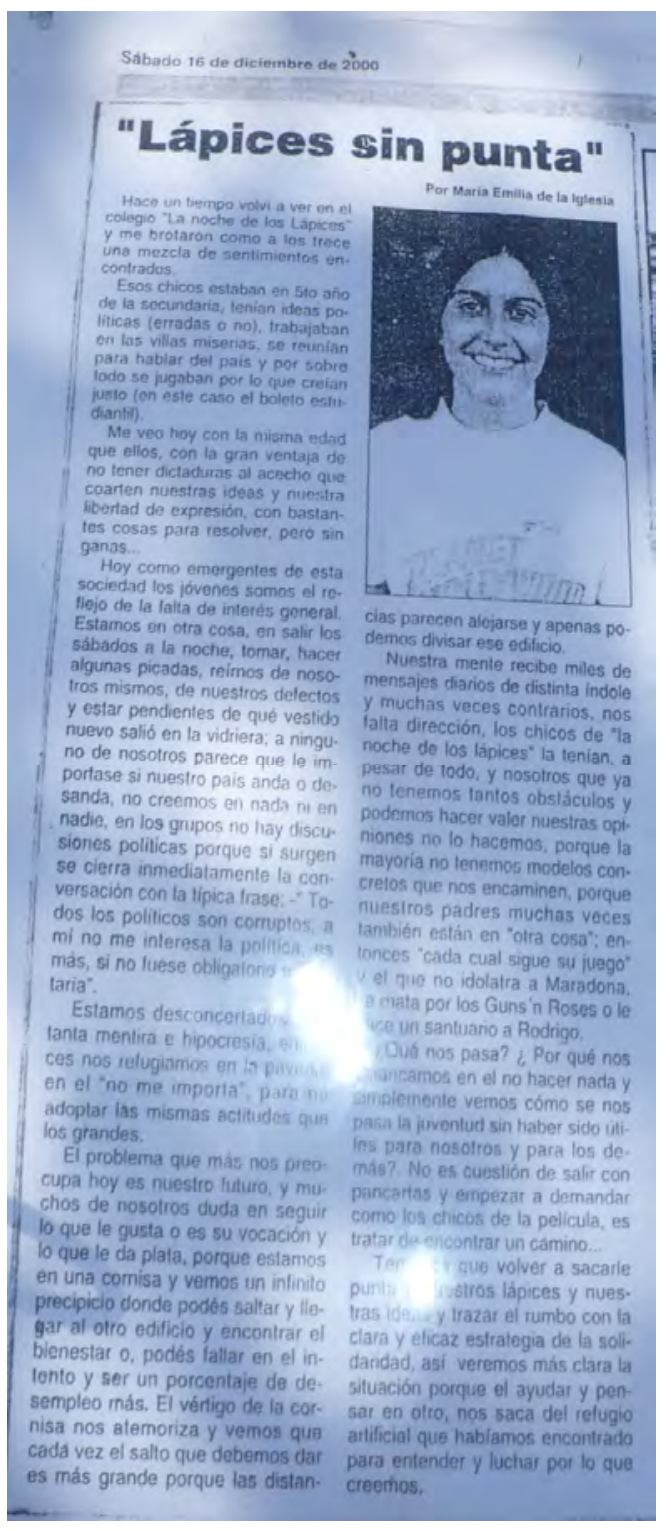

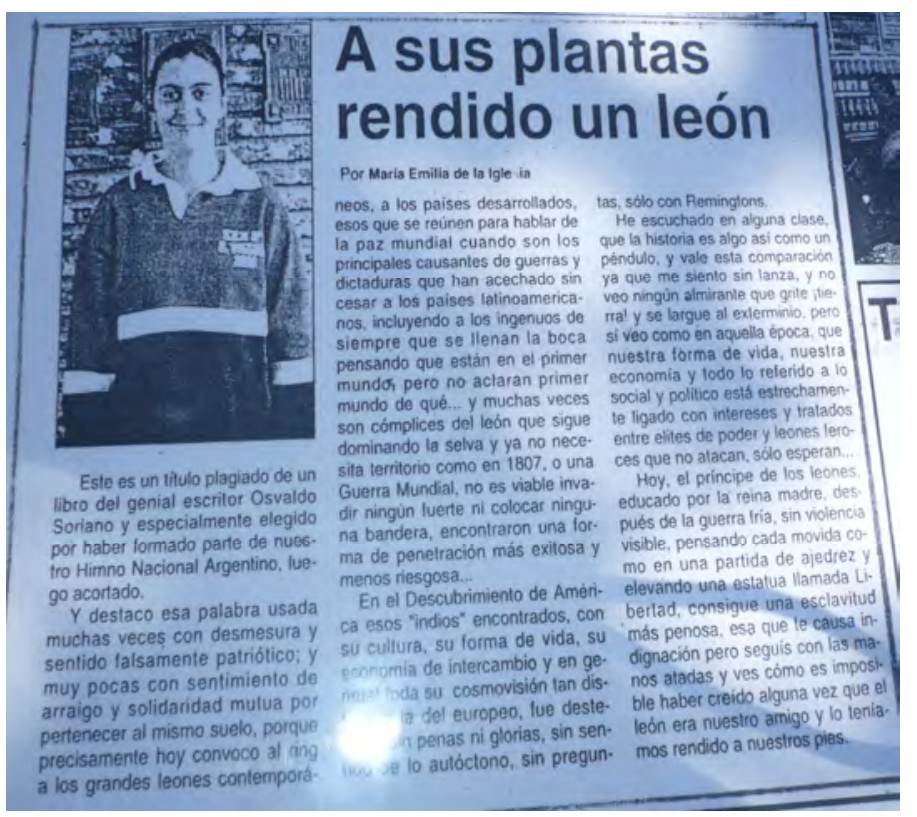

